\title{
A cutting culture: gender and identification in the figured world of surgery
}

Citation for published version (APA):

Hill, E. J. R. (2014). A cutting culture: gender and identification in the figured world of surgery. [Doctoral Thesis, Maastricht University]. Datawyse / Universitaire Pers Maastricht. https://doi.org/10.26481/dis.20141211eh

Document status and date:

Published: 01/01/2014

DOI:

10.26481/dis.20141211eh

Document Version:

Publisher's PDF, also known as Version of record

\section{Please check the document version of this publication:}

- A submitted manuscript is the version of the article upon submission and before peer-review. There can be important differences between the submitted version and the official published version of record.

People interested in the research are advised to contact the author for the final version of the publication, or visit the DOI to the publisher's website.

- The final author version and the galley proof are versions of the publication after peer review.

- The final published version features the final layout of the paper including the volume, issue and page numbers.

Link to publication

\footnotetext{
General rights rights.

- You may freely distribute the URL identifying the publication in the public portal. please follow below link for the End User Agreement:

www.umlib.nl/taverne-license

Take down policy

If you believe that this document breaches copyright please contact us at:

repository@maastrichtuniversity.nl

providing details and we will investigate your claim.
}

Copyright and moral rights for the publications made accessible in the public portal are retained by the authors and/or other copyright owners and it is a condition of accessing publications that users recognise and abide by the legal requirements associated with these

- Users may download and print one copy of any publication from the public portal for the purpose of private study or research.

- You may not further distribute the material or use it for any profit-making activity or commercial gain

If the publication is distributed under the terms of Article $25 \mathrm{fa}$ of the Dutch Copyright Act, indicated by the "Taverne" license above, 
A cutting culture: gender and identification in the figured world of surgery

Elspeth Jane Rose Hill

MAASTRICHT UNIVERSITY 2014 
This research was carried out at Maastricht University

in the School of Health Professions Education

C Copyright Elspeth Hill, Maastricht 2014

All rights reserved

ISBN 9789461593801

Photography: Max Downer

Production: Datawyse | Universitaire Pers Maastricht 


\section{A cutting culture: gender and identification in the figured world of surgery}

\section{PROEFSCHRIFT}

ter verkrijging van de graad van doctor aan de Universiteit Maastricht, op gezag van de Rector Magnificus, Prof. dr. L.L.G. Soete, volgens het besluit van het College van Decanen,

in het openbaar te verdedigen

op donderdag 11 december 2014 om 14.00 uur

door

Elspeth Jane Rose Hill

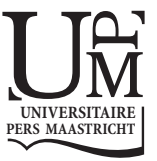




\section{Supervisors}

Prof. dr. T. Dornan

Prof. dr. Y. Solomon, Manchester Metropolitan University, UK

Co-supervisor

Dr. R.E. Stalmeijer

Beoordelingscommissie

Prof. dr. A.J.J.A. Scherpbier (voorzitter)

Prof. dr. A. Bleakley, Peninsula Medical School, UK

Prof. dr. S. Ponzer, Karolinska Institute, Sweden

Dr. P. Teunissen

Dr. D.M.L Verstegen 


\section{Table of contents}

1 Introduction

2 The only girl in the room: how paradigmatic trajectories deter 31 female students from surgical careers

3 You've got to know the rules to play the game:

how medical students negotiate the hidden curriculum of surgical careers

4 Can I cut it? Medical students' perceptions of surgeons and 71 surgical careers

5 Gender and careers decisions: the illusion of choice?

6 You become a man in a man's world: is there discursive space 97 for women in surgery?

7 Discussion

$8 \quad$ English summary

9 Dutch summary

10 Valorisation

11 Acknowledgements

12 Curriculum Vitae 

Chapter 1

INTRODUCTION

The under-representation of women in surgery:

A Figured Worlds approach 


\section{Representation of women in surgical careers}

The last hundred years have seen major changes in the structure and composition of the medical workforce, as a largely male profession has admitted more women and other minority groups (Royal College of Physicians 2009). Over half of all medical graduates in many countries are now women, and this has seen corresponding rises in the number of women holding senior positions in almost all medical specialties (BMA Board of Medical Education 2005; Department of Health 2005; van der Velden et al. 2008; Jolliff et al. 2011; NHS Health and Social Care Information Centre 2011). In this climate of increasing gender equality, surgery as a specialty remains a notable exception where women remain under-represented - a pattern that holds consistently across countries (Greatorex \& Sarafidou 2010; Kaderli et al. 2010; McNally 2012; Makama et al. 2012; Tomizawa 2013).

The under-representation of women in surgical careers is a pattern repeated in many countries worldwide, though to differing degrees. In the USA women currently make up $10 \%$ of the fully-trained surgical workforce (Center for Workforce Studies 2012), 9\% in Australia (Li et al. 2013) and 7\% in the Netherlands (Pas et al. 2011). In the UK, which provides the context for this thesis, only $7 \%$ of consultant (fully-trained) surgeons in the UK are female (Greatorex \& Sarafidou 2010). The proportion of female consultant surgeons in the UK grew to reach a peak of around $8 \%$ in 2005 and has since plateaued around this level, despite initiatives to increase the number of women in surgery (McNally 2012; Royal College of Surgeons of England 2013).

Discrepancies exist not purely between surgery and other specialties; there are also marked differences between women's representation within surgical subspecialties, a pattern which also holds across countries (Center for Workforce Studies 2012; Li et al. 2013). In the UK, 20\% of consultant paediatric surgeons are female, which is in starkest contrast to maxillofacial surgery where only $4 \%$ are female (Greatorex \& Sarafidou 2010).

Many studies have considered where in the surgical training pathway this demographic difference first appears, given that women are in the majority at medical school. The pattern begins to develop at medical school, where male students show a greater preference for surgical careers even from their first year, whereas female students' preferences are for general practice, paediatrics or gynaecology (van Tongeren-Alers et al. 2014). After graduation, women are less likely to apply for surgical training posts than their male counterparts, though they are as likely to succeed in being appointed (McNally 2012). Once appointed, however, women are more likely to leave the profession before the completion of their postgraduate training, with numbers of female surgeons steadily decreasing at each level of seniority (McNally 2012). The average length 
of surgical training in the UK is ten years (Singh et al. 2014). Given this, the increase in the proportion of women at medical schools, which accelerated in the early 1990s, should have begun to manifest in the number of fully-trained surgeons in the mid-2000s; yet, this is not the case. Indeed, there is considerable attrition in the UK training pathway with the proportion of female to male surgeons roughly halving with each application stage (McNally 2012). These differences between male and female surgeons, although well established via demography, have not yet been well explained. These patterns have been recognised as a problem by The Royal College of Surgeons of England (RCS), the body governing UK surgical training, who set a target for a $20 \%$ female surgical workforce by 2010; however, to date no clear strategy has been advanced for how to achieve such a goal.

There are a number of arguments in favour of studying women's underrepresentation in surgery. Chief among these is the issue of social justice, of considering the equality of opportunity, equal access to a surgical career. There has been much emphasis within medicine, including by the RCS, on promoting equality and diversity within the workforce (Royal College of Physicians 2009; NHS Health and Social Care Information Centre 2011; Royal College of Surgeons of England 2013). Further, the UK Department of Health (2005) has made it clear that the medical workforce should be broadly representative of the population it serves. With such a gender disparity in surgery, it is clear that there is much progress to be made towards these stated goals. Whilst social justice alone represent a strong case for investigating gender inequalities in surgery, there are also pragmatic reasons to investigate why they exist.

There has been worldwide concern raised from within surgery regarding falling application numbers to postgraduate training in general surgery in the last decade (Marschall \& Karimuddin 2003; Cockerham et al. 2004; Signer \& Beran 2005; Fischer 2007; McDonald \& Sutton 2009; Pikoulis et al. 2010; Are et al. 2011; McHugh et al. 2011). Surgery as a field has repeatedly called for the recruitment of the "best and brightest" of medical graduates to its ranks (Magovern \& Simpson 2011), hence the decrease in applications is thought to be a threat to the future of surgery in terms of quality of care (Cofer \& Burns 2008; McDonald \& Sutton 2009; Stewart et al. 2013). As female students and junior doctors now comprise the majority of surgery's potential recruitment pool, there would seem an imperative to address what McDonald and Sutton (2009) term the "recruitment crisis" via considering the issue of women's under-representation.

Accompanying the change in the medical workforce has been a welldocumented change in demand for healthcare due to the changing pathologies associated with ageing populations and increasing levels of chronic disease 


\section{CHAPTER 1}

(World Health Organisation 2011). Internationally, we must ensure that a future workforce has the capacity to deliver this care. Any strategic planning must take into account the changing demography of the trainee workforce, particularly the increase in female trainees. It is acknowledged that female doctors are less likely to work full time, and as a result there is likely to be an increased demand for part-time contracts (Davidson et al. 2002). As other specialties find ways to adapt to the changing working needs of their practitioners, there is evidence that surgery has been slower to adapt (Washburn 2000). This is likely to cause future surgical recruitment and service delivery problems as the larger workforce further diversifies.

In both medical journals and the popular press, commentators have considered the implications of increasing the numbers of women in medicine as a whole so-called feminisation (Dacre 2008; McKinstry 2008; Boseley 2009; Bleakley 2013; Thomas 2014). There appear to be some differences in the practice of female doctors when compared to their male counterparts. Female doctors are more likely to prioritise communication in consultations, demonstrating greater empathy and intimacy towards their patients (Boerma \& van den Brink-Muinen 2000; Buddeberg-Fischer et al. 2003; Boulis \& Long 2004; Wolfe 2005; Wolosin \& Gesell 2006). They are also more likely to value a collaborative work environment (Maiorova et al. 2008). Further, it has been demonstrated that their practice leads to better patient outcomes and fewer complaints (Dacre 2008; National Patient Safety AgencyNational Clinical Assessment Service 2010). While the literature on whether patients are concerned with their doctor's gender is inconclusive (Wolosin \& Gesell 2006), in some circumstances patients prefer surgeons who practice more communally, regardless of gender, which correlates with female doctors' priorities (Dusch et al. 2014).

Yet concerns have been raised that female doctors are less able to deal with risk, and are less efficient than their male colleagues - spending more time with patients and referring more often (McKinstry 2008). These differing perspectives, one which, at its core, argues for centring healthcare around an ethic of justice, of equitable distribution of healthcare resources, and the other for an ethic of care, are ranged in opposition to each other (Dacre 2008; McKinstry 2008; Bleakley 2013). There are clearly implications for provision of healthcare if more women practise medicine than in the past, yet more work is needed to better understand how to integrate the differing priorities given the now inevitable demographic change. Hence, there are compelling ethical and pragmatic reasons to understand the reasons for, and how we might address, surgery's gender gap. 


\section{Career decisions}

There have been many studies seeking to identify factors that predict an individual's decision to pursue a career in surgery (Neumayer et al. 2002; Azizzadeh et al. 2003; Mihalynuk et al. 2006; Sanfey et al. 2006; Laurence \& Elliott 2007; Drinkwater et al. 2008; Maiorova et al. 2008), many of which consider gender differences. Of these, the factors that appear repeatedly, derived from different study designs are: exposure to and participation within a surgical specialty (Azizzadeh et al. 2003; Mihalynuk et al. 2006; Maiorova et al. 2008), derivation of satisfaction from surgery (Azizzadeh et al. 2003; Laurence \& Elliott 2007), access to role models (Neumayer et al. 2002; Sanfey et al. 2006; Drinkwater et al. 2008), and perceived lifestyle or work-life balance (Azizzadeh et al. 2003; Sanfey et al. 2006; Drinkwater et al. 2008; Maiorova et al. 2008). Whilst there is considerable emphasis placed by the literature on identification of these factors, few studies explore more deeply to understand the processes underlying such correlations.

The effect of medical school clerkships on specialty preference has been explored via a longitudinal study of medical students, where exposure to a specialty increased attraction to that specialty (Maiorova et al. 2008). In contrast to other studies, gender did not impact upon career preferences, although the study was carried out in the Netherlands, a country with higher rates of women training in surgery. Those students attracted to surgical careers showed preferences for dealing with acutely unwell patients and technical work, and attached greater importance to prestige and career opportunities, yet lacked preference for a "controllable lifestyle" (Azizzadeh et al. 2003; Maiorova et al. 2008). Drinkwater et al. (2008) explored the issue of lifestyle more deeply and found that while male and female medical students assigned equal importance to issues surrounding work-life balance and compatibility with family life, women more readily compromised professional attainment to achieve such a balance. This was reported to be due to the influence of gendered stereotypes and a lack of professional role models.

Past research has attributed lower rates of application among women to a perceived lack of fit between themselves and their perceptions of what a surgeon must be, leading to lower career motivation among female graduates (Peters et al. 2012). 'Perception of fit' is a psychological concept used to describe how an individual's personal identity (who they think they are) fits in with their professional identity (who they think surgeons are). Female surgical trainees' perception of their own fit, when compared to consultant surgeons is significantly less than that of their male counterparts (Peters et al. 2012). The further they progress in their training, the more male trainees' perception of fit increases, whilst females' perception of fit decreases. Even from this individualistic perspective, we are able to see how conflict can exist between an 


\section{CHAPTER 1}

individual's sense of themselves and their sense of who they need to be for their chosen career. We may infer, then, from the literature that a lack of role models and the nature of the social structure of surgery may have resulted in fewer cultural resources for women to draw upon in this process of forming an understanding of themselves as a surgeon.

\section{Availability of role models}

Postgraduate medical training occurs largely in patient care settings, with workbased learning forming a significant proportion of trainees' experience (Hager \& Hodkinson 2009). This type of situated, relational learning makes role modelling an integral part of training, and positive role models enable success at medical school (Lempp \& Seale 2004). We know that gender is an important factor when choosing a role model (Nicholson 2002; Lempp \& Seale 2004; Rose et al. 2005) and that when selecting a role model, students are usually limited to those clinicians with whom they come into contact. In view of the paucity of female surgeons, direct access to a positive female role model is not always possible. For example, the UK has only twelve female consultant neurosurgeons; there are no visible female neurosurgical role models present in the majority of medical schools. Many hospitals do not have a female consultant surgeon in any subspecialty, limiting the impact that existing female surgeons can have via direct role modelling. In addition, some female surgeons are not perceived to be suitable mentors by students, as they have adopted a more masculine persona in order to succeed in their career (Bickel 2011). This has serious implications for female students and junior doctors, as they may lack the role models and accompanying social capital that promote aspiration into the specialty (Ravindra \& Fitzgerald 2011). This is supported by the work of Sanfey et al. (2006), who found that medical students training in hospitals with few or no female surgeons were significantly less likely to pursue a career in surgery when compared to students training in hospitals with abundant and prominent female surgical role models.

One of the effects of experience and role models is to aid an individual's socialisation into the culture of a specialty (Lempp \& Seale 2004; Gofton \& Regehr 2006). This involves developing an understanding of the culture, beliefs and values that are collectively held by those working in the field of surgery. This includes a range of things, from learning to value manual dexterity (Darzi 1999) to learning how to behave based on one's role in the surgical social structure (Lingard et al. 2002; Gardezi et al. 2009). This is a complex process that has been shown to affect career decisions, as students evaluate, perhaps unconsciously, whether their own values 'align' with that of a specialty, or could do so in future (Gofton \& Regehr 2006). One of the aspects of culture that students draw on are stereotypes. 


\section{Stereotypes of surgery and surgeons}

In order to interact in the complex social world, stereotypes are an important resource. Stereotypes are largely constructed by imagination and social structure, rather than direct personal contact. They act as shortcuts to make assumptions about an individual quickly (Heilman \& Parks-Stamm 2007). Stereotypes are widespread in medicine, where there are a large number of different specialties and professions working together in an often fast-paced environment (Davidson et al. 2002). While there is little existing literature examining gendered stereotypes within medical careers, gender stereotypes persist outside of medicine, and span countries, cultures and decades. Williams and Best (1982) demonstrated consistent gender stereotypes across 25 countries, with men highly associated with qualities related to agency (dominance, autonomy, achievement), and women associated with qualities related to communality (kindness, nurturing, affiliation). It is important to consider the historical and contemporary stereotypes that describe surgeons and their profession, and how these may affect the participation of women.

Historically, the surgeon was "a decisive and efficient man of action driving forcefully to achieve his goals in an impersonal and autocratic manner" (Zimny \& Thale 1970), a stereotype reinforced in more recent anthropological work describing:

"The "iron surgeon" powerful, invulnerable, untiring. Those trained by him pass on the mystique, transmitting from one surgical generation to the next an embodied professional ethos. The iron surgeon does battle with death, exterminates disease, declares war on softness, sloth, and error. He is technically brilliant, clinically astute, technologically sophisticated. His feelings, if he has any, are private; his inner life, if he has time for one, is unengaged by his work. The feelings of his patients are also private. Their personalities, problems, hopes, aspirations, are irrelevant. The iron surgeon's task is to excise disease. The rest is for nurses or social workers."

Cassell (2000)

Clearly, this account is powerfully gendered; surgery is portrayed as a form of decisive, masculine perfection.

Psychological research, studying women in the workplace, described the mismatch that may occur between an individual's assumed capabilities and the presumed requirements of a role (Heilman \& Parks-Stamm 2007). They classified gender stereotypes as "descriptive" (what women are like) or "prescriptive" (what women should be like). Prestigious and high-authority positions were again associated with masculine characteristics pertaining to 
agency; women were considered deficient in these qualities, and therefore not equipped to handle these positions, or succeed. The authors suggest these expectations of failure, arising from stereotypes, may bias women's decisions regarding career progression. Prescriptive gender stereotypes provide a cultural framework for what are and are not suitable behaviours for women. Caring, social attributes are encouraged, with characteristics of agency discouraged. Prescriptive stereotypes promote gender bias by invoking disapproval or penalties when women violate them, for example by exhibiting agency. Women also meet with disapproval in the workplace in a more passive way by not fulfilling expected norms, such as displaying caring attributes associated with communality (Heilman \& Parks-Stamm 2007).

More recent work regarding the surgical domain from Lithuania showed that surgery was still perceived as masculine, and stereotypes were persistent (Riska $\&$ Novelskaite 2008). A discourse analysis of interviews with surgeons revealed that the male-gendered characteristics of control and strength (both mental and physical) predominated as the descriptive stereotype of a good surgeon. These assumptions were reinforced by surgeons regardless of gender, however female surgeons also described empathy and compassion as valuable attributes. Although women have the ability to be equally able surgeons, perhaps the overt masculinity of the surgical descriptive stereotype may contribute to the gap in representation. The masculine surgical stereotype from this study was an exception among medical specialties. In contrast, the descriptive stereotype of a good paediatrician was powerfully feminine - an extension of motherhood.

In addition to descriptive stereotypes, female surgeons may also encounter prescriptive gender stereotypes:

"you know, there are stereotypes, about the monster female surgeon, how scary she is...She is not feminine. Nobody likes her. [People think] how dare she, she's supposed to be raising children!" Middle-aged female surgeon."

Riska \& Novelskaite (2008)

Hence, in occupying a male domain, female surgeons may be perceived negatively as they violate the prescribed suitable behaviours of a woman.

\section{Summary and critique}

Examining the literature on gender and career decision, broadly, the studies may be categorised as either demographic - taking a population level view to identify patterns and factors using large scale surveys - or descriptive whereby questionnaires are employed to determine individuals' priorities. Of the remaining papers, many that have looked deeper have focussed on 
cognitive processes within the individual, necessitating an 'individualistic' understanding of cognition (Palermos 2012). Those studies that have attempted to explore the mechanisms underlying the observed demographic patterns suggest they are a consequence of self-exclusion by women or of discrimination. The evidence supporting these hypotheses have been criticised for lacking conclusiveness, hence, the underlying mechanisms of the gender gap remain unclear (Peters et al. 2012). Further, given the widespread failure of interventions designed to increase the number of women in surgery, and the ethical reasons to support their ability do so, there is an imperative for research that considers the issue from a different angle.

To develop a deeper understanding requires a move away from the largely quantitative and individualistic research that dominates the field, to consider the issue of women in surgery from a sociocultural perspective. Cassell's (2000) anthropological work, for example, stands out for its consideration of the social world of surgery, and the place of individuals within it. A sociocultural approach could include what we already know about the importance of role models, the culture of surgery and stereotypes in women's career decisions, but could employ the tools provided by contemporary social science to consider how 'culture in practice' mediates career decisions. This approach would frame the problem in a new way, as inherently social, rather than placing the locus within individuals or institutional policy; it would consider how the complexity of interaction between individuals and society gives rise to the underrepresentation of women in surgery. 


\section{CHAPTER 1}

\section{Theoretical Framework}

\section{Identity and Agency in Cultural Worlds}

As described, work regarding gender, career choice and surgical culture has largely taken an individualistic stance. This thesis seeks to better understand how surgical culture and gender influence career decisions, and thus takes a sociocultural stance. This enables exploration of relationships, culture, power, hierarchy, learning, identity, practice, imagination and societal structure and their interplay, to further our understandings of why women remain underrepresented in surgical careers.

This thesis uses the theory of Figured Worlds by Holland et al. (1998) as its theoretical framework, drawn from the book 'Identity and Agency in Cultural Worlds'. This theoretical amalgam draws together sociocultural concepts of Vygotsky (1978; 1986), Bakhtin (1981; 1986), and Bourdieu (1986) to explore "identity in practice".

Figured Worlds may be considered a theory of identity, though it is not specifically grounded in the literature on identity. Rather, the Figured Worlds perspective on identity arises from a sociocultural critique, often setting aside much of the 'identity literature'. What arises is a formulation of 'identity in practice' which allows us to consider questions of, "how does identity work?" or "how do people identify in practice?" From such a perspective, identity may be considered a process of becoming; people are continuously shaping and being shaped by the world around them. Identity is not something an individual possesses; rather it is constantly being negotiated between an individual and the social world (Monrouxe 2010). Identity may be viewed as the point of intersection where past experiences and current practice meet, and the individual and society interact (Tsouroufli et al. 2011); the focus of Figured Worlds becomes about the ways in which people identify - their processes of identification.

The concept of a 'figured world' is used to describe a collectively realised 'as-if' realm: "People have the propensity to be drawn to, recruited for, and formed in these worlds, and to become active in and passionate about them." (Holland et al. 1998, p49). As Holland et al. (1998, p49) humourously put it, "What if there were a world called academia, where books were so significant that people would sit for hours on end, away from friends and family, writing them?". A figured world, therefore, exists at the interaction of person and society, which are considered "alike as sites, or moments, of the production and reproduction of social practices" (Holland et al. 1998, p270). While this confers substantiality to both loci, person and society, it rejects consideration of the two as dichotomous. Further, figured worlds are "sociohistoric, historic, contrived interpretations or imaginations that mediate behaviour... [which] becomes 
embodied over time through continual participation." (Holland et al. 1998, p53). Hence, Figured Worlds provides a framework within which to consider processes of identification within the "doubly historical landscape" (Holland et al. 1998, p270) comprising the person and society; it is within this space that the key concepts of Figured Worlds are situated.

Figured Worlds makes use of Vygotsky's concept of 'semiotic mediation', in part based on Engels' ideas that tools exist dialogically with their users; that tools shape hands - the muscles and neurological control of motion - as effectively as tools are shaped for their intended use. Vygotsky extended this principle from objects to signs and, hence, to language. Individuals assign meanings to external signs - meanings that are not individually produced, but that draw on historically and collectively formed meanings. These sociohistorical meanings may be termed discourses - the shared narratives, norms, values, perceptions and practices of a society, which 'discourse analysis' as a research method seeks to uncover (Gee 2005). Discourses can become internalised, automatic and unconscious over time, in an individual's "inner voice" or their activity 'fossilised' in Vygotsky's terms. The internalised "inner voice" that develops is drawn from sociohistorical meanings and mediated semiotically - through objects or signs, including language.

Other individuals may also mediate discourse in a similar way; they occupy a similar role in the Figured Worlds framework, in which they are represented as figures. Within the Figured Worlds framework, figures represent the people shaping and being shaped by the figured world. Figures do not merely represent the reality of an individual, but take into account the history, culture, and past of an embodied identity. Hence, in this thesis surgery will be considered a figured world, with, for example, surgeons as figures within the surgical realm. The surgeons are figures in Bakhtin's sense: they carry disposition, social identification, and thus meaning (Bakhtin 1981; 1986).

"A figured world is peopled by the figures, characters, and types who carry out its tasks and who also have styles of interacting within, distinguishable perspectives on, and orientations toward it."

Holland et al. (1998, p53)

These figures are mediated via cultural models and signs - that is, semiotically in addition to actual embodiments (Williams 2011). The figure of a surgeon, therefore, may be symbolic; through discursive use of such a symbol, individuals may position themselves relative to it, thereby dialogically constructing a sense of their own identity. 


\section{CHAPTER 1}

Another facet of Figured Worlds is its consideration of social positioning and power - in terms of positional identities constructed in dialogue with socially identified others. Thus, positionality, is an important strength of the Figured Worlds framework. Figures have a position within the figured world, inextricably linked to their social and cultural capital, from which they draw their status and power. This position is always constructed in relation to socially identified others. Certain members may be privileged or disprivileged within the figured world due to, for example, their gender, social background, ethnicity or accent.

"Positional identities have to do with the day-to-day and on-the-ground relations of power, deference and entitlement, social affiliation and distance - with the social-interactional, social-relational structures of the lived world."

Holland et al. (1998, p127)

Here, Holland et al. draw on the concepts of the sociohistorical school and Bourdieu to understand the relative privilege of individuals within a social structure, and the ways positional identities are constructed. An individual carries or embodies its history, which is manifest through interaction with the social world. Through the interaction of this embodied 'history-in-person' and the figured world, affordances to and constraints on an individual's actions are constructed, and, thus, too is a positional identity. Positionality is therefore dynamic - being constantly negotiated - and dependant as much on the an individual's history as the world with which they interact.

As Figured Worlds situates itself in the interaction between identity and structure - in practice - identity evolves and is constantly fluid and changing in response to a journey through a structured social landscape. In Figured Worlds this is the space of self-authoring, where individuals narrate their identities to the world around them.

"The meaning that we make of ourselves is... 'authoring the self', and the site at which this authoring occurs is a space defined by the interrelationship of differentiated 'vocal' perspectives on the social world. ...The self is a position from which meaning is made, a position that is "addressed" by and "answers" others and the "world" (the physical and cultural environment). In answering (which is the stuff of existence), the self "authors" the world-including itself and others. ...Because the self is the nexus of a continuing flow of activity and is participating in this activity, it cannot be finalized... The self authors itself, and is thus made knowable, in the words of others."

Holland et al. (1998, p173) 
In Figured Worlds this self-authorship is dialogic: with every utterance - which, for Bakhtin (1981, p354-5), range "from a brief response in a casual dialogue to major verbal-ideological works (literary, scholarly and others)" - one is answering and addressing others and the world, and is positioning and being positioned within a complex web of social connections and interrelations. This perspective on identification draws extensively on Bakhtin's position on language and identification:

"It might be said... that in the makeup of almost every utterance spoken by a social person... a significant number of words can be identified that are implicitly or explicitly admitted as someone else's, and that are transmitted by a variety of different means. Within the arena of almost every utterance an intense interaction and struggle between one's own and another's word is being waged, a process in which they oppose or dialogically interanimate each other. The utterance so conceived is a considerably more complex and dynamic organism than it appears when construed simply as a thing that articulates the intention of the person uttering it, which is to see the utterance as a direct, single-voiced vehicle for expression."

Bakhtin (1981, p354-355)

Within Figured Worlds, whilst the constraints and limitations on self-narration are acknowledged and delineated, so are the possibilities for becoming - not merely self-authoring within the bounds of society, culture and practice, but also the possibility of creative improvisation - wherein lies an individual's agency, or capacity for self-direction.

One critique of sociocultural theories is that they are deterministic, even pessimistic, in their ideas of constraints on an individual's ability to innovate and exert a degree of agency. In Figured Worlds, an individual's 'history in person' carries momentum; thus the ways in which a person identifies allows them a degree of self-direction. This becomes especially possible if it occurs collectively, and Holland et al. use the example of the Nepalese Tij festivals where women perform annual songs and dances. The festival's dukha and rajniti songs include traditional Hindu discourses of womanhood, but, each year, the women collectively imagine, through songs, a vision of an alternative world where women are more valued. Hence, through the Tij songs, old discourses of womanhood are met with the new; the women engage in what Holland et al. term 'world-making'. Through the continual, dynamic fashioning and refashioning of the self, through processes of identification and selfauthoring, self-direction can occur and thus a degree of agency is possible. Agency can manifest in a multitude of ways, from the mundane or accidental, to 


\section{CHAPTER 1}

large shifts in thinking, or fashioning of new figured worlds altogether. Much of the time individuals are largely unaware of the constraints and affordances invisibly constraining and guiding their actions and practices.

"The everyday aspects of lived identities... may be relatively unremarked, unfigured, out of awareness, and so unavailable as a tool for affecting one's own behavior... [But] Ruptures of the taken-for-granted can remove these aspects of positional identities from automatic performance and recognition to commentary and re-cognition."

Holland et al. (1998, p140-141)

Holland et al. suggest it is the moments when an individual has no experience of or rules for how to act in a new situation - moments of rupture - that improvisation and agency can occur.

"Improvisations are the sort of impromptu actions that occur when our past, brought to the present as habitus, meets with a particular combination of circumstances and conditions for which we have no set response. Such improvisations are the openings by which change comes about from generation to generation. The improvisations of the parental generation are the beginning of a new habitus for the next generation. Improvisations... are, when taken up as symbol, potential beginnings of an altered subjectivity, an altered identity."

Holland et al. (1998, p17-18)

Holland et al. emphasise that, while improvisations represent change, they remain grounded in existing sociohistorical discourses. Hence, it is from orchestration of the collectively held and compulsory discourses available that an individual can improvise; thus, the possibility of liberation as well as the impossibility of escape from discursive constraints exist simultaneously.

"The same semiotic mediators, adopted by people to guide their behaviour, that may serve to reproduce structures of privilege and the identities, dominant and subordinate, defined within them, may also work as a potential for liberation from the social environment. .... When individuals learn about figured worlds and come, in some sense, to identify themselves in those worlds, their participation may include reactions to the treatment they have received as occupants of the positions figured by the worlds."

Holland et al. (1998, p143) 
Thus, through improvisation and orchestration of discourse, figured worlds may become refigured. This is the basis of agency within figured worlds - worlds which shape, and are shaped by, the individuals within them.

This thesis considers the interaction between individual agents (female surgeons and aspiring surgeons) and their social environment (the surgical world), hence, Figured Worlds as a theoretical framework confers several advantages. First, Figured Worlds is a global theory of self and society, rather than a specific theory of, for example, learning or of culture. This allows simultaneous examination of society and practice as a whole. Second, the Figured Worlds understanding of identity brings together society and the individual, and permits space to examine of issues of gender and surgery at a micro- and macro-level simultaneously. Third, Figured Worlds is notable within sociocultural theories for combining the 'optimism of becoming' with the 'pessimism of sociocultural determinism'; Figured Worlds is an ideal framework in which to study agency and sociocultural change.

\section{Sociocultural theories of learning}

The thesis employs Figured Worlds as a meta-theory, or theoretical umbrella, informing research questions, study design and the theoretical stance of the four studies conducted. However, individual studies within the thesis have drawn more heavily on Figured Worlds' theoretical antecedents, including a sociocultural theory of learning, Wenger's Communities of Practice (1998). In this section we outline how sociocultural theories may inform an epistemology of learning.

It is important to highlight the implications of a sociocultural approach for an epistemology of learning, and the difference from an individualist epistemology. From a sociocultural perspective, learning is understood to occur through the interaction of an individual with society, via participation or practice; hence, it is intrinsically social. This separates it from other, more individualist, perspectives, which treat learning more as acquisition taking place in the individual, and thus memory and knowledge are self-held and 'owned' and, further, are potentially tradable and exchangeable. In social learning theory, learning, memory and knowledge are held collectively in a community or social group. To delineate this further we may highlight the classic distinction between the works of Piaget and Vygotsky, both constructivist in their approach, in that they consider the role of the social world. While Piaget did concern himself with social interaction in learning, learning remained something that took place within the individual, and could only be measured in terms of what the individual could do alone, as a result of cognitive maturation or reflective abstraction. For social learning theorists, learning exists and can only exist between people; without others 


\section{CHAPTER 1}

there can be no learning, as learning is essentially social and thus exists the essential role of others within it. Holquist goes further,

"In dialogism, the very capacity to have consciousness is based on otherness. ...in dialogism consciousness is otherness."

Holquist (2002, p18)

Hence, the 'mind' or locus of learning therefore, in a sociocultural perspective is not merely found in the individual, but between people in dialogue. Learning can also be held and mediated by artifacts or cultural tools; a surgical example of this is the scalpel, which Bleakley et al. (2011) frame as "a concrete example of distributed cognition" whereby progression of expertise, of experimentation with different shapes, materials and uses are held within a set of objects distributed between individuals. Here, while intended purpose and the human hand determine the shape of the scalpel, the scalpel also, dialogically, shapes the hand, in that surgeons, through the scalpel, learn to make effective incisions using their hands. Holland et al., drawing on the concepts of Bakhtin, put it in terms of 'self-authoring' oneself into existence:

"The self is a position from which meaning is made, a position that is "addressed" by and "answers" others and the "world" (the physical and cultural environment). In answering (which is the stuff of existence), the self "authors" the world-including itself and others."

Holland et al. (1998, p173)

In this sense, learning is 'change' in the figured world, whether change of oneself, of others, or of a practice. If learning is change, then, for example, medical students learn more than a medical school's formal curriculum during their time at university. This idea has been framed within medical education as the 'hidden curriculum', which Hafferty and Hafler (2011) have defined as the culture, beliefs, and behaviours enacted by those within a community, passed to students, who subsequently enact it themselves. Another sociocultural learning theorist, Wenger further emphasises this idea of situated learning that is socioculturally mediated:

"No matter what is said, taught, prescribed, recommended, or tested, newcomers are no fools; once they have actual access to the practice, they soon find out what counts."

Wenger (1998, p156)

Indeed, Communities of Practice may be said to be a true sociocultural theory of learning, in that it concerns itself primarily with learning, whereas the Figured Worlds framework may be considered a global theory. In Communities of 
Practice, in accordance with sociocultural theories, the interaction of the self with the social world is essential for change, and Wenger terms this 'participation'. Learners may be seen to have a 'trajectory' within a community of practice, wherein, through participation, they progress in competency and legitimacy, both of which are continually negotiated within the community. In Communities of Practice, identity is very important; again, it is a dynamic concept, which occurs by three 'modes of identification' identified by Wenger: imagination, whereby individuals envisage themselves as a member of a community; participation, whereby they engage with the practices of the community; and finally, alignment, whereby they uncover and adopt the community's values. There are clear parallels, then, with Figured Worlds' concept of identity in that, fundamentally, identity is 'identity in practice' and occurs through the interaction of the self and society. Indeed, Wenger (2010) stipulates that Communities of Practice is compatible with a myriad of other sociocultural theories in what he terms a 'plug and play' relationship.

\section{Sociocultural perspectives of gender and feminism}

In society, when we talk of gender, of men and women, it usually refers directly to biological sex. In this commonly-held sense, people can be either a man or a woman, a categorisation understood to be based on their anatomy: "a person is a gender, and is one in view of his or her sex" (Butler 2007). Ontologically this assumes that the body, and gender, exist independently of the social world. So widely held is this perspective, it has been termed hegemonic. It forms the basis of the vast majority of the literature on gender in medical education (Bleakley 2013). A sociocultural perspective considers gender as a discourse, which becomes internalised, in a manner akin to Vygotsky's concept of the development of higher cognitive function via semiotic mediation. To extend this, discourses of gender, too, become 'fossilised'. It is with this perspective on gender that contemporary feminism is concerned.

In what have retrospectively been termed 'three waves', feminism has evolved over the the past century to consider gender as discursive. Feminism's 'first wave' was prominent in the early twentieth century, when suffragettes campaigned for extending the vote to women. By the middle of the twentieth century, suffrage had been extended to women in most countries, and the 'second wave' of feminism considered more the equality of opportunity in the workplace and home, and wider issues of social justice. Further, the advent of the contraceptive pill provided a focus for women to campaign for control of their reproductive capabilities. 'Third wave' or poststructuralist feminism emerged in the 1980s from consideration of gendered discourse. Butler's influential book Gender Trouble (1990), published at the end of that decade, critiqued "the assumption that the term women denotes a common identity". Her ideas stemmed from the insight that the placement of 'women' as the 
subjects of feminism compounded the issue, through reproducing the gendered discourses from whose grasp feminists were seeking emancipation.

Butler developed a perspective of gender as performative; people do gender, in contrast to simply being either a man or a woman. In this sense, people learn to 'do gender' as discourses of gender become internalised and hence 'written' on the body - 'fossilised'. This idea necessitated an ontological shift from the hegemonic model, and certainly the medical model, of the body. If gender is considered performative, the body's reality is constituted by bodily acts; the body cannot be said to exist outside of performance, outside of what Butler terms "fabrications". Gender, then, is the learned enactment of sociohistorical discourses collectively-held within a culture.

The hegemonic nature of the prevailing discourses of gender and femininity, notably of gender in terms of biology, make it difficult to communicate research that considers gender in terms of discourse. This is especially true when representing narratives of individuals who construct gender identities within the hegemonic discourse. While this thesis draws on poststructuralist feminism, its studies are situated in the field of medical education; hence, pragmatically, this necessitates adopting hegemonic discourse to communicate to the commonly held sense of gender, for example by referring to 'women' and 'female' as common identities.

There are direct parallels between discursive theories of poststructuralist feminism and Figured Worlds, and Holland et al.'s discussion of hegemonic gender discourses illustrates how the two overlap:

"These feminist critiques see many cultural discourses as impositions, pushing women and men to behaviour compatible with the structures and institutions that favour members of one social category over another. Feminists, then, provide yet another basis for suspecting descriptions of seemingly holistic, coherent, integrated cultures. They ask: Whose accounts of "the" culture is being privileged? Whose view is being constructed as though it were the only one? And they answer: "Not the view of those in positions of restricted privilege." Accounts of culture that ignore the importance of social position surreptitiously participate in the silencing of those who lack privilege and power."

Holland et al. (1998, p25)

Whilst many scholars' primary research focus is gender itself, the primary focus of this thesis is surgical culture, and the discourses and processes of identification to be explored therein. Importantly, the studies in this thesis do not originate from an explicitly feminist stance, but rather from a sociocultural 
perspective, in which discourses and embodiment of gender are considered aspects of 'culture in practice'. However, to explore gender from such a perspective, using the sociocultural theories outlined above, is to adopt many of the concepts of poststructuralist feminism; indeed, these ideas undoubtedly contributed to this thesis. Both the research questions and the study findings could be said to address, and may be identified by many as, a feminist research agenda; yet this is not the stance from which this thesis originates. Adopting a primarily feminist stance when seeking to understand a complex problem has many strengths. It is possible to privilege the voices and positions of those most often silenced by the dominant masculine voices and discourses. Equally, it allows blurring of distinctions due to gender and 'making strange' the phenomenon under study (Kuper et al. 2013). However, it also comes at a cost automatically focusing the research on gendered phenomena. In this thesis, the culture, discourses and processes of identification are of primary interest. This includes how gender interacts with and mediates these, but not solely how it does; it is the interaction and complex interplay of power, class, background of history-in-person, and its interaction with the figured world - that is the focus of this thesis. Allowing gender to emerge from data via subsequent analysis represents a better position from which to understand this complexity. 


\section{CHAPTER 1}

\section{Thesis overview}

\section{Thesis aims}

By employing a sociocultural perspective, this thesis seeks to explore surgical culture - the figured world of surgery. In doing so, the studies seek to learn about the discourses of the surgical world, and the ways in which women are positioned, and position themselves, within those discourses. Such an approach aims to to better explain why women are under-represented in surgery.

More specifically, the studies contained in this thesis aim to understand medical students' experiences of surgery and their perceptions of surgery and surgeons. This will inform a sociocultural analysis of the push and pull factors influencing pursuit of a surgical career trajectory and the culture of surgery. Extending this sociocultural critique into issues of gender will permit exploration of female surgeons' experiences and identities and of why women continue to be underrepresented in surgery. Fulfilment of these aims would make it possible to inform national policy development, to better support aspiring surgeons, both male and female, and to better support women already in surgical training or practice.

In summary, this thesis seeks to explore the culture of the figured world of surgery, how individuals experience this, and how certain groups, and specifically women, are positioned within this culture. Further, it seeks to examine how individuals identify within the figured world of surgery.

\section{Context}

This research was undertaken within The University of Manchester and affiliated UK National Health Service (NHS) hospitals. Manchester Medical School is a large UK medical school with approximately 450 medical students per year of a five year undergraduate curriculum. There are two pre-clinical years, which include 'early experience' of clinical care in hospital and community settings. Thereafter follow three clinical years based in teaching hospital, district general hospitals and community settings, with the first surgical placement coming in third year. Manchester also has a pre-medical course for those wishing to transition to medical school but without the required science entry requirements. It is also relatively common for students to 'intercalate', taking a year out of medical school, to pursue a specialist Bachelors, Masters or, rarely, a Doctoral degree. Importantly for consideration of surgical careers, Manchester has an active undergraduate surgical society. Named 'Scalpel', this organisation runs careers lectures and events and actively promotes surgery as a career option to male and female students. Manchester has similar societies for other careers, such as oncology and dermatology. 
Postgraduate surgical training in the UK has undergone large scale change over the past decade, which has included several revisions of the post-graduate surgical training pathways. After graduation from medical school there is currently a recommended surgical career trajectory (Table 1). Each stage requires competitive application, meaning many aspiring surgeons take years 'out-of-programme' to build their competitiveness through research, teaching or extra training. It is also possible to train part-time for all or some of the training. Different surgical subspecialties vary in training length. Therefore, combining these factors, the length of surgical training can vary between trainees depending on their individual route. The greatest 'bottlenecks' to advancement along this trajectory have changed with each overhaul of the training pathway. At the moment, this falls between Core Surgical Training and Specialty Training (Table 1), with an application ratio of five core trainees to every two specialty trainee posts (McNally 2012). There have also been trainees caught between training pathway overhauls, who have been forced to be innovative with their own route. There are also 'staff-grade' and 'associate specialist-grade' (SAS) posts. SAS doctors, previously called 'non-training' grades, train outside the traditional year-by-year advancement pathway.

\begin{tabular}{|c|c|c|}
\hline Length & Grade / stage & \\
\hline \multirow[t]{2}{*}{ Medical school } & 5 years & $\begin{array}{l}\text { +/- BSc/Masters/PhD } \\
\text { +/- sabbaticals }\end{array}$ \\
\hline & Competitive application & \\
\hline \multirow[t]{2}{*}{ Foundation training } & 2 years & +/- sabbaticals \\
\hline & Competitive application & \\
\hline \multirow[t]{2}{*}{ Core surgical training } & 2 years & +/- sabbaticals \\
\hline & Competitive application & \\
\hline \multirow[t]{2}{*}{ Specialist surgical training } & $\begin{array}{l}5-7 \text { years } \\
\text { depends on surgical specialty }\end{array}$ & $\begin{array}{l}\text { +/- fellowships } \\
\text { +/- higher degrees } \\
\text { +/- sabbaticals }\end{array}$ \\
\hline & Competitive application & \\
\hline Consultant post & Remainder of career & \\
\hline
\end{tabular}

Table 1 - Outline of the UK surgical career pathway 
UK surgical training is overseen by three Royal Colleges of Surgeons (RCS variously of England, Edinburgh and Glasgow), bodies whose membership is governed by a membership exam, the intercollegiate MRCS. An idiosyncrasy of British surgical training is that, once surgeons have taken their membership exams they traditionally stop using ' $D r$ ' as a form of address and readopt the title 'Mr', or 'Miss', 'Mrs' or 'Ms' for females. This tradition dates back to the sixteenth century, when physicians alone were entitled to practice medicine and to use the title 'Dr'. Henry VIII established the Company of BarberSurgeons, the predecessor of the modern-day RCS; hence, the idiosyncrasy of renouncing the title of ' $D r^{\prime}$ ' upon membership of the RCS remembers the distinct provenance of surgery as a trade guild. The UK has a national organisation called 'Women in Surgery', based within the RCS, whose mission statement is "To encourage, enable and inspire women to fulfil their surgical ambitions". This organisation promotes networking as a way to encourage female medical students to engage in surgical careers, and support female surgeons at all levels of training. 


\section{Chapter outlines and research questions}

This thesis comprises seven chapters exploring surgical culture and its influence on career decisions, with a special focus on women in surgery. As this PhD thesis includes five individual papers published within research journals, some repetition of subject matter between chapters was unavoidable.

Chapter 2 comprises the first empirical study of this thesis. The study seeks to answer the research questions: what are medical students' experiences of surgery? And, what is the role of paradigmatic trajectories? The empirical study consists of a qualitative analysis of semi-structured interviews with medical students, both male and female, regarding their experiences at medical school. The data analysis makes use of the concept of 'paradigmatic trajectories' from Communities of Practice (Wenger 1998). Hence, the chapter represents a sociocultural analysis of how medical students experience the surgical world.

Published as: Hill EJR, Vaughan S (2013). The only girl in the room: how paradigmatic trajectories deter female students from surgical careers. Med Educ, 47(6):547-56.

Chapter 3 reports another empirical study exploring medical students' thoughts, beliefs and experiences regarding career decisions and surgery. The study seeks to answer the research question: is there a hidden curriculum of surgical careers? And, if so, how do medical students encounter and negotiate this, and what influence does it have on who chooses a surgical career? An exploratory questionnaire informed the discussion schedule for semi-structured individual interviews. Data collection and analysis were iterative using constructivist grounded theory, with analysis following each interview, and guiding adaptation of our discussion schedule to further our evolving model. This chapter builds upon Chapter 2, in that it explores in more detail, using the concepts of Bourdieu, how students encounter and negotiate surgery's 'culture in practice'.

Published as: Hill EJR, Bowman KA, Stalmeijer RE, Hart J (2014). You've got to know the rules to play the game: how medical students negotiate the hidden curriculum of surgical careers. Med Educ, In Press.

Chapter 4 is an empirical study that explores medical students' perceptions of surgery and surgeons, and how these influence their ideas about surgical careers. Exploratory free-text questionnaires were administered to a purposive sample of students to capture perceptions of surgeons and surgery. Analysis of questionnaire data was used to develop a schedule for in-depth semi-structured individual interviews, exploring students' perceptions in greater detail. Discourse analysis was used to elucidate the sociocultural effects of stereotypes 


\section{CHAPTER 1}

on career decisions. This complements Chapters 2 and 3, by examining more closely students' understanding of the surgical world.

Submitted as: Hill EJR, Bowman KA, Stalmeijer RE, Solomon Y, Dornan T (2014). Can I cut it? Medical students' perceptions of surgeons and surgical careers.

Chapter $\mathbf{5}$ is a commentary piece, published to accompany a meta-analysis of gender and medical students' career intentions (van Tongeren-Alers et al. 2014). The commentary explores potential sociocultural explanations for differential career preferences amongst male and female medical students. In this sense it embeds the findings of both Chapters 2-4 in the wider literature, as well as including a sociocultural critique of previous medical education papers on 'career choice'. Drawing a contrast between individualist and sociocultural, and hence deterministic, theories, the commentary questions the extent to which students are 'free' to 'choose' a career. In particular, it discusses how sociocultural constraints affect individuals differently, and how such constraints, for example differential access to participation, may influence the career paths accessible to students.

Published as: Hill EJR, Giles JA (2014). Career decisions and gender: the illusion of choice? Perspect Med Educ, In Press.

Chapter 6, the final study, uses Figured Worlds explicitly to focus on those women who do pursue a surgical career, asking how they, as female surgeons, self-narrate their identities. This chapter builds on Chapters 2-5, which raise the issue of sociocultural constraints to a career in surgery acting on some students, to examine the identities of women who have decided to engage in a surgical career. The study comprises fifteen individual interviews with women throughout surgical careers, from medical students aspiring to surgery to senior consultant surgeons. Data were explored via discourse analysis with a priori themes derived from the literature on women in surgery and Figured Worlds. The study seeks to understand participants experiences of surgery, and how they positioned themselves, and were positioned by others, in the surgical world, and, further, what 'identity work' they engaged in to do this.

Submitted as: Hill EJR, Solomon Y, Dornan T, Stalmeijer RE (2014). You become a man in a man's world: is there discursive space for women in surgery?

Chapter 7 provides an integrated discussion of Chapters 2-6. Specifically, it reflects on the findings from each study, and aims to synthesise their findings to demonstrate what this thesis, as a whole, adds to the body of literature; it situates this thesis in the field of gender and surgical culture, and makes recommendations for both practice and future research. 


\section{References}

Are C, Stoddard HA, Prete F, et al. (2011). An international perspective on interest in a general surgery career among final-year medical students. Am J Surg, 202(3):352356.

Azizzadeh A, McCollum CH, Miller CC, et al. (2003). Factors influencing career choice among medical students interested in surgery. Curr Surg, 60(2):210-213.

Bakhtin MM (1981). The dialogic imagination: four essays. Austin, TX: University of Texas Press.

Bakhtin MM (1986). Speech genres and other late essays. Austin, TX: University of Texas Press.

Bickel J (2011). Women's career development: what does this have to do with men? Ann Surg, 253(4):644-646.

Bleakley A (2013). Gender matters in medical education. Med Educ, 47(1):59-70.

Bleakley A, Bligh J, Browne J (2011). Learning from Learning Theory. In: Medical Education for the Future. London: Springer, p33-42.

BMA Board of Medical Education (2005). The demography of medical schools: a discussion document. London: British Medical Association.

Boerma WG, van den Brink-Muinen A (2000). Gender-related differences in the organization and provision of services among general practitioners in Europe: a signal to health care planners. Med Care, 38(10):993-1002.

Boseley S (2009). The future is female - how women are transforming face of the health service. London: Guardian News and Media Ltd. Available from: http:// www.theguardian.com/society/2009/jun/03/women-doctors-nhs-medicine-review [Date accessed: 21 April 2014]

Boulis AK, Long JA (2004). Gender differences in the practice of adult primary care physicians. J Womens Health (Larchmt), 13(6):703-712.

Bourdieu P (1986). The Forms of Capital. In: Handbook of Theory and Research for the Sociology of Education. New York, NY: Greenwood, p46-58.

Buddeberg-Fischer B, Klaghofer R, Abel T (2003). The influence of gender and personality traits on the career planning of Swiss medical students. Swiss Med Wkly, 133:535-540.

Butler JP (1990). Gender Trouble, 1st ed. London: Routledge.

Butler JP (2007). Gender Trouble, 2nd ed. London: Routledge.

Cassell J (2000). The Woman in the Surgeon's Body. London: Harvard University Press.

Center for Workforce Studies (2012). 2012 Physician Specialty Data Book. Washington, DC: Association of American Medical Colleges.

Cockerham WT, Cofer JB, Biderman MD, Lewis PL, Roe SM (2004). Is there declining interest in general surgery training? Curr Surg, 61(2):231-235.

Cofer JB, Burns RP (2008). The Developing Crisis in the National General Surgery Workforce. J Am Coll Surg, 206(5):790-795.

Cole M, John-Steiner V, Scribner S, Souberman Eeds (1978). Mind in society: the development of higher psychological processes. Cambridge, MA: Harvard University Press.

Dacre J (2008). Are there too many female medical graduates? No. BMJ, 336(7647):749.

Darzi A (1999). A measure of scalpel skills. London: TSL Education Limited. Available 


\section{CHAPTER 1}

from: http://www.timeshighereducation.co.uk/news/a-measure-of-scalpel-skills/ 147683.article [Accessed 21 April 2014]

Davidson JM, Lambert TW, Goldacre MJ, Parkhouse J (2002). UK senior doctors' career destinations, job satisfaction, and future intentions: questionnaire survey. BMJ, 325(7366):685-686.

Department of Health (2005). Hospital, Public Health Medicine (PHM) and Community Health Service (CHS) Medical and Dental Workforce Census, England, at 30 September 2004 - detailed results. Leeds: Department of Health Publications.

Drinkwater J, Dornan T, Tully MP (2008). The effect of gender on medical students' aspirations: a qualitative study. Med Educ, 42(4):420-426.

Dusch MN, O'Sullivan PS, Ascher NL (2014). Patient perceptions of female surgeons: how surgeon demeanor and type of surgery affect patient preference. J Surg Res, 187(1): 59-64.

Fischer JE (2007). The impending disappearance of the general surgeon. JAMA, 298(18): 2191-2193.

Gardezi F, Lingard L, Espin S, et al. (2009). Silence, power and communication in the operating room. J Adv Nurs, 65(7):1390-1399.

Gee JP (2005). An introduction to discourse analysis: Theory and method, 2nd ed. London: Routledge.

Gofton W, Regehr G (2006). What we don't know we are teaching: unveiling the hidden curriculum. Clin Orthop Relat Res, 449:20-27.

Greatorex R, Sarafidou K (2010). Surgical Workforce 2010: Profile and Trends. London: Royal College of Surgeons of England.

Hafferty FW, Hafler JP (2011). The Hidden Curriculum, Structural Disconnects and the Socialization of New Professionals. Innovation and Change in Professional Education, 6:17-35.

Hager P, Hodkinson P (2009). Moving beyond the metaphor of transfer of learning. $\mathrm{Br}$ Educ Res J, 35(4):619-638.

Heilman M, Parks-Stamm EJ (2007). Gender stereotypes in the workplace: Obstacles to women's career progress. Advances in Group Processes, 24:47-77.

Holland D, Lachicotte W Jr, Skinner D, Cain C (1998). Identity and Agency in Cultural Worlds. London: Harvard University Press.

Holquist ME (2002). Dialogism, 2nd ed. London: Routledge.

Jolliff L, Leadley J, Coakley E, Sloane RA (2011). Women in U.S. Academic Medicine and Science: Statistics and Benchmarking Report. Washington, DC: Association of American Medical Colleges.

Kaderli R, Guller U, Muff B, Stefenelli U, Businger A (2010). Women in surgery: a survey in Switzerland. Arch Surg, 145(11):1119-1121.

Kuper A, Whitehead C, Hodges BD (2013). Looking back to move forward: using history, discourse and text in medical education research: AMEE guide no. 73. Med Teach, 35(1):e849-60.

Laurence C, Elliott T (2007). When, what and how South Australian pre-registration junior medical officers' career choices are made. Med Educ, 41(5):467-475.

Lempp $\mathrm{H}$, Seale $\mathrm{C}$ (2004). The hidden curriculum in undergraduate medical education: qualitative study of medical students' perceptions of teaching. BMJ, 329(7469):770773. 
Li R, Buxey K, Ashrafi A, Drummond KJ (2013). Assessment of the role of a student-led surgical interest group in surgical education. J Surg Educ, 70(1):55-58.

Lingard L, Reznick R, Espin S, Regehr G, DeVito I (2002). Team communications in the operating room: talk patterns, sites of tension, and implications for novices. Acad Med, 77(3):232-237.

Magovern GJ, Simpson KA (2011). Curriculum innovation: the key to recruiting the best and brightest. J Thorac Cardiovasc Surg, 141(5):1114-1115.

Maiorova T, Stevens F, Scherpbier A, van der Zee J (2008). The impact of clerkships on students' specialty preferences: what do undergraduates learn for their profession? Med Educ, 42(6):554-562.

Makama JG, Garba ES, Ameh EA (2012). Under representation of women in surgery in Nigeria: by choice or by design? Oman Med J, 27(1):66-69.

Marschall JG, Karimuddin AA (2003). Decline in popularity of general surgery as a career choice in North America: review of postgraduate residency training selection in Canada, 1996-2001. World J Surg, 27(3):249-252.

McDonald K, Sutton J (2009). Surgical workforce: an emerging crisis. Bull Am Coll Surg, 94(5):21-26.

McHugh S, Corrigan M, Sheikh A, et al. (2011). Factors influencing career choice after initial training in surgery. World J Surg, 35(3):487-492.

McKinstry B (2008). Are there too many female medical graduates? Yes. BMJ, 336(7647): 748.

McNally SA (2012). Surgical Training: Still Highly Competitive But Still Very Male. Bull $R$ Coll Surg Engl, 94(2):53-55.

Mihalynuk T, Leung G, Fraser J, Bates J, Snadden D (2006). Free choice and career choice: Clerkship electives in medical education. Med Educ, 40(11):1065-1071.

Monrouxe LV (2010). Identity, identification and medical education: why should we care? Med Educ, 44(1):40-49.

Neumayer L, Kaiser S, Anderson K (2002). Perceptions of women medical students and their influence on career choice. Am J Surg, 183(2):146-150.

NHS Health and Social Care Information Centre (2011). NHS Staff 2001-2011 (Medical and Dental). Leeds: NHS Health and Social Care Information Centre.

Nicholson S (2002). 'So you row, do you? You don't look like a rower.' An account of medical students' experience of sexism. Med Educ, 36(11):1057-1063.

Palermos SO (2012). Extending Cognition in Epistemology. Edinburgh: The University of Edinburgh.

Pas B, Peters P, Eisinga R, Doorewaard H, Lagro-Janssen T (2011). Explaining career motivation among female doctors in the Netherlands: the effects of children, views on motherhood and work-home cultures. Work Employment Society, 25(3):487-505.

Peters K, Ryan M, Haslam SA, Fernandes H (2012). To belong or not to belong: Evidence that women's occupational disidentification is promoted by lack of fit with masculine occupational prototypes. J Personnel Psychol, 11(3):148-158.

Pikoulis E, Avgerinos ED, Pedeli X, et al. (2010). Medical students' perceptions on factors influencing a surgical career: the fate of general surgery in Greece. Surgery, 148(3): 510-515.

Ravindra P, Fitzgerald JEF (2011). Defining surgical role models and their influence on career choice. World J Surg, 35(4):704-709. 


\section{CHAPTER 1}

Riska E, Novelskaite A (2008). Gendered Careers in Post-Soviet Society: Views on Professional Qualifications in Surgery and Pediatrics. Gender Issues, 25(4):229-245.

Rose G, Rukstalis MR, Schuckit MA (2005). Informal Mentoring Between Faculty and Medical Students. Acad Med, 80(4):344.

Royal College of Physicians (2009). Women and medicine. London: Royal College of Physicians.

Royal College of Surgeons of England (2013). Women in Surgery (WinS). Available from: http://surgicalcareers.rcseng.ac.uk/wins [Accessed 21 April 2014]

Sanfey HA, Saalwachter-Schulman AR, Nyhof-Young JM, Eidelson B, Mann BD (2006). Influences on Medical Student Career Choice: Gender or Generation? Arch Surg, 141(11):1086-1094.

Signer MM, Beran RL (2005). Results of the National Resident Matching Program for 2005. Acad Med, 80(6):610-612.

Singh P, Aggarwal R, Darzi A (2014). Review of Selected National Surgical Curricula: Quantity is Not the Sole Marker of Quality. J Surg Educ, 71(2):229-240.

Stewart RM, Liao LF, West M, Sirinek KR (2013). The general surgery workforce shortage is worse when assessed at county level. Am J Surg, 206(6):1016-1023.

Thomas JM (2014). Why having so many women doctors is hurting the NHS: A provocative but powerful argument from a leading surgeon. London: Associated Newspapers Ltd. Available from: http://www.dailymail.co.uk/debate/ article-2532461/Why-having-women-doctors-hurting-NHS-A-provovcative-powerfulargument-leading-surgeon.html [Accessed 21 April 2014]

Tomizawa $Y$ (2013). Women in surgery: little change in gender equality in Japanese medical societies over the past 3 years. Surg Today, 43(10):1202-1205.

Tsouroufli M, Rees CE, Monrouxe LV, Sundaram V (2011). Gender, identities and intersectionality in medical education research. Med Educ, 45(3):213-216.

van der Velden LFJ, Hingstman L, Heilingers PJM, Hansen J (2008). Toenemend percentage vrouwen in de geneeskunde: verleden, heden en toekomst. Nederlands Tijdschrift voor Geneeskunde, 152(40):2165-2171.

van Tongeren-Alers M, Dielissen P, van Leerdam L, Lagro-Janssen A (2014). Gendered specialties during medical education: a literature review. Perspect Med Educ, In Press.

Vygotsky LS (1986). Thought and language. Cambridge, MA: MIT Press.

Washburn ER (2000). Are you ready for generation X? Physician Exec, 26(1):51-57.

Wenger E (1998). Communities of Practice. Cambridge: Cambridge University Press.

Wenger E (2010). Communities of Practice and Social Learning Systems: the Career of a Concept. In: Blackmore C, ed. Social Learning and Communities of Practice. London: Springer.

Williams (2011). Teachers telling tales: the narrative mediation of professional identity. Research in Mathematics Education, 13(2):131-142.

Williams JE, Best DL (1982). Measuring Sex Stereotypes: A Thirty-Nation Study. Newbury Park, CA: Sage Publications.

Wolfe CV (2005). Women in medicine: an unceasing journey. Arch Phys Med Rehabil, 86(7):1283-1286.

Wolosin RJ, Gesell SB (2006). Physician gender and primary care patient satisfaction: no evidence of "feminization". Qual Manag Health Care, 15(2):96-103. 
INTRODUCTION

World Health Organisation (2011). Global Health and Aging. New York, NY: World Health Organisation.

Zimny GH, Thale TR (1970). Specialty choice and attitudes toward medical specialists. Soc Sci Med, 4(2):257-264. 



\section{Chapter 2}

\section{EXPERIENCES OF SURGERY}

\section{The only girl in the room:}

how paradigmatic trajectories deter female students from surgical careers

\section{Published as:}

Hill EJR, Vaughan S (2013). The only girl in the room: how paradigmatic trajectories deter female students from surgical careers. Med Educ, 47(6):547-56. 


\section{CHAPTER 2}

\section{Abstract \\ Objectives}

Over $60 \%$ of UK medical students are female, yet only $33 \%$ of applicants to surgical training are women. Role modelling, differing educational experiences and disidentification in female medical students have been implicated in this disparity. We are yet to fully understand the mechanisms that link students' experiences with national trends in career choices. We employ a hitherto unused concept from the theory of Communities of Practice: paradigmatic trajectories. These are visible career paths provided by a community and are cited by Wenger (1998) as potentially the most influential factors shaping the learning of newcomers. We pioneer the use of this theoretical tool in answering the research question: How do paradigmatic trajectories shape female medical students' experiences of surgery and subsequent career intentions?

\section{Methods}

This qualitative study comprised a secondary analysis of data sourced from 19 clinical medical students. During individual, in-depth, semi-structured interviews, we explored these students' experiences at medical school. We carried out thematic analysis using sensitising concepts from communities of practice theory, notably that of 'paradigmatic trajectories'.

\section{Results}

Female students' experiences of surgery were strongly gendered; they were positioned as 'other' in the surgical domain. Four key processes - seeing, hearing, doing and imagining - facilitated the formation of paradigmatic trajectories, on which students could draw when making career decisions. Female students were unable to see or identify with other women in surgery. They heard about challenges to being a female surgeon, lacked experiences of participation, and struggled to imagine a future in which they would be successful surgeons. Thus, based on paradigmatic trajectories constructed from exposure to surgery, they self-selected out of surgical careers. By contrast, male students had experiences of 'hands-in' participation and were not marginalised by paradigmatic trajectories.

\section{Conclusions}

The concept of the paradigmatic trajectory is a useful theoretical tool with which to understand how students' experiences shape career decisions. Paradigmatic trajectories within surgery deter female students from embarking on careers in surgery. 


\section{Introduction}

Over $60 \%$ of UK medical students are female, yet only $33 \%$ of applicants to surgical training are women (Greatorex \& Sarafidou 2010; NHS Health and Social Care Information Centre 2011; McNally 2012). This pattern is mirrored in many countries, yet we do not fully understand the reasons why fewer women enter careers in surgery. Differing experiences, access to role models and identity formation are likely to be important in explaining this disparity (Babaria et al. 2011; Ravindra \& Fitzgerald 2011; Peters et al. 2012).

Female students have different educational experiences to their male peers (Babaria et al. 2011), and it has been shown that within medical education women are significantly more likely to suffer sexual harassment or abuse (Oancia et al. 2000; McAvoy 2003; Hinze 2004; Witte et al. 2006; Rees \& Monrouxe 2011). 'Subtle' or everyday sexism has a less overt, but arguably greater, impact on students' experiences. The cumulative effect of repetitive moments of inequity, often too minor to be challenged easily, results in feelings of not belonging (Beagan 2001). Barbaria et al. (2011) explored this further, creating a taxonomy of the ways in which female students' experiences were gendered and describing how expectations of the future influenced subsequent specialty choices. With regard to surgery, Stratton et al. (2005) demonstrated that inequity of experience affected medical students' choice of specialty.

For students considering future careers and access to learning opportunities, role models are important (Rose et al. 2005; Yazigi et al. 2006; Elzubeir \& Rizk 2008). Students who have a surgical role model are more likely both to aspire to a career in surgery and to feel they have an understanding of what such a career would entail (Ravindra \& Fitzgerald 2011). Gender is important in the choice of a role model (Elzubeir \& Rizk 2008; Lempp \& Seale 2004); however, the division of labour in a clinical learning environment continues to be clearly gendered as women take on more of the lower paid work in this setting (Davies 2003). A lack of women in senior positions, particularly women surgeons, may have an impact on medical students' experiences of surgery. The embodied nature of surgical learning is often at odds with societal expectations of what it is to be feminine; female newcomers to this domain can therefore find themselves engaging in deliberate actions to reproduce or challenge these expectations (Cassell 1996). With few role models to support students' reconciliation of the surgical and gender roles, many potential future surgeons may find identification with this career path difficult.

Research has demonstrated that female surgical trainees identify less with senior surgeons than their male counterparts (Peters et al. 2012). In one study, the stereotypically male attributes of physical strength and competitiveness, valued within surgery, led to the disidentification of female medical students 


\section{CHAPTER 2}

(Lempp \& Seale 2006). Other analyses of stereotypes in workplaces and within medical learning environments have highlighted the significant and complex influences they can have on women's identity formation, and the treatment of and experiences afforded to women in such contexts (Conway et al. 1996; Nicholson 2002; Heilman \& Parks-Stamm 2007; Danaher \& Crandall 2008; Drinkwater et al. 2008; Brescoll et al. 2011; Ceci \& Williams 2011; Taylor et al. 2011).

In summary, gendered experiences, lack of access to role models, and disidentification all impact on medical students' experiences of surgery; however, no work has explored the process underlying the interaction of these factors. While macro-level patterns indicate fewer women apply to enter surgical careers, micro-level analysis reveals that female medical students have different, and often negative, experiences compared with their male counterparts. Here, we employ a hitherto unused concept from the theory of Communities of Practice (Wenger 1998) to explore the underlying mechanisms linking these two phenomena.

From the perspective of Communities of Practice theory, learning is conceived as a trajectory and often as a process of increasing participation in the practices of a community. Its key focus is the bridge between identity and practice. Wenger (1998) describes the importance of 'paradigmatic trajectories', which are visible career paths provided by a community that shape how individuals negotiate and find meaning in their own experiences. These paradigmatic trajectories are constructed via community members, who offer living examples of potential journeys through a community. Likewise, composite stories can be constructed from many people's experiences to become a paradigmatic trajectory. Importantly, Wenger proposes:

"Exposure to this field of paradigmatic trajectories is likely to be the most influential factor shaping the learning of newcomers. In the end, it is its members - by their very participation - who create a set of possibilities to which newcomers are exposed as they negotiate their own trajectories. No matter what is said, taught, prescribed, recommended, or tested, newcomers are no fools; once they have actual access to the practice, they soon find out what counts."

Wenger 1998

Students are highly sensitive to these paradigmatic trajectories; they need to know 'what counts' in order to establish increasing legitimacy and to access participation within a community. This study aims to examine how paradigmatic trajectories shape female medical students' experiences of surgery and subsequent career intentions. 


\section{Methods}

Data were collected as part of a larger study examining medical students' participation in clinical learning environments. Ethics approval was granted by The University of Manchester Research Ethics Committee. An overwhelming, yet unexpected, story that emerged from the data was that of female students' non-participation in surgery. This prompted a secondary analysis of all data pertaining to surgery, which were interrogated via thematic analysis, employing the concept of paradigmatic trajectories as a sensitising concept.

\section{Setting and participants}

The research was carried out within the medical school at The University of Manchester, a large UK medical school with a 5-year, problem-based learning (PBL) medical curriculum, which includes the early provision of clinical experience in the first 2 years. Participants $(n=19)$ were medical students in the clinical phase (Years 3 and 4) of their training. The year groups were approximately $60 \%$ female. In order to gather a range of experiences for this larger primary study, students were sampled purposively by gender, base teaching hospital, academic achievement and ethnicity. Participants who met the inclusion criteria were invited by email to take part in the study. It is important to note that because the present study represents a secondary analysis, there was no iterative process between data collection and analysis. This meant that we were restricted to the original dataset and could not sample according to emerging findings. For example, in our dataset, none of the female students interviewed experienced a particularly hands-on form of participation, but our methodology precluded the subsequent recruitment of women with these experiences.

\section{Data collection and analysis}

Semi-structured individual interviews lasting a maximum of 90 minutes were carried out. Interviews explored students' experiences and began with the question: 'Could you tell me about your experience of becoming a doctor?' The interviewer went on to ask further questions, such as 'Can you describe any moments when you felt you particularly belonged?' and 'Have there been any times you felt you didn't belong or felt excluded?' All interviews were carried out by SV, a female non-medic. Although students were prompted to discuss any gender-related experiences, surgery was not specifically discussed and instead was a topic raised by participants. Data were transcribed verbatim and pseudonymised.

Thematic analysis of the interview data was undertaken (Ziebland \& McPherson 2006; Silverman 2009). Thematic analysis is a tool that can be used across a range of epistemological positions, but which also stands as a foundational method in its own right (Braun \& Clarke 2006). Data interrogation was carried 


\section{CHAPTER 2}

out via an iterative process between the transcripts and the evolving analysis. Our analysis was both inductive, in that themes were allowed to emerge from the data, and theoretical. In order to further explore our research question, we introduced a priori themes derived from communities of practice theory and the literature to serve as sensitising concepts (Wenger 1998). These themes included 'being a newcomer', 'learning the ropes', 'interactions with old-timers' and 'how to get ahead'. Using these themes allowed us to operationalise the concept of paradigmatic trajectories and investigate its explanatory power with regard to female students' surgical career choices.

EH and SV individually and collaboratively examined participants' narratives of their experiences. A selection of the transcripts were reanalysed by a researcher outwith the research team. The socio-cultural approach taken acknowledged the ongoing co-construction of data between participant and researcher, who together make sense of, and derive meaning from, experiences discussed. Reflexivity was maintained by the research team through the analysis and writing by recording, discussing and challenging established assumptions. In addition, both $\mathrm{EH}$ and SV kept reflexive diaries.

\section{Results}

Participants identified a range of paradigmatic trajectories within medicine, which differed across specialties. These trajectories directly impacted on learning practices as students engaged in activities that they strategically related to success. Paradigmatic trajectories particularly deterred female students from engaging in the surgical world. Firstly, we describe how students' experiences were gendered. Secondly, we consider how four key processes seeing, hearing, doing and imagining - explain how paradigmatic trajectories shape medical students' career choices.

What medical students see, hear and do defines what they can imagine and, subsequently, the career choices they make.

\section{Gendered experiences}

A striking initial finding was that gendered narratives of surgery came exclusively from female participants. These dealt predominantly with the incompatibility of being a woman in the surgical domain. We defined a gendered experience as any experience that brought a participant's gender to the fore. These were sometimes overt, but at other times more subtle. For example: 
"...there was one reg [trainee], yeah I got on with him really well, but he was kind of saying, "Oh, you're wearing a lovely dress. You look nice today." And I was like, but would you say that...?"

Nadine

Although this experience is not specifically about gender, it prompted the student to become aware of and reflect on her gender. Female students were positioned as 'other', whereas male participants' accounts of their surgical experiences were not gendered. Table 1 provides an overview of students' narratives.

\section{Seeing}

What and, importantly, whom students see in their learning environment form key aspects of paradigmatic trajectories. Students see who succeeds in a given field and what it takes for them to do so. Jasper, a mature student, described how he saw one aspect of the surgical career trajectory:

"I mean, friends who have gone through the system to be like surgeons and stuff, you spend years being somebody else's dogsbody."

Jasper

Seeing a space in which to belong was important for all participants; however, this was not always possible for female students because very few women surgeons or trainees were apparent:

"Every other doctor on the [vascular surgery] ward was male and the consultant ... didn't really think very highly of girls and expected surgeons should be male. It's not very nice, it's really not. Every firm you're on there's just so many more male doctors like everywhere... I'd literally be the only girl in the room."

Nadine

Nadine literally could not see a female surgeon. Consequently, she felt like an outsider, unable to see a space in which she could belong. In this environment, in which all successful members were male, she saw that success was linked to gender (not least in the mind of the consultant). The lack of visible women and resultant feelings of not belonging were reinforced by what students heard and the stories they were told. We considered that Nadine's evocation of the feelings of 'otherness' and isolation imposed by perceptions of gender captured the narrative of our paper. 


\begin{tabular}{|c|c|c|c|}
\hline Name & $\begin{array}{l}\text { Experiences of } \\
\text { participation }\end{array}$ & $\begin{array}{l}\text { Considering a } \\
\text { surgical career }\end{array}$ & $\begin{array}{l}\text { Gendered accounts } \\
\text { of surgery }\end{array}$ \\
\hline \multicolumn{4}{|c|}{ Female students' narratives: } \\
\hline Emily & Surgical placement & Not discussed & None \\
\hline Hannah & $\begin{array}{l}\text { Previous surgical } \\
\text { society committee } \\
\text { member, surgical } \\
\text { placements }\end{array}$ & $\begin{array}{l}\text { No, but not } 100 \% \\
\text { decided }\end{array}$ & None \\
\hline Kate & None mentioned & No & $\begin{array}{l}\text { Sees surgery as male- } \\
\text { dominated. Some } \\
\text { women can do it, but } \\
\text { it's not compatible } \\
\text { with having children. }\end{array}$ \\
\hline Kristina & Surgical placement & No & $\begin{array}{l}\text { Surgery incompatible } \\
\text { with having children, } \\
\text { though the discourse } \\
\text { is changing }\end{array}$ \\
\hline Luan & $\begin{array}{l}\text { Surgical elective, } \\
\text { father is a surgeon } \\
\text { and has taught her at } \\
\text { home }\end{array}$ & $\begin{array}{l}\text { No, but keeping an } \\
\text { open mind }\end{array}$ & None \\
\hline Nadine & $\begin{array}{l}\text { Had a good surgical } \\
\text { tutor }\end{array}$ & No & $\begin{array}{l}\text { Not fitting in and } \\
\text { feeling like an } \\
\text { outsider }\end{array}$ \\
\hline Olivia & $\begin{array}{l}\text { Being taught by a } \\
\text { surgeon about hip } \\
\text { replacements and } \\
\text { going into surgery, } \\
\text { surgical society } \\
\text { committee member }\end{array}$ & $\begin{array}{l}\text { Recently considering } \\
\text { surgery after a good } \\
\text { teaching experience }\end{array}$ & None \\
\hline Ruth & $\begin{array}{l}\text { Work experience with } \\
\text { cardiac surgeon, } \\
\text { which was good but } \\
\text { shocking }\end{array}$ & No & $\begin{array}{l}\text { Success in surgery } \\
\text { requires a strong } \\
\text { mindset, which most } \\
\text { women in surgery } \\
\text { must have. }\end{array}$ \\
\hline Susan & None mentioned & No & None \\
\hline
\end{tabular}

Table 1 - Summary of participants' experiences of surgery, organised by gender. 
EXPERIENCES OF SURGERY

\begin{tabular}{|c|c|c|c|}
\hline Name & $\begin{array}{l}\text { Experiences of } \\
\text { participation }\end{array}$ & $\begin{array}{l}\text { Considering a } \\
\text { surgical career }\end{array}$ & $\begin{array}{l}\text { Gendered accounts } \\
\text { of surgery }\end{array}$ \\
\hline \multicolumn{4}{|c|}{ Male students' narratives } \\
\hline Adam & $\begin{array}{l}\text { Yes, quizzed about } \\
\text { anatomy by surgeons }\end{array}$ & Not discussed & None \\
\hline Andrew & $\begin{array}{l}\text { Surgical placements, } \\
\text { arranged extra days } \\
\text { in theatre }\end{array}$ & $\begin{array}{l}\text { Yes, worried about if } \\
\text { it is achievable due } \\
\text { to competition }\end{array}$ & None \\
\hline Daniel & $\begin{array}{l}\text { Many negative } \\
\text { experiences, one } \\
\text { keen teacher }\end{array}$ & No & None \\
\hline Geoffrey & $\begin{array}{l}\text { Surgical electives, } \\
\text { extra projects }\end{array}$ & Yes & None \\
\hline Graham & $\begin{array}{l}\text { Surgical placement, } \\
\text { being "arm deep" in a } \\
\text { kidney transplant } \\
\text { patient }\end{array}$ & Yes & None \\
\hline James & None mentioned & Not discussed & None \\
\hline Jasper & $\begin{array}{l}\text { Felt excluded from } \\
\text { participation, noticed } \\
\text { class differences in } \\
\text { participation }\end{array}$ & No & None \\
\hline Luqman & None mentioned & Not discussed & None \\
\hline Matthew & $\begin{array}{l}\text { Surgical placements, } \\
\text { able to "help out" } \\
\text { during a surgical } \\
\text { elective, 'hands-in' } \\
\text { experience }\end{array}$ & Yes & None \\
\hline Owen & $\begin{array}{l}\text { Experienced being } \\
\text { 'nameless' on a } \\
\text { surgical placement }\end{array}$ & No & None \\
\hline
\end{tabular}




\section{CHAPTER 2}

\section{Hearing}

Participants described the importance of talking to senior students and practitioners, and of using the narratives of others to plot trajectories for themselves:

"[A female surgical registrar] said, "It's not easy, I struggle every day because I know that if my child is sick and I have to go... but I know that the male surgeons, they will think, 'Why do you have to go? Can't anyone else look after your child?" "... I think she's the one person that's actually told me straight out, this is what's going on within this specialty, and it's actually quite... it's been talked about quite a lot because it's going to change over the next years. There's a big thing in surgery that this whole thing is changing but it's just things that you pick up here and there..."

Kristina

Not all stories were afforded the same degree of importance; what students heard from within actual communities had greater legitimacy than messages directed at students through institutional channels (such as the 'big thing' referred to in Kristina's comment). Kate reflected on the stories she had heard about changes within surgery aiming to improve the experiences of women:

"I still think you can, you know, you definitely can be a surgeon and they are trying to make it easier. They are trying to do this like, erm, what's it called? It's like less than full-time and sort of flexible training, so it would take longer to train as a surgeon but obviously if you could do it full-time you train in 7 years, but, you know, part-time might take you 10, 11, 12 years to do. Erm, so I think, you know, I think you'd get there in the end but I don't know."

Kate

Another student described the perception that engaging in behaviours more often linked to masculinity was important to success and how this was reinforced by a consultant:

"I was speaking to one of the male surgeons but he had a female SHO [senior house officer] and she was sort of, she was very sort of like strong, like strong mindset...

Interviewer: Masculine?

Yeah [laughter] basically. And he wasn't talking about her particularly but he was just saying that like a lot of females in surgery are like that 
because, you know, to try and get ahead really and it is like a maledominated like profession kind of thing."

Ruth

Several female students discussed the incompatibility between a future career in surgery and having children:

"I guess like being a girl, like quite a lot of doctors have actually said to me like obviously you're female so you'll have children and all this sort of stuff. It's a bit like it's obvious but at the same time you're a bit sort of... I've never really like thought about it [like] that...

Interviewer: In what context would they talk to you about that then?

...like becoming like a consultant or whatever. They don't say it in sort of any like discriminating way or anything but it's just sort of like, you know, it will take you a little bit longer if you want to have children, that sort of thing, which at first I was a bit shocked by because obviously it wasn't really anything that l'd sort of thought about particularly...

Interviewer: So have you thought about it now then? Has it sort of made you think a little bit more?

Yeah. I think yeah you do have to think about it and I think it is just like nature isn't it that like a girl is going to have a baby, you know, so it is going to hold you back a little bit if you do want a family kind of thing."

Ruth

Prompted by discussions with seniors, Ruth had developed the understanding that being female meant wanting children, which was incompatible with being a successful surgeon. These assumptions remained unchallenged: Ruth conceded that this was 'just nature'. This discourse was mirrored in other students' accounts:

"Surgery is so competitive that if you take a year out to be, you know, to have maternity leave or something, it's really hard to get back in and kind of get respected for what you're doing because it's like an unwritten rule and I don't want that."

Kristina

These narratives had the clear potential to impact on students' participation. The stories heard became the stories told as students' came to understand who 


\section{CHAPTER 2}

would be able to engage in this domain. This was important because participation in the operating theatre afforded students another opportunity to construct paradigmatic trajectories within the field.

\section{Doing}

Participation in surgery was an important activity through which students encountered the people and practices of the domain. Accounts of participation were set exclusively within the restricted physical space of the operating theatre, in which students gained direct insight into how it is to be a surgeon. Many students described participatory moments in the operating theatre. All of these students were male, with one exception:

"And then we actually went into surgery and he talked us through it, asked us questions about complications of surgery and stuff, which came in useful because we had that in our exams, and it was just, it was fun and we learned a lot and you just, you come out feeling like, okay, l've actually done some work today."

Olivia

Amongst the female students in this study, Olivia's experience of supported participation was unique; instead, it was much more common to experience a lack of interaction with seniors:

"[On a surgery firm] there's no real circumstances usually where sort of your consultant... I've not had... this should happen but it's not really happened - erm, where your consultant will watch you sort of do an examination or something and give you feedback directly."

Hannah

Whereas Olivia's experience was one of participation, several male students described a much more 'hands-in' form of engagement:

"Like I stayed once till about 9.30 pm doing a kidney transplant, and I was in theatre arm-deep in a kidney transplant..."

Graham

"I mean, for one patient I had my hand in this guy's abdomen for a good four hours, which was like, do you know what, I probably, I didn't know we're an hour into your surgery yet [the surgeon operating had] taken the opportunity to teach me and get me involved."

Geoffrey 
These activities contributed significantly to students' identification of themselves as future surgeons. All students who described moments of participation in theatre were exposed to a wider range of possible trajectories. They were more likely to see a space for themselves and their development within the surgical world. These students intended to pursue surgical careers.

\section{Imagining}

The three processes we have described so far - seeing, hearing and doing shaped students' understandings of the surgical field and their chances of success and happiness within it. This defined what they imagined to be possible. Here, Matthew identifies his intention to become a surgeon, projecting what he has seen, heard and done onto his imagined future:

"I've done a couple of orthopaedic modules... the second one I didn't entirely want to do but I thoroughly enjoyed it and I got to help out in the surgeries, which I really enjoyed and... because that was a practical hands-on approach with one-to-one teaching, where you had a sort of role model there, somebody to show you how it should be done and talk you through your mistakes and so on... Like that was the kind of thing that was really beneficial to me and seeing what I could be doing in the future like, actually doing the surgeries myself with him guiding me, and obviously like I wasn't doing a huge amount, like it was still good fun for me to practise it and get an experience of it."

Matthew

Despite Olivia's strongly positive experiences in theatre, she remained tentative in her career aspirations:

"I've been looking at sort of anaesthetics or critical care for quite a while but then I really enjoyed my orthopaedic placement as well and I've never really considered surgery but I'm starting to think about orthopaedics, but I don't know."

Olivia

For female students, a lack of visible female role models, alternative discourses and experiences of participation made it difficult for them to imagine an alternative surgical world that was more open to women and therefore open to them:

"Surgery's still very, very male-dominated... I've conceded myself that it is quite impractical. Some people do it and some people obviously are amazing, you know, they'll have sort of the family life and they'll have, 


\section{CHAPTER 2}

you know, this amazing like surgical career but, you know, there are certain specialties that, you know, just because they're sort of, you know, unsociable hours, their on-call is quite demanding, erm you know, it's not... you know, it just doesn't go together."

Kate

Kate seemed to struggle to put into words exactly why surgery was unsuitable for women, but described 'conceding', redirecting her imagined self elsewhere as she felt a surgical future was unobtainable. This highlights the power of paradigmatic trajectories in shaping what students believe to be possible, and how the lack of alternative trajectories can restrict imagination and, most importantly, career choices. Being unable to imagine belonging to the surgical world meant that these students did not even attempt to enter it. Surgical paradigmatic trajectories were strongly gendered, shaped by the processes we have outlined. The self-perpetuating power of these 'paths of possibility' was clear: the stories heard by students sustained the gendered discourses surrounding surgery, and the lack of any other avenues through which female students might form their perceptions of the surgical world left these discourses unchallenged.

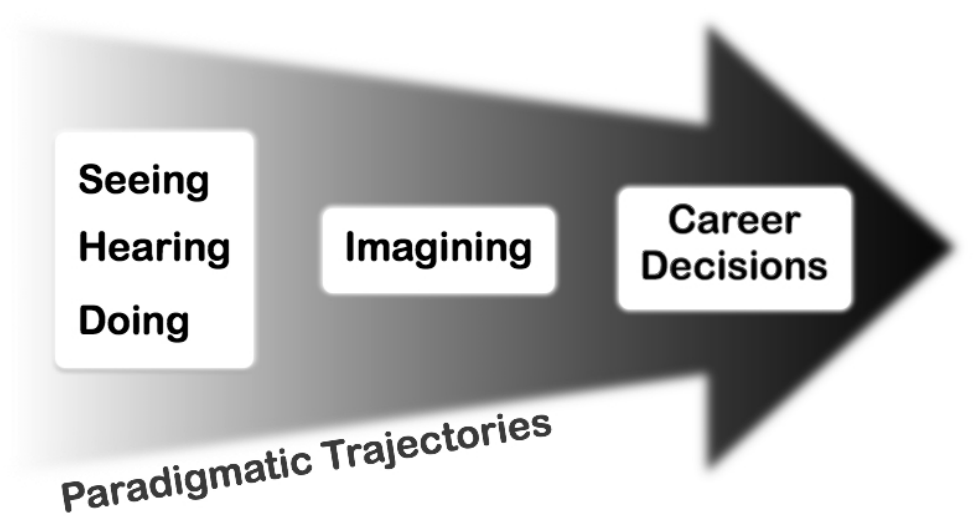

Figure 1 - Model showing how paradigmatic trajectories influence career decisions 


\section{Discussion}

The processes of seeing, hearing, doing and imagining combined to form paradigmatic trajectories on which students could draw when making career decisions. They served as a 'hidden curriculum', in which the culture, beliefs and behaviours enacted by those within surgery shaped students' experiences, participation and learning (Hafferty 1998). Students interpreted these explicit and implicit messages about which practices led to success and who could engage in them.

Female students were unable to see or identify with other women in surgery. They heard about the challenges of being a woman in surgery, lacked experiences of participation, and found it difficult to imagine a future in which they would be successful surgeons. Thus, based on paradigmatic trajectories constructed from exposure to surgery, they self-selected out of surgical careers. By contrast, male students had experiences of 'hands-in' participation and were not marginalised by paradigmatic trajectories. In relation to their participation in the surgical world, we can consider students to be engaging in gendered activities, and to conform to wider societal expectations and discourses and engage in practices accordingly (Cassell 1996). Elements of the trajectory of 'being a woman' include having a family and sacrificing work in order to do so (Hinze 2000), which essentially creates conflict between the trajectory of a woman and that of a surgeon, which may in part explain why fewer women embark on surgical careers.

Paradigmatic trajectories can help us understand the socio-cultural processes linking micro-level experiences and broader patterns of non-participation. The availability of role models influences career decisions (Sanfey et al. 2006; Drinkwater et al. 2008; Ravindra \& Fitzgerald 2011) and female students who train in departments with higher proportions of female surgeons are significantly more likely to engage in surgical careers. This fits well with our analysis, although we suggest the mechanism is more complex than a unidirectional effect of role modelling on the student by the role model. Rather, we suggest that, through exposure to actual communities, the students in these studies were afforded opportunities to see, hear and do more with female surgeons, which broadened the paradigmatic trajectories available, and thus were more able to see a space to belong in a surgical career.

Unexpectedly, in the present study, only female students had gendered experiences of surgery and only male students described 'hands-in' participation. Important parallels may be drawn with Billett's account of affordances in workplace learning, which represent the invitational qualities of a workplace for individuals' participation, engagement and learning (Billett 2001). Male participants were afforded increased access to learning 


\section{CHAPTER 2}

opportunities in the operating theatre and thus greater opportunities for 'hands-in' engagement.

Nearly all female participants disidentified with a surgical career trajectory. Imagination is an important element in learning (Wenger 1998); it allows us to explore new areas before we participate fully (Holland et al. 1998; Ryan \& Edge 2012). We present a framework to link the past, present and future of students' learning by incorporating experience and imagination into participation, which explains how students' experiences direct their future behaviour. We know that students 'try on' possible selves as they learn (Burack et al. 1997), behaviour that supports our claims that imagination and exposure to an actual community are important in making career decisions. We suggest that female students have fewer opportunities to benefit from such exposure and this makes them less likely to enter surgical careers. Furthermore, those who do enter training disidentified with their seniors and as a result were less willing to commit to surgical careers (Peters et al. 2012). Our research would suggest that paradigmatic trajectories may play a role in this disidentification process even after the subject has embarked on a surgical career trajectory. Paradigmatic trajectories are constantly negotiated; each time a trainee is required to apply for the next stage of his or her training, the trainee is necessarily stimulated to reflect on likely pathways to success. This forced reification may explain the observed attrition of women in surgery.

Our analysis was strengthened by our own contrasting perspectives as, respectively, a medical student who aspires to a surgical career and who was familiar with the discourses within the surgery-related talk of medical students, and a medical sociologist 'outsider'. Throughout the analysis, we considered different aspects of the data, challenging one another's interpretations and providing 'creative disturbances' (Fairclough 2001) that encouraged a deeper level of analysis and reflexivity (Bourdieu 1990). Further, the theoretical framework and analysis were developed in partnership with, and reviewed by, external collaborators.

This study represents a secondary analysis of an existing dataset. Participants were sampled purposively by gender, hospital sector, academic achievement and ethnicity, the last two of which were not relevant to this study. We may have encountered a broader range of narratives had we purposively sampled for degree of exposure to surgery. Participants were asked about their experiences at medical school as part of a study exploring participation, and were not specifically asked about surgery. Therefore, not every participant discussed surgery and we may have generated richer data had we asked specifically about this. However, such an approach meant all surgical narratives arose organically from the interviews and the data were not prejudiced by our 
asking of specific surgery-related questions. All interviews were carried out by SV, a medical sociologist. We acknowledge that we might have gathered different data if the interviewer had been a medical practitioner. However, participants may have felt freer to discuss traditionally taboo issues and discourses, such as personal success and failure, and may have made their narratives more explicit because their interviewer had a non-clinical background.

Because this research derives from a single-site study, its generalisability is subject to limitations. In Manchester, there exists a prominent undergraduate surgical society, which actively encourages both male and female students to consider surgical careers; therefore, this may represent a 'microclimate' in the context of surgical culture and our participants' exposure to surgery may not represent 'average' experiences. We cannot know how these students eventually acted in terms of whether they moved beyond imagination to engagement in a surgical career trajectory. Thus, the final stage of the paradigmatic trajectories model (Figure 1) remains theoretical.

Making the processes of seeing, hearing, doing and imagining more explicit enables them to be challenged and renegotiated. The interaction of these elements is also important; the way students first encounter a domain merits attention. To increase the number of female surgeons, this research suggests we should support female medical students imagining of surgery as a viable career. Maximising students' interactions with female surgeons would augment what they see and hear, and how they participate, creating new paradigmatic trajectories. This could be achieved if medical schools, surgeons and surgical societies were to consciously encourage female surgeons to give lectures, lead clinical firms and electives, and increase their contact with medical students alongside their male surgical peers.

Students supplement experience with information derived from official or popular discourses. Although these sources were given less weight by participants, they were incorporated into what students saw and heard in a figurative sense. Increasing the prominence of female surgeons in policy, the press and social media would provide students with a diverse range of female surgeons' narratives, thereby creating 'champions', as recommended in the Royal College of Physicians 2010 report 'Women in Medicine' (Elston 2010).

A key question subsequent to this work is: What shapes identity formation in female medical students and surgeons? Our data deal only with students' experiences, yet paradigmatic trajectories are also likely to influence women at all stages of training. Furthermore, the concept of paradigmatic trajectories represents a powerful tool with which to explore boundaries and may be 


\section{CHAPTER 2}

suitable for the investigation of other periods of transition, such as those from classroom learner to clinical learner, and from medical student to qualified doctor.

\section{Conclusions}

Students quickly draw information from multiple sources in order to make sense of new specialties they encounter. They use what they see, the stories of others, and their experiences of participation to imagine a future career in that domain. The concept of paradigmatic trajectories is useful to explain these processes. The lack of successful, female surgical paradigmatic trajectories deters female students from participating in surgical careers. 


\section{References}

Babaria P, Bernheim S, Nunez-Smith M (2011). Gender and the pre-clinical experiences of female medical students: a taxonomy. Med Educ, 45(3):249-260.

Beagan B (2001). Micro Inequities and Everyday Inequalities: 'Race,' Gender, Sexuality and Class in Medical School. Can J Sociol, 26(4):583.

Billett S (2001). Learning through work: workplace affordances and individual engagement. J Workplace Learn, 13(5):209-214.

Bourdieu P (1990). In Other Words: Essays Towards a Reflexive Sociology. Cambridge: Polity Press.

Braun V, Clarke V (2006). Using thematic analysis in psychology. Qual Res Psychol, 3(2): 77-101.

Brescoll V, Uhlmann EL, Moss-Racusin C (2011). Masculinity, Status, and Subordination: Why Working For a Gender Stereotype Violator Causes Men to Lose Status. J Exp Soc Psychol, 48:254-257.

Burack JH, Irby DM, Carline JD, et al. (1997). A study of medical students' specialty-choice pathways: trying on possible selves. Acad Med, 72(6):534-541.

Cassell J (1996). The Woman in the Surgeon's Body: Understanding Difference. American Anthropologist, 98(1):41-53.

Ceci S, Williams W (2011). Understanding current causes of women's underrepresentation in science. Proc Natl Acad Sci USA, 108(8):6.

Conway M, Pizzamiglio MT, Mount L (1996). Status, communality, and agency: Implications for stereotypes of gender and other groups. J Personal Social Psychol, 71(1):14.

Danaher K, Crandall C (2008). Stereotype Threat in Applied Settings Re-Examined. J Appl Social Pyschol, 38(6):17.

Davies K (2003). The body and doing gender: the relations between doctors and nurses in hospital work. Sociol Health \& IIIness, 25(7):720-742.

Drinkwater J, Dornan T, Tully MP (2008). The effect of gender on medical students' aspirations: a qualitative study. Med Educ, 42(4):420-426.

Elzubeir MA, Rizk DEE (2008). Identifying characteristics that students, interns and residents look for in their role models. Med Educ, 35(3):272-277.

Fairclough N (2001). Language and Power, 2nd ed. London: Pearson Education.

Greatorex R, Sarafidou K (2010). Surgical Workforce 2010: Profile and Trends. London: Royal College of Surgeons of England.

Hafferty FW (1998). Beyond curriculum reform: confronting medicine's hidden curriculum. Acad Med, 73(4):403-407.

Heilman M, Parks-Stamm EJ (2007). Gender stereotypes in the workplace: Obstacles to women's career progress. Advances in Group Processes, 24:47-77.

Hinze SW (2000). Inside Medical Marriages: The Effect of Gender on Income. Work and Occupations, 27(4):464-499.

Hinze SW (2004). 'Am I Being Over-Sensitive?' Women's Experience of Sexual Harassment During Medical Training. Health, 8(1):101-127.

Holland D, Lachicotte W Jr, Skinner D, Cain C (1998). Identity and Agency in Cultural Worlds. London: Harvard University Press.

Lempp $\mathrm{H}$, Seale C (2004). The hidden curriculum in undergraduate medical education: 


\section{CHAPTER 2}

qualitative study of medical students' perceptions of teaching. BMJ, 329(7469):770773.

Lempp $\mathrm{H}$, Seale C (2006). Medical students' perceptions in relation to ethnicity and gender: a qualitative study. BMC Med Educ, 6(1):17.

McAvoy BR (2003). Workplace bullying. BMJ, 326(7393):776-777.

McNally SA (2012). Surgical Training: Still Highly Competitive But Still Very Male. Bull $R$ Coll Surg Engl, 94(2):53-55.

NHS Health and Social Care Information Centre (2011). NHS Staff 2001-2011 (Medical and Dental). Leeds: NHS Health and Social Care Information Centre.

Nicholson S (2002). 'So you row, do you? You don't look like a rower.' An account of medical students' experience of sexism. Med Educ, 36(11):1057-1063.

Oancia T, Bohm C, Carry T, Cujec B, Johnson D (2000). The influence of gender and specialty on reporting of abusive and discriminatory behaviour by medical students, residents and physician teachers. Med Educ, 34(4):250-256.

Peters K, Ryan M, Haslam SA, Fernandes H (2012). To belong or not to belong: Evidence that women's occupational disidentification is promoted by lack of fit with masculine occupational prototypes. J Personnel Psychol, 11(3):148-158.

Ravindra P, Fitzgerald JEF (2011). Defining surgical role models and their influence on career choice. World J Surg, 35(4):704-709.

Rees CE, Monrouxe LV (2011). 'A morning since eight of just pure grill': a multischool qualitative study of student abuse. Acad Med, 86(11):1374-1382.

Rose G, Rukstalis MR, Schuckit MA (2005). Informal Mentoring Between Faculty and Medical Students. Acad Med, 80(4):344-348.

Ryan V, Edge A (2012). The role of play themes in non-directive play therapy. Clin Child Psychol Psychiatry, 17(3):354-369.

Sanfey HA, Saalwachter-Schulman AR, Nyhof-Young JM, Eidelson B, Mann BD (2006). Influences on Medical Student Career Choice: Gender or Generation? Arch Surg, 141(11):1086-1094.

Silverman D (2009). Doing Qualitative Research. London: Sage Publications.

Stratton TD, McLaughlin MA, Witte FM, Fosson SE, Nora LM (2005). Does Students' Exposure to Gender Discrimination and Sexual Harassment in Medical School Affect Specialty Choice and Residency Program Selection? Acad Med, 80(4):400.

Taylor C, Lord C, McIntyre R (2011). The Hillary Clinton effect: When the same role model inspires or fails to inspire improved performance under stereotype threat. Group Processes \& Intergroup Relations, 14(4):447-459.

Wenger E (1998). Communities of Practice. Cambridge: Cambridge University Press.

Witte FM, Stratton TD, Nora LM (2006). Stories from the Field: Students: Descriptions of Gender Discrimination and Sexual Harassment During Medical School. Acad Med, 81(7):648-654.

Yazigi A, Nasr M, Sleilaty G, Nemr E (2006). Clinical teachers as role models: perceptions of interns and residents in a Lebanese medical school. Med Educ, 40(7):654-661.

Ziebland S, McPherson A (2006). Making sense of qualitative data analysis: an introduction with illustrations from DIPEx (personal experiences of health and illness). Med Educ, 40(5):405-414. 


\section{Chapter 3}

HIDDEN CURRICULUM OF SURGERY

\section{You've got to know the rules to play the game:}

how medical students negotiate the hidden curriculum of surgical careers

Published as:

Hill EJR, Bowman KA, Stalmeijer RE, Hart J (2014). You've got to know the rules to play the game: how medical students negotiate the hidden curriculum of surgical careers. Med Educ, 48(9): 884-94. 


\section{CHAPTER 3}

\section{Abstract \\ Objectives}

The hidden curriculum may be framed as the culture, beliefs and behaviours of a community passed to students outside formal course offerings. Medical careers involve diverse specialties, each with a different culture, yet how medical students negotiate these cultures has not been fully explored. Using surgery as a case study, we aimed to establish, first, whether a specialty-specific hidden curriculum existed for students, and second, how students encountered and negotiated surgical career options.

\section{Methods}

Using a constructivist grounded theory approach, we explored students' thoughts, beliefs and experiences regarding career decisions and surgery. An exploratory questionnaire informed the discussion schedule for semi-structured individual interviews. Medical students were purposively sampled by year group, gender, and career intentions in surgery. Data collection and analysis were iterative, with analysis following each interview, and guiding adaptation of our discussion schedule to further our evolving model.

\section{Results}

Students held a clear sense of a surgical hidden curriculum. To successfully negotiate a surgical career, students first must build a network, as careers information flowed through relationships. They subsequently enacted what was learned, by accruing the accolades ('ticking the boxes') and appropriating the dispositions ('walking the talk') of 'future surgeons'. This allowed them to identify themselves and be identified by others as a 'future surgeon', and gain participation in the surgical world. Participation then enabled further network building, and access to careers information, in a positive feedback loop. For some, negotiating the hidden curriculum was more difficult, which, for them, rendered a surgical career unattractive or unattainable.

\section{Conclusions}

Students perceived a clear surgery-specific hidden curriculum. Via a constructivist grounded theory approach we have developed a model of how students encountered, uncovered and enacted this hidden curriculum to succeed. Drawing on concepts of Bourdieu, we discuss unequal access to the hidden curriculum, which excluded many from the possibility of a surgical career. 


\title{
Introduction
}

Students at the same medical school, who share a curriculum, make different career decisions (Goldacre et al. 2004). This is perhaps unsurprising, as educational experiences and the specialties students encounter are as variable as the students themselves. A student's understanding of a specialty is derived from their experiences, whether or not these involve formalised careers information:

\begin{abstract}
A great deal of what is taught - and most of what is learned - in medical school takes place not within formal course offerings but within medicine's "hidden curriculum".
\end{abstract}

Hafferty, (1998)

Though many descriptions exist, Hafferty and Hafler (2011) frame the hidden curriculum as the culture, beliefs, and behaviours enacted by those within a community, passed to students, who subsequently enact it themselves. This sociocultural understanding implies that situated learning forms a significant proportion of students' experiences (Gofton \& Regehr 2006). The hidden curriculum, then, encompasses many factors that have been shown to affect students' career choices; indeed, medical school has been theorised as an opportunity for students to "try on possible selves" as they encounter a new specialty and imagine a place for themselves within it (Burack et al. 1997). Increased exposure to, and enjoyment of, a specialty increase the likelihood of a student pursuing the career (Maiorova et al. 2008). Lifestyle factors are also a major consideration in this process (Dorsey et al. 2005), with work-life balance being a priority for many, especially women (Drinkwater et al. 2008). Additionally, the people encountered hold significant influence: positive role models and good teachers in a specialty attract students to that career, and predict their success therein (Lempp \& Seale 2004; Rose et al. 2005; Ravindra \& Fitzgerald 2011). Relationships are the medium through which students learn the hidden curriculum (Lempp \& Seale 2004; Hager \& Hodkinson 2009), which further holds with a sociocultural perspective.

The bulk of the literature exploring the hidden curriculum considers its influence on students' understanding and enactment of professionalism, and professional identity formation. Studies on the topic theorise development of the identity of a doctor as a homogenous whole; few consider the similarities and differences of discrete medical specialties. Surgery is discursively positioned as different to other specialties (Coombs et al. 1993; Gofton \& Regehr 2006), with a distinct culture (Cassell 2000). Surgery polarises medical students, being commonly cited as either their most or least popular career option (Cleland et al. 2012). This suggests students develop early ideas of surgery, making it an ideal context in which to explore their understanding of surgery's culture, 


\section{CHAPTER 3}

beliefs and behaviours - its hidden curriculum. Of further interest is the unequal demographic spread in surgery; women's continued underrepresentation highlights differential engagement in the specialty (McNally 2012), and there is evidence of differing access, with female students having negative experiences compared with their male counterparts (Hill \& Vaughan 2013). Hence, using surgical culture as a context to explore the hidden curriculum and career decisions allows exploration of issues of engagement, access and exclusion.

We hypothesise that students become socialised into the culture of different specialties whilst at medical school, suggesting the existence of specialtyspecific hidden curricula. Yet we do not understand how students experience and negotiate the hidden curricula of different specialties. Using surgery as a case study, we aimed to establish first, whether a specialty-specific hidden curriculum existed for students, and second, how students encountered and negotiated surgical career options.

\section{Methods}

\section{Overview}

To explore our research questions, we used constructivist grounded theory as described by Charmaz (2000). Implicit within a constructivist approach is the assumption that "data do not provide a window on reality. Rather, the 'discovered' reality arises from the interactive process and its temporal, cultural, and structural contexts" (Charmaz 2000; Mills et al. 2006). Hence, data and analysis were co-constructed between participants and researchers, and sensitising concepts from the literature informed our research questions, interview discussion, and analysis - notably concepts relating to the hidden curriculum and sociocultural concepts concerning identity and relationships (Wenger 1998; Cassell 2000; Hafferty \& Hafler 2011). Researcher positioning and its impact on the data collected warrants reflexivity; EH and KB were both medical students within the institution during data collection, $\mathrm{EH}$ planning a surgical career, and KB undecided about a future career path. RS and JH were from non-medical backgrounds, and their outsider positioning facilitated 'creative disturbances' to challenge data interpretation (Fairclough 2001). Reflexivity diaries were kept by $\mathrm{EH}$ and $\mathrm{KB}$ throughout data collection and analysis. This study took place within a large UK medical school, which has a five-year undergraduate problem-based learning curriculum. Ethical approval was granted from The University of Manchester Research Ethics Committee (Ref No: 11314). 


\section{Data Collection}

We administered an exploratory questionnaire to 46 students, purposively sampled to represent as broad a range of surgical experience as possible $(n=46$ : $59 \%$ female, $17 \%$ pre-clinical, $46 \%$ considering a surgical career). In addition to demographic and career intention information, the questionnaire included open-ended questions such as, "Are there any unwritten rules about surgical careers?", "Describe a typical surgeon", "What would help you succeed in a surgical career?", and "What would hold you back?" Our analysis of questionnaire data informed the discussion schedule for subsequent interviews. Individual, semi-structured interviews were used to explore in-depth themes from the questionnaire's open-ended answers. An open invite to all medical students was issued via an announcement on the student intranet. Of those who responded $(n=30)$, a separate cohort of interview participants were purposively sampled by year group, gender, degree of experience of surgery, and interest in a surgical career $(n=12$; Table 1$)$.

\begin{tabular}{|c|c|c|c|}
\hline Pseudonym & & Year & Career intentions \\
\hline Ben & \multirow[t]{4}{*}{ Preclinical students } & 1 & Not considering surgery \\
\hline Rebecca & & 1 & Not considering surgery \\
\hline Rachel & & 2 & Unsure \\
\hline Isabella & & 2 & Future surgeon \\
\hline Charlotte & \multirow[t]{4}{*}{ Clinical students } & 3 & Unsure \\
\hline Stephen & & 3 & Not considering surgery \\
\hline Hannah & & 4 & Not considering surgery \\
\hline Harry & & 4 & Future surgeon \\
\hline Neela & \multirow[t]{4}{*}{ Final year students } & 5 & Future surgeon \\
\hline Tom & & 5 & Future surgeon \\
\hline Luke & & 5 & Not considering surgery \\
\hline Lily & & 5 & Future surgeon \\
\hline
\end{tabular}

Table 1 - Summary of interview participants, organised by year of medical school 


\section{CHAPTER 3}

Given the politically sensitive nature of the subject matter, we took deliberate steps to facilitate honest, frank interviews with students. Interviews were carried out by a medical student 'insider' (KB) who explained to participants that she was undecided about her own career, could not be offended, appreciated honesty, and that the medical school would not have access to their transcripts. Interviews were audio recorded and transcribed verbatim. After each interview or two, we conducted and reviewed the analysis, adapting the discussion schedule for subsequent interviews. This included the removal of saturated areas from discussion, the addition of questions to elaborate on emerging areas, and the purposive recruitment of 'missing voices' from the participant group. For example, in the final phase of data collection, we actively recruited a participant who had positive and inclusive experiences of surgery yet did not want to be a surgeon. This provided a new perspective to challenge our theory, and advance our model. After twelve interviews the research team agreed that no new themes pertinent to the research questions were emerging, and that thematic saturation had been met (Morse 1995).

\section{Data Analysis}

Analysis was iterative and ongoing throughout the period of data collection. In the initial open coding stage, all issues of interest in the transcripts were assigned a code. Codes were constantly updated, negotiated and reviewed whilst being compared to other data. EH and KB undertook analysis collaboratively, challenging each other's interpretations throughout. JH recoded the data independently, generating alternative interpretations from her nonmedical stance. Once emergent themes were established, exploration of the links and relationships between themes, or axial coding, was undertaken by the full team; we moved through increasing degrees of abstraction to organise themes into a cohesive model grounded in the data. We performed iterations of this analysis following each phase of interviews, and established a synthesis of the full dataset, wherein new interview data were used to elaborate or challenge areas of our working model. Final analysis stages involved discussions within the research team and with peers from diverse backgrounds within the field, during which we situated our evolving model amongst wider theory. The work of Pierre Bourdieu was raised recurrently as having resonance with our model and providing greatest explanatory power (Bourdieu 1977a; 1977b; 1990a; 1990b; 1993; Watson et al. 2009); thus, we used Bourdieusian concepts to discuss the implications of our model and relate our findings to the wider context of medical education and learning. 


\section{Results}

Students universally saw surgery as a career distinct from other specialties, with a clearly defined culture in which there were distinct ways to achieve success. In this sense, students perceived a clear hidden curriculum in surgery, expressing a deeply held sense of the "rules" of a surgical career.

"There's a quite clearly defined game to a career in surgery... you're either aware of that or you're not... if you're not aware of it then I think its much more difficult um... to become a [surgeon], even if you have the time and the motivation... You have to have a contact with the, the rules [of surgical careers] in some way."

Luke, 5th year, not considering surgery

Interestingly, students felt these rules could only be uncovered outwith their school's formal course curriculum, in keeping with Hafferty's definition of the hidden curriculum (Hafferty 1998).

"I don't think there's very much guidance at undergraduate level... it's not something that's explicitly taught or told, you don't have specific careers events run by the medical school, it's outside of erm, the remit of... it's seen as outside of the remit of the delivery of the curriculum by the medical school..."

Tom, 5th year, future surgeon

We now present our results for how students encountered and negotiated the mechanisms of success and thus engaged in the surgical domain. Furthermore, at each stage of this process, we include the voices of some students who were either unwilling or who felt unable to engage; for them, it was not a matter of simply choosing not to participate in a surgical career, but of being excluded from the possibility of doing so.

\section{Building a network: encountering and uncovering the hidden curriculum}

Students described relationships as fundamental to understanding how to engage in the surgical world; building a network was critical to encountering and uncovering the surgical hidden curriculum. A perceived lack of explicit, formal careers information meant students relied heavily on "word of mouth", with students suspecting "who you know rather than what you know" was important, making a network crucial to "get ahead". Students valued connections with a diverse group including "consultants", "SHOs" (Senior House Officers - mid-level surgical trainees), "anatomy demonstrators", "parents", "students in older years", "peers" (particularly those interested in surgery) and "Scalpel" (Manchester's undergraduate surgical society). Perhaps unexpectedly, 


\section{CHAPTER 3}

a surgeon was not necessarily the most valuable person to have in a network; rather, it was the insight into the rules of success these relationships afforded that mattered most, regardless of the role or seniority of the contact. This exchange of information took place in a range of environments, including clinical placements, extra-curricular events, lectures and via social media.

"I think you just really have to inform yourself about [a career in surgery] ... speaking to people who are doing it... I really like speaking to erm, SHOs who are doing it because they really have a, I guess, realistic opinion about what it's like... In terms of information or anything about surgery, I think most of my surgical hints and tips have come from other students that are interested in surgery."

Neela, 5th year, future surgeon

However, access to these important relationships was not equally distributed amongst students; for those without, it was difficult to admit they lacked an understanding of the hidden curriculum, and they variably expressed anxiety, frustration and sometimes despair over their future careers. Their anxiety stemmed from having vague encounters with the hidden curriculum without the relationships or prior understanding to uncover its complexities.

"I feel like I don't really know what I'm supposed to be doing, at all, for anything. Like any career I'd wanna do I don't know what, how I should be working towards it."

Charlotte, 3rd year, unsure

Even students with a developed network and understanding of the hidden curriculum experienced anxiety, believing they couldn't afford not to develop the best network possible to gain future advantages.

"In a fair world it wouldn't make a difference that you know them. But if you know them and you've made a really good impression there's a possibility that it might."

Isabella, 2nd year, considering surgery

Building a network was easier for some students than others. Some students' advantage stemmed from the ease with which they were able to meet new people and build a network within the surgical domain, whilst others had existing contacts in their family or wider social network. 
"One girl I was talking about, she has two surgeons as parents. So she's got contacts, so it's a bit easier for her to organise it [extra surgical placements], and they can obviously help her through this."

Rachel, 2nd year, not considering surgery

Success in surgery was perceived by students as not purely meritocratic; indeed, nor was it meritocratic by our analysis, with students possessing differential access to a network, and therefore differential access to the hidden curriculum of surgical careers.

\section{Enacting the hidden curriculum}

In order to engage further in the surgical domain, students needed to operationalise what they had learned through their network. This was achieved via two key processes, which we term 'ticking the boxes' and 'walking the talk', and whose importance Luke articulates.

"So I think... if you have a really clear sense of that, and you know that you can tick all those boxes then I think its very easy, if you don't know how to portray yourself, what measurable things are important and you don't have a sense of the people in the game then I think its [success in surgery is] very, very difficult."

Luke, 5th year, not considering surgery

\section{Ticking the boxes}

Students clearly identified the achievements required to pursue a surgical career, or "boxes that need to be ticked". The majority of these were activities set outside the formal medical school curriculum.

"Research is an essential skill, like sort of publications and presentations are really sort of seen as essential things that you need to have... going to courses, surgical careers days learning suturing techniques, erm, and things like that."

Tom, 5th year, future surgeon

Among students who felt they understood what was required to succeed, there was consensus on the accolades and skills needed to "set yourself apart", though this was paradoxical as all future surgeons engaged in these activities. Completing "audits", "teaching", "getting prizes", "knowing anatomy" and "doing really well" in formal examinations were universally deemed important. "Technical ability", such as being able to suture, was also important, and future surgeons practiced surgical skills in their spare time. 


\section{CHAPTER 3}

\section{Walking the talk}

In addition to ticking the boxes, participants felt it was necessary to "fit yourself into that [surgical] mould": employing dispositions in keeping with the ideal of a successful future surgeon.

"If you can be as much like the surgeons you know as possible then you're probably more likely to do well."

Hannah, year 4, not considering surgery

Students had to distinguish themselves by their behaviour via showing "initiative", "drive" and "dedication" in seeking out means to get ahead, and by enacting valued characteristics via being "confident", "harsh", "assertive" and "competitive". Although it was well-defined and agreed what future surgeons were like (the talk), not all students were willing or felt able to embody these dispositions (to walk the talk).

"I think a lot of [students who want to do surgery] are really driven. If they know at this stage they want to do it, they will sort of go out of their way... just very determined. Like if they know they want to do it they will do anything they can to get there... making the most of all opportunities they get really."

Rachel, 2nd year, not considering surgery

In summary, enacting the hidden curriculum involved the complex interplay of 'ticking the boxes' and 'walking the talk'.

"Um, l've never really considered myself for surgery, no... because a) I'm, I'm like really clumsy and b) I just think I'm not what's the word um... driven enough. I mean... I've not got any interest in being the best... like getting the best mark in the year ... I know probably you don't have to be the top, the best, to be any kind of surgeon... but I don't know, I just, I just don't have that that drive."

Stephen, 3rd year, not considering surgery

Stephen articulates a combination of reasons for not pursuing surgery. Relating to 'ticking the boxes' is his perceived clumsiness and not getting top marks, whilst relating to 'walking the talk' is his lack of 'drive' and lack of interest in "being the best... in the year". For some, walking the talk was effortless because, for them, such dispositions were innate. Others, having uncovered which dispositions were valued, modified their behaviour, whether consciously or unconsciously, to suit the surgical domain. A further group was excluded, being unwilling or feeling unable to enact this way of being. 
"I haven't felt excluded in what I'm able to do, I've... I've excluded myself, thinking, "I don't want to be like you"... if I find an environment too blokey I often withdraw."

Luke, 5th year, not considering surgery

Notably, the behaviours required to enact the hidden curriculum were strongly gendered, making them more accessible to male students than females, and to some men more than others.

"I can think of one girl in particular who wants to be a surgeon and she's definitely very very driven and she's been, she's been described as scary before, erm, but for the boys... I suppose it's girls; they'd be more different perhaps..."

Hannah, year 4, not considering surgery

Students felt you needed to adopt masculine characteristics to adapt to the "predominately male environment".

"I think it's hard if... how you think of yourself really and what you decide to portray in an interview are complete diametric opposites... for example... I don't like doing the blokey banter stuff and they were a panel of four men, I would do that... not obviously make sexist jokes or whatever but I dunno a different tone to the way you speak..."

Luke, 5th year, not considering surgery

Akin to building a network, again there was differential access to the hidden curriculum - this time because some students were unwilling or felt unable to enact dispositions in the manner required by the hidden curriculum - meaning a further subset were excluded from surgical careers.

\section{Fitting in as a future surgeon}

The differential willingness or perceived ability of students to enact the beliefs, attitudes, and behaviours valued in the surgical domain meant that "future surgeons" emerged as a clearly identifiable group.

"It's just like the surgery group *laughs* and then the people who don't have a clue yet!"

Rachel, 2nd year, not considering surgery

Making others aware of an intention to become a surgeon, by saying it out loud, was an important part of the hidden curriculum; this act in itself simultaneously allowing future surgeons to identify, and be identified by others, as a future surgeon. 
"Obviously most medical students don't know what they want to do but I've found that those who want to do surgery are very keen and... they're very clear minded, like "that's what I want to do", and that's probably what they'll go on to do."

Neela, 5th year, future surgeon

Simply stating a desire to become a surgeon was not enough; the most legitimate future surgeons walked the talk publicly in an "obvious" way, gaining recognition from surgeons in the process; it was important others were aware of your "competitiveness" and "drive" to accumulate surgical accolades. However, some students deemed the perceived necessity of displaying such characteristics as unattractive or impossible for them. This caused them to "think twice" about surgery or to disidentify completely with it possible career path, not fitting with the "type of person" the hidden curriculum required them to be.

"I haven't anything against them... they just have a certain drive, like, not that I lack but... I dunno, I think they're just a different type of person to me."

Rachel, 2nd year, not considering surgery

Again, as with building a network and enacting the hidden curriculum, not all students identified, nor were identifiable, as a future surgeon to the same degree. This particular difference became important as fitting in was essential to gain participation in the surgical domain, most notably in the operating theatre.

\section{Gaining participation in the surgical world}

Participation in theatre was a key event; those struggling to participate felt excluded from the surgical world, whilst others described extremely positive experiences derived via enhanced participation.

"Until you've got into theatre and you're scrubbing in, that's when like you realise what they're actually doing and how they're doing it. So yeah the only way to get included really is to get scrubbed in and try and assist. But like it's quite difficult to actually do."

Harry, 4th year, future surgeon

"Scrubbing in" was synonymous with participation in the surgical world, though many discussed the challenging negotiation preceding being able to scrub. While future surgeons stated confidently that you should always seek to scrub, other students struggled to understand the etiquette of surgical theatres as 
they did not have a network of relationships whereby these unwritten rules had been made explicit to them. Such rules included "getting to theatre early", "asking questions", "showing you are keen" and "being proactive". Those that did access this form of participation valued the experience immensely, as it offered opportunities to belong, feel involved and be included. For students like Neela, understanding the rules and embodying the expected dispositions of a future surgeon facilitated participation.

"I was doing a surgical placement and I think I showed them that I was really interested and really keen and... I'm really not punctual but I was in at like 7.30 every morning, and not even just my consultant but other surgical consultants were like "if you've got nothing to do in the afternoon or the morning come by and help us out in theatre" and I did that for like a whole week where, even though it was just like holding retractors and they let me do like a few stitches and things like that, that was like actually really nice because they weren't just my team but it was like other surgical teams as well erm, so I felt quite involved... so that's sort of an important experience."

Neela, 5th year, future surgeon

Participation encompassed more than operating: the "banter" occurring in theatre and amongst future surgeons was an important phenomenon which medical students needed to either enjoy or be "tolerant" of in order to be accepted.

"Some people complain about consultants and stuff, and I think you've gotta be a bit tolerant...'cause in reality that's what happens in theatre... and tolerant of their behaviours because obviously they've got to where they are because they're good at what they do...but in terms of joining in it's not vital but I think it does help to maintain that relationship with the consultant, like to show that you're a bit, I don't know, a bit sociable."

Harry, 4th year, future surgeon

Harry shows some recognition that this behaviour would be somehow unacceptable outside theatre and might marginalise other students, yet he normalises it as "sociable"; he does not contemplate challenging this behaviour, rather stating that to align yourself with the behaviour will help build relationships. An understanding of the importance of fitting in and being accepting of surgical culture in order to engage in a surgical career meant that, for Hannah, who felt the banter in theatre clashed with her own values, surgery was not a career she could contemplate. Being party to, and thus feeling complicit in this banter was upsetting and made her intensely uncomfortable. 
"They were including me in their banter but I hated it. So in a way it was including me but just in such a way that was awful."

Hannah, 4th year, not considering surgery

The necessity students felt to "fit in" with surgeons and surgery, and their understanding of "the rules" not only left some students feeling that were they unable to challenge the existing ideals; there was also a strong sense that surgery as a practice was static, and unlikely to change.

"I think surgery has been shaped by the surgeons and the surgeons shape the future surgeons."

Hannah, 4th year, not considering surgery

\section{5) Completing the cycle}

For the remaining students who wished to become a surgeon, participation in surgery was invaluable for its opportunities to further develop their networks and understanding of surgical careers. This represented a positive feedback loop, represented in our cyclical model (Figure 1) of how students negotiate the surgical hidden curriculum.

Our model summarises the processes by which students negotiate the hidden curriculum. Students accumulated information regarding the hidden curriculum via relationships and building a network. Students could enact the hidden curriculum of surgery in two main ways: accumulating the achievements required, and displaying the personal characteristics expected of surgeons. This allowed them to identify themselves, and be identified by others, as future surgeons. Students were thus able to fit in, gaining them access to participation in the operating theatre. Participation was an important way to further expand their network and gain more surgical careers information. 


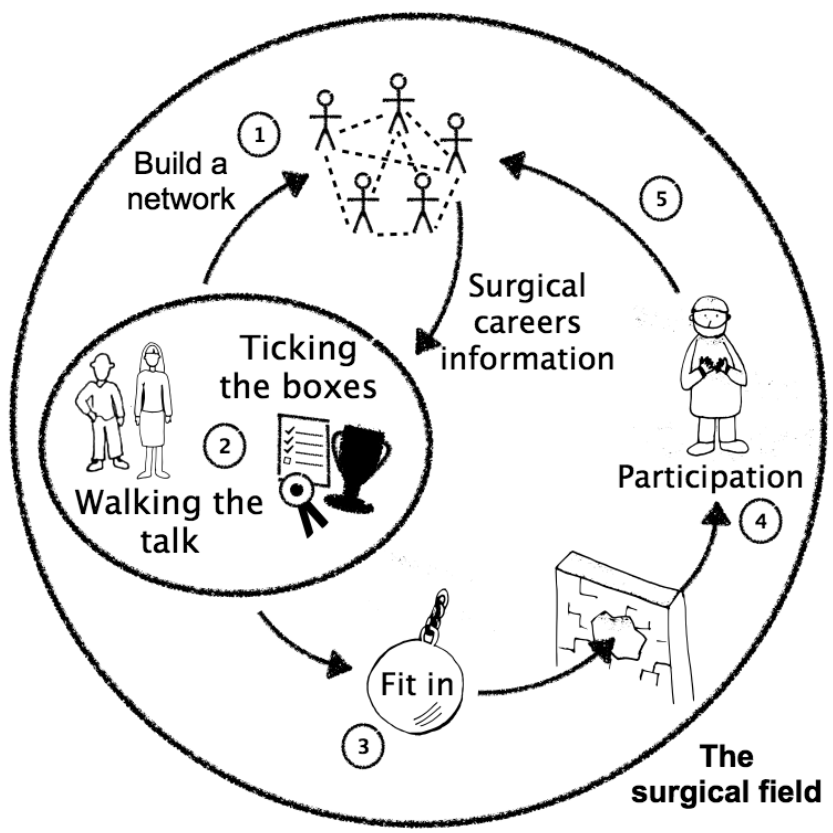

Figure 1 - Model of how students encounter and negotiate the hidden curriculum of surgical careers.

1. Building a network allowed students to undercover the hidden curriculum of surgical careers, as information flowed through relationships. 2. Enacting the hidden curriculum involved students operationalising what they learnt from their network; pursuing legitimate accolades and skills, and embodying legitimate dispositions. 3. Fitting in as a future surgeon through enactment of the hidden curriculum identified some students as future surgeons, possessing legitimacy in the surgical domain. 4. Gaining participation in the surgical world was more readily available to those who fitted in, most notably in the operating theatre. 5. Completing the cycle occurred when students used their experiences of participation to further develop their network and understanding of the surgical hidden curriculum, in a positive feedback loop.

Animated model available: Hidden Curriculum of Surgery on Youtube 


\section{CHAPTER 3}

\section{Discussion}

As our data show, negotiating the hidden curriculum of surgery, a new and unfamiliar domain, was challenging for students; however, for those who struggled to fit in with its expectations and cultural values, this was even more difficult. Pierre Bourdieu's concepts of habitus, capital and field are useful theoretical tools to explain students' differing participation in the surgical domain (Watson et al. 2009). The surgical domain may be seen as a field, in which certain behaviours appear to be reasonable, for example learning in an operating theatre via standing scrubbed in a room not touching or saying anything. This behaviour would not make sense in another field, for example general practice, where the same behaviour would seem absurd. The field, then, gives meaning to activities. Every field has its own "logic", a "game", in which individuals compete for a better position in the field (Bourdieu 1993). Bourdieu asserts that players must have a "feel for the game" - an inherent, often unconscious, understanding for the values and goals of a field, gained through experience in the field (Bourdieu 1990b). A "feel for the game" equates to an understanding of the hidden curriculum, and, as Luke discusses, students have differential access to this: "There's a quite clearly defined game to a career in surgery... you're either aware of that or you're not... if you're not aware of it then I think its much more difficult."

Habitus refers to an individual's dispositions: ways of thinking, acting and feeling formed by social interaction, including family life. These dispositions include practical skills, tastes, styles and expectations that determine how an individual will encounter the social world.

And when habitus encounters a social world of which it is the product, it is like a 'fish in water': it does not feel the weight of the water and it takes the world about itself for granted.

Bourdieu, in Wacquant (1989)

Within our model, 'walking the talk' can be seen as the process of internalising the conditions of the field - developing a practical efficiency in the surgical world. Thus individuals come to embody the dispositions necessary to identify themselves and be identified by others as a future surgeon. Harry and Hannah's differing experience of surgical banter are explained by Harry's being a 'fish in water' - taking the social reality of the operating theatre for granted.

Bourdieu's concept of capital can take economic, cultural, social or symbolic forms. In our data, students must tick the boxes; they must accrue recognised cultural capital ("knowing anatomy") and symbolic capital (rotation at a surgical "centre of excellence"), in addition to the social capital of their network, which 
facilitated participation in the surgical field - an activity reserved for those in more successful positions.

Uncovering the surgical hidden curriculum, then, related to understanding the importance of the accrual of relevant capital and embodiment of surgical dispositions - development of a feel for the game. This understanding resonates with Hafferty's definition discussed earlier (Hafferty 1998). Yet accrual of capital and embodiment of dispositions are not simple processes, and Bourdieu would emphasise how surgical practice preserves its underlying social structure. Our model shows students felt they must fit in with surgical practice in order to participate. Many are disprivileged by the existing practice; habitus, for example, is largely determined by family and community, and Rachel discusses the benefits of having surgeons as parents. Equally, the dispositions of the surgical field were gendered, meaning masculine characteristics and behaviours were privileged, marginalising many, including some men. In Bourdieusian terms, the necessity to fit in may be seen as reproduction, with the powerful maintaining their positions through unequal accumulation of capital and the privileging of certain habitus. Students felt the rules and hidden curriculum of surgery were implicit and non-negotiable - "doxa" in the Bourdieusian sense: principles "beyond question and which each agent tacitly accords by the mere fact of acting in accord with a social convention" (Bourdieu 1977a). While students must conform (and feel they must conform) to engage in surgical careers, the surgical field, its privileged habitus and the nature and distribution of its capital will remain unchanged. By making the surgical hidden curriculum explicit and thus enabling criticism, challenge and reform of the existing ideals, change and innovation in the field could occur, broadening both the number and type of students able to identify and be identified as future surgeons.

Our research approach had significant strengths. First, the frankness of our interview data was facilitated by the position of KB, a medical student, as interviewer. Second, the interview schedule was informed by analysis of questionnaire data, allowing us to examine our research question in both breadth and depth. Third, iterative data collection and analysis was undertaken by $\mathrm{EH}$ and $\mathrm{KB}$ working in partnership; resultantly, interpretations of the data were constantly challenged, and renegotiated furthering the academic rigour of the work. Despite the mixed theoretical backgrounds of the research team, we were heavily sensitised to social theories of learning, which have informed the concepts that emerged from the data; had this data been analysed by another research team, a different model may have emerged. This is acknowledged in the constructivist grounded theory approach; however, we kept reflexivity diaries throughout data collection and analysis, to understand how such factors influenced analysis. 


\section{CHAPTER 3}

In terms of limitations, as a single-site study, we examined one culture at a single institution. Our institution has a prominent undergraduate surgical society, which facilitates student-surgeon interaction before formal curricular surgical placements. Thus, networking opportunities may be more readily available at an earlier stage, and the importance of peer support may be exaggerated in our data. Further, our interview discussion schedule was heavily informed by questionnaire responses, rather than having open discussions, and consequently we may have focused our data collection prematurely.

Our model has clear practical implications. There may be significant benefit in identifying and making explicit aspects of the hidden curriculum; medical schools could support medical students' engagement in specialist career societies, to facilitate relationship building. Formal peer-mentoring may also offer such opportunities. Clinicians may explicitly share with students their own narratives of why they chose their career, the achievements and dispositions expected within it, and consciously create opportunities for participation. Further, it is clear that medical schools cannot assume that the provision of standardised surgical placements equips all students with an equal opportunity to learn and engage in surgery.

Our study focused on surgical careers, and exploration of the model in other contexts, for example in other cultures, specialties and training stages, may add greatly to its transferability. Alternative methodologies, particularly social networks analysis, using focused interviews or large-scale surveys could elucidate what relationships are important, for whom, and in what contexts, and also further explore the nature of information flowing through these relationships. Though we suggest that making the hidden curriculum explicit may be of benefit, we acknowledge that a new game could emerge that may privilege (and disprivilege) people in new ways; hence, further study is necessary to evaluate the ramifications of such an intervention.

\section{Conclusion}

We present a model of how students negotiate the hidden curriculum of surgery. Our model suggests students uncover the hidden curriculum of surgery through building a network of relationships. Students enact the hidden curriculum by accumulating the practical achievements required, and displaying the personal characteristics expected, of surgeons. Thus, they identify themselves, and are identified by others, as future surgeons, able to fit it in and access participation in surgery; an important way to further expand their network and gain more surgical careers information. Unequal access to the hidden curriculum of surgical careers at each stage of this process excluded many from the possibility of considering a surgical career. 


\section{References}

Bourdieu P (1977a). Outline of a Theory of Practice. Cambridge: Cambridge University Press.

Bourdieu P (1977b). Reproduction in education, society and culture. London: Sage Publications.

Bourdieu P (1990a). The Logic of Practice. Palo Alto, CA: Stanford University Press.

Bourdieu P (1990b). In Other Words: Essays Towards a Reflexive Sociology. Cambridge: Polity Press.

Bourdieu P (1993). Some Properties of Fields. In: Sociology in Question. Thousand Oaks, CA: Sage Publications, p72-77.

Burack JH, Irby DM, Carline JD, et al. (1997). A study of medical students' specialty-choice pathways: trying on possible selves. Acad Med, 72(6):534-541.

Cassell J (2000). The Woman in the Surgeon's Body. London: Harvard University Press.

Charmaz K (2000). Grounded theory: Objectivist and constructivist methods. In: Denzin NK, Lincoln YS, eds. Handbook of Qualitative Research. Thousand Oaks, CA: Sage Publications.

Cleland J, Johnston PW, French FH, Needham G (2012). Associations between medical school and career preferences in Year 1 medical students in Scotland. Med Educ, 46(5):473-484.

Coombs RH, Fawzy Fl, Daniels ML (1993). Surgeons' personalities: the influence of medical school. Med Educ, 27(4):337-343.

Dorsey ER, Jarjoura D, Rutecki GW (2005). The Influence of Controllable Lifestyle and Sex on the Specialty Choices of Graduating U.S. Medical Students, 1996-2003. Acad Med, 80(9):791.

Drinkwater J, Dornan T, Tully MP (2008). The effect of gender on medical students' aspirations: a qualitative study. Med Educ, 42(4):420-426.

Fairclough N (2001). Language and Power, 2nd ed. London: Pearson Education.

Gofton W, Regehr G (2006). What we don't know we are teaching: unveiling the hidden curriculum. Clin Orthop Relat Res, 449:20-27.

Goldacre MJ, Turner G, Lambert TW (2004). Variation by medical school in career choices of UK graduates of 1999 and 2000. Med Educ, 38(3):249-258.

Hafferty FW (1998). Beyond curriculum reform: confronting medicine's hidden curriculum. Acad Med, 73(4):403-407.

Hafferty FW, Hafler JP (2011). The Hidden Curriculum, Structural Disconnects and the Socialization of New Professionals. Innovation and Change in Professional Education, 6:17-35.

Hager P, Hodkinson $\mathrm{P}$ (2009). Moving beyond the metaphor of transfer of learning. $\mathrm{Br}$ Educ Res J, 35(4):619-638.

Hill E, Vaughan S (2013). The only girl in the room: how paradigmatic trajectories deter female students from surgical careers. Med Educ, 47(6):547-556.

Holland D, Lachicotte W Jr, Skinner D, Cain C (1998). Identity and Agency in Cultural Worlds. London: Harvard University Press.

Lempp $\mathrm{H}$, Seale $\mathrm{C}$ (2004). The hidden curriculum in undergraduate medical education: qualitative study of medical students' perceptions of teaching. BMJ, 329(7469):770773. 


\section{CHAPTER 3}

Maiorova T, Stevens F, Scherpbier A, van der Zee J (2008). The impact of clerkships on students' specialty preferences: what do undergraduates learn for their profession? Med Educ, 42(6):554-562.

McNally SA (2012). Surgical Training: Still Highly Competitive But Still Very Male. Bull $R$ Coll Surg Engl, 94(2):53-55.

Mills J, Bonner A, Francis K (2006). The Development of Constructivist Grounded Theory. Int J Qual Methods, 5(1):25-35.

Morse JM (1995). The Significance of Saturation. Qual Health Res, 5(2):147-149.

Ravindra P, Fitzgerald JEF (2011). Defining surgical role models and their influence on career choice. World J Surg, 35(4):704-709.

Rose G, Rukstalis MR, Schuckit MA (2005). Informal Mentoring Between Faculty and Medical Students. Acad Med, 80(4):344-348.

Wacquant LJD (1989). Towards a Reflexive Sociology: A Workshop with Pierre Bourdieu. Sociological Theory, 7(1):26-63.

Watson J, Nind M, Humphris D (2009). Strange new world: applying a Bourdieuian lens to understanding early student experiences in higher education. Brit J Sociol Educ, 30(6):665-681.

Wenger E (1998). Communities of Practice. Cambridge: Cambridge University Press. 


\section{Chapter 4}

\section{STEREOTYPES OF SURGERY}

\section{Can I cut it?}

\section{Medical students' perceptions of surgeons and surgical careers}

Published as:

Hill EJR, Bowman KA, Stalmeijer RE, Solomon Y, Dornan T (2014). Can I cut it? Medical students' perceptions of surgeons and surgical careers. Am J Surg, In Press. 


\section{CHAPTER 4}

\section{Abstract}

\section{Background}

Recent years have seen a significant drop in applications to surgical residencies. Existing research has yet to explain how medical students make career decisions. This qualitative study explores students' perceptions of surgery and surgeons, and the influence of stereotypes on career decisions.

\section{Methods}

Exploratory questionnaires captured students' perceptions of surgeons and surgery. Questionnaire data informed individual interviews, exploring students' perceptions in depth. Rigorous qualitative interrogation of interviews identified emergent themes, from which a cohesive analysis was synthesized.

\section{Results}

Respondents held uniform stereotypes of surgeons as self-confident and intimidating; surgery was competitive, masculine, and required sacrifice. To succeed in surgery, students felt they must fit these stereotypes, excluding those unwilling, or who felt unable, to conform. Deviating from the stereotypes required displaying such characteristics to a level exceptional even for surgery; consequently, surgery was neither an attractive nor realistic career option.

\section{Conclusions}

Strong stereotypes of surgery deterred students from a surgical career. As a field, surgery must actively engage medical students to encourage participation and dispel negative stereotypes that are damaging recruitment into surgery. 


\section{Introduction}

Application numbers to general surgery training have fallen over the last decade in the USA (Cockerham et al. 2004; Signer \& Beran 2005; Fischer 2007; McDonald \& Sutton 2009; Are et al. 2011), a pattern reflected in many countries worldwide (Marschall \& Karimuddin 2003; Pikoulis et al. 2010; McHugh et al. 2011). This is a worrying trend, which not only has ramifications for recruitment of the best candidates into surgical careers (Cockerham et al. 2004), but in the long term could jeopardize the quality and standard of surgical care we are able to deliver (Cofer \& Burns 2008; McDonald \& Sutton 2009; Stewart et al. 2013). Further, it is well established that although women comprise a considerable proportion of the medical workforce, they continue to be under-represented in surgical specialties, further depleting surgery's recruitment pool (Davis et al. 2011; Center for Workforce Studies 2012; McNally 2012). Could general surgery, and perhaps surgery in general, be heading for a major recruitment crisis?

Many students are unwilling to consider a surgical career (Tambyraja et al. 2008), a decision that may be taken even before they begin clinical training (Cleland et al. 2012). In order to explain the pattern of students' applications to surgical training, we first need to understand the perceptions and experiences influencing their career choices. Many studies have sought to identify predictive factors for an individual choosing a career in surgery (Neumayer et al. 2002; Azizzadeh et al. 2003; Mihalynuk et al. 2006; Sanfey et al. 2006; Laurence \& Elliott 2007; Drinkwater et al. 2008; Maiorova et al. 2008). Factors predicting such a choice that recur in the literature include exposure to and participation within a surgical specialty (Azizzadeh et al. 2003; Mihalynuk et al. 2006; Maiorova et al. 2008), perceived lifestyle or work-life balance (Azizzadeh et al. 2003; Sanfey et al. 2006; Drinkwater et al. 2008; Maiorova et al. 2008; Are et al. 2012), access to role models (Neumayer et al. 2002; Sanfey et al. 2006; Drinkwater et al. 2008; Drolet et al. 2014), derivation of satisfaction from surgery (Azizzadeh et al. 2003; Laurence \& Elliott 2007), and gender (Ek \& Ek 2005; Signer \& Beran 2005; Davis et al. 2011; Hill \& Vaughan 2013). Female students have differing and negative experiences of surgery (Hill \& Vaughan 2013), perceive a lack of fit between their perceptions of themselves and of what a surgeon must be (Peters et al. 2012), and are significantly more likely to pursue surgery if they train in a hospital with abundant and prominent female role models (Sanfey et al. 2006). Whilst there has been considerable emphasis by researchers on identifying these factors, few studies have considered how and why they may explain reluctance to engage in a surgical career. Hence, we propose an in-depth exploration of students' perceptions of surgery and surgeons, with a focus on stereotypes. 


\section{CHAPTER 4}

Stereotypes are cultural models which reflect social prototypes; they are not conjured from nowhere, but neither are they necessarily drawn from direct personal contact. Rather, they are socially and culturally derived figures which signal what is normal and what is not, and which are so deeply embedded in everyday life that they frequently go unnoticed. They consequently act as shortcuts to make assumptions about an individual quickly (Heilman \& ParksStamm 2007): in all human social interaction we rely on social scripts and stereotypes to a certain extent in order to function effectively in the world. Medicine is no different, and it is populated by a large number of specialized professionals, which may mean that stereotyping of particular specialties may be more likely.

In ethnographic work undertaken in the 1990s, Cassell (2000) provides us with a strong surgical stereotype,

"The "iron surgeon" powerful, invulnerable, untiring. Those trained by him pass on the mystique, transmitting from one surgical generation to the next an embodied professional ethos. The iron surgeon does battle with death, exterminates disease, declares war on softness, sloth, and error. He is technically brilliant, clinically astute, technologically sophisticated. His feelings, if he has any, are private; his inner life, if he has time for one, is unengaged by his work. The feelings of his patients are also private. Their personalities, problems, hopes, aspirations, are irrelevant. The iron surgeon's task is to excise disease. The rest is for nurses or social workers."

Cassell (2000)

This picture portrays surgeons in terms of decisive, masculine perfection; by implication surgeons do not display weakness or emotion, nor spare thought for communication or family - issues which, if raised, are positioned as contradictory to their role. This potentially discourages anyone whose values or personal characteristics do not align with such a portrayal.

If students decide against a career in surgery before exposure to it (Cleland et al. 2012), we must assume that they have strong preconceptions of surgery. In order to understand this phenomenon we must consider the nature of surgical stereotypes, and how they influence students' opinions of surgical careers. Whilst existing studies have focused on identifying predictive factors and correlations amongst large groups, the exploration of why such factors are powerful requires a different type of research, and there has been a call for more qualitative research within our field (Rich \& Grey 2003; Gooberman-Hill \& Fox 2011). Employing novel research strategies not typical for the surgical domain, namely discourse analysis, we undertook to answer the research 
questions: What stereotypes of surgeons and surgery exist among medical students? And how do these stereotypes influence students' ideas about surgical careers?

\section{Methods}

\section{Setting}

Ethical approval was granted by The University of Manchester Research Ethics Committee (Ref No: 11314). We conducted this study within a researchintensive UK medical school which trains approximately 450 students across five year groups. The University has a prominent surgical society and students are exposed to clinical surgical rotations in their first clinical year (Year 3) without exception. The medical school comprises four major teaching hospitals, each with a high turnover of surgical cases.

\section{Summary}

This study took a qualitative approach, employing exploratory open-ended questionnaires grounded in the literature, to gain insight into students perceptions, further explored in-depth via individual interviews, for triangulation of the research subject.

\section{Exploratory questionnaires}

We advertised for participants via the student intranet. We undertook purposive sampling of those who responded, to achieve representativeness in terms of year group and gender, while also including a broad range of career intentions. Of the sample $(n=46), 59 \%$ were female; the group was evenly spread across the five year groups; and $45 \%$ were considering a surgical career. In the open-ended questionnaires, which had been previously piloted, we asked students to provide descriptions of a typical surgeon, and of a positive and negative surgical experience; we also asked them to share their hints about what would aid or hinder success in a surgical career. Analysis occurred alongside data collection, and questionnaire data were interrogated via qualitative analysis, isolating important themes that emerged pertaining to the research question. After analysis of 46 questionnaires the research team reached consensus that no new themes were emerging, and recruitment was stopped. The analysis was used to inform the design of in-depth interviews.

\section{In-depth interviews}

We invited a further cohort, who had not completed questionnaires, to participate in in-depth face-to-face interviews, again via the student intranet. We purposively sampled students $(n=12)$ by career intentions (surgery, not surgery, or unsure) to gain the broadest range of views, and by year group and gender to ensure representativeness (Table 1). KB, a medical student, was 


\section{CHAPTER 4}

chosen to conduct the interviews to facilitate frank, honest discussion. Students were interviewed on a first-come, first-served basis until our sampling framework was fulfilled. We undertook in-depth individual interviews exploring students' experiences and perceptions of surgery and surgeons, and their subsequent career intentions. Questions were derived from analysis of the questionnaire data and included: "What are your experiences of surgery?", "What are your perceptions about a surgical career?", "What are surgeons like?", "Are there any stereotypes of surgeons?", "Are the surgeons you have met like their stereotypes?". Interviews were audio-recorded, transcribed verbatim and pseudonymized.

\begin{tabular}{|c|c|c|c|}
\hline Pseudonym & & Year & Career intentions \\
\hline Ben & \multirow[t]{4}{*}{ Preclinical study } & 1 & Not considering surgery \\
\hline Rebecca & & 1 & Not considering surgery \\
\hline Joanne & & 2 & Unsure \\
\hline Isabella & & 2 & Considering surgery \\
\hline Charlotte & \multirow[t]{4}{*}{ Clinical study } & 3 & Unsure \\
\hline Stephen & & 3 & Not considering surgery \\
\hline Hannah & & 4 & Not considering surgery \\
\hline Harry & & 4 & Considering surgery \\
\hline Neela & \multirow[t]{4}{*}{ Final year study } & 5 & Considering surgery \\
\hline Tom & & 5 & Considering surgery \\
\hline Luke & & 5 & Not considering surgery \\
\hline Lily & & 5 & Considering surgery \\
\hline
\end{tabular}

Table 1 - Interview Purposive Sample

We undertook qualitative analysis, coding the transcripts according to emergent themes in the data (Braun \& Clarke 2006; Ziebland \& McPherson 2006; Silverman 2009). This process was undertaken by researchers independently ( $\mathrm{EH}$ and $\mathrm{KB}$ ) and then discussed within the research team in order to challenge interpretations of the data. Further, an external researcher coded a random selection of transcripts to ensure rigor and minimize bias. We then synthesized the emergent themes and hierarchically organized them into meta-themes pertinent to the research questions. To best explore the nature and impact of stereotypes, we undertook a secondary discourse analysis, a 
methodology with which to examine language as a tool to understand individuals' assumptions, perceptions and beliefs, in this case about surgery. In accordance with Gee (2005), data was further interrogated to examine power systems, assumptions, beliefs, values, and cultural models within the data. This allowed examination not only of stereotypes explicitly voiced by participants, but also how they subsequently consciously or unconsciously subscribed to them in the interview.

\title{
Results
}

\section{Summary}

Remarkably uniform stereotypes of surgery and surgeons ran throughout participants' responses. Even though they were aware of the stereotypes they were drawing on, students believed surgeons were confident and intimidating, and that the surgical realm was a competitive and masculine domain requiring sacrifice. Students believed success in surgery required fitting into the stereotypes and possessing this battery of impressive personal characteristics. To deviate from this norm, for example in terms of gender or character, required being exceptional even within the surgical domain. This left many students feeling that surgery was not a possible career for them, often before they had clinical exposure to it.

\section{What surgeons are like:}

\section{Confident}

Students held stereotypes of surgeons as self-confident.

"I think to be a surgeon you've got to be... confident of your abilities... very sure of yourself and, if you aren't, I suppose you have to be very good at portraying confidence and... hiding that part of you."

Hannah, 4th year, not considering surgery

\begin{abstract}
"In order to get things done you have to be very like, harsh... and blunt... I understand when they are like that 'cause when they say things, they need things to get done... Like especially when people's lives are literally on the table, then you have to... get things done properly, and assert the authority so that when you know things need to be done, you get them done."
\end{abstract}

Charlotte, 3rd year, unsure

As these extracts demonstrate, students often felt that excessive selfconfidence and authority were integral characteristics of a surgeon, necessary both to engender trust from patients and to command and lead a team, excusing surgeons from behavior perceived as "rude". This included their very 


\section{CHAPTER 4}

direct communication style, which, while interpreted favorably by some as "honest" and "frank" by some, was seen as "brutal" and "mean" by many. This dual interpretation also applied to surgeons' self-confidence, which was often perceived as arrogance.

"When you think of a surgeon, that's the sort of person you think of, like quite smug and thinks he's like... the absolute best."

Ben, 1st year, not considering surgery

For students, the "typical arrogant surgeon" stereotype was extremely negative, whilst simultaneously being inseparable from and necessary to the role of a surgeon.

\section{Intimidating}

Participants respected individual surgeons for being "hard working", "skilled", "knowledgeable", "calm under pressure", and "good teachers". Yet surgeons were stereotypically "intimidating" due to their "aggressive" and "impersonal" nature and being "always busy", which made students apprehensive of future interactions.

"Sometimes it feels like you can't ask [questions], because... they seem very, quite, intimidating people, surgeons."

Charlotte, 3rd year, unsure

The negative stereotypes persisted even when in direct conflict with students' actual experiences of surgeons as "encouraging", "keen to teach" and "friendly"; meeting surgeons who did not conform was insufficient to dispel the stereotypes.

"So far many of them have lived up to their stereotypes... some surgeons don't, some surgeons are really, really nice, erm the other vascular surgeon on the firm, the lead, he was really lovely and I have a lot of respect for him, but a lot of surgeons can be quite boyish and like playing with their toys and I know it's a stereotype but I do think sometimes, sometimes it's true."

$$
\text { Hannah, 4th year, not considering surgery }
$$

Many students retold stories and rumors of surgeons' behavior. While students may not have had direct negative experiences of surgeons themselves, they came to expect, through such stories, that such events were possible within surgical culture. 
"And like just the fear of them being like the stereotypical surgeon. And then, not really like not understanding if, you know, you've done something wrong that you might want, you know, some, like, some counsel or like to be told how to do it better. They just kind of like make fun of you, you know, for doing it wrong. And that would be quite intimidating."

Isabella, 2nd year, considering surgery

Further, for those with direct experience, the stories and rumors became normalized, rendering such behavior acceptable.

"It may seem bad but um, I think 'cause the fact that patients are like anesthetized... like there's more of a relaxed atmosphere and more jokey, like obviously you can say things without offending the patient, 'cause they don't know what you're saying as such."

Harry, 4th year, considering surgery

Such expectations, driven by stereotypes, meant it was harder for clinical students to approach and engage with surgeons. This further reduced their enjoyment and experience of surgical placements.

\section{What surgery is like:}

Students of all year groups, including those who had not yet had contact with surgeons in clinical training, held consistent stereotypes of the culture and practice of surgery as competitive, masculine and requiring sacrifice.

\section{Competitive}

Every participant described surgery as competitive. It was seen as competitive in three senses, all closely related yet subtly different. First, the perceived competition to enter the career, through developing skills and achievements to stand out from peers. Second, the perceived importance of displaying competitive personality traits in order to fit into the domain, by appearing the most proactive and high-performing, and by putting themselves forward and taking opportunities, even at others' expense. Third, the perceived ruthless culture of competitiveness within surgery, promoting non-collaborative working and lack of collegiality. Competitiveness was such an inherent and important part of surgery that it was simply unimaginable that surgery could be any other way.

"Erm, I think most people know it's competitive. So you know you have to stand out from the crowd."

Joanne, 2nd year, not considering surgery 


\section{CHAPTER 4}

"I think you have to... just make sure you've got the competitive edge compared to other people because it is so competitive."

Charlotte, 3rd year, unsure

"I think the competitiveness of it all can put people off."

Hannah, 4th year, not considering surgery

As a result, some people did not wish to devote the time and energy to accruing accolades they saw as necessary to enter the career. Neither did they see themselves as possessing the competitive personality traits, nor even aspiring to do so. But most importantly, while some participants felt perfectly able to compete, they were deterred by their perception of the competitive culture.

"I just know it's really competitive and I'm a competitive person but probably not as competitive as other people I know who want to be surgeons... people I know who say they want to be surgeons now, they all kind of fit into like a certain type. Like they're really, really quite competitive. So no, I really can't see myself being a surgeon. *laughs*"

Rebecca, 1st year, not considering surgery

\section{Masculine}

Surgery was also seen as a masculine domain, with both male and female students ascribing a male gender to their surgical stereotypes.

"Stereotypes? Men. It's always men."

Neela, 5th year, considering surgery

"People have a view of a typical surgeon kind of like a rugby lad... especially orthopedics everyone says that the orthopedics, of all the surgeons, are like the lad surgeons..."

Isabella, 2nd year, considering surgery

However, it was not just that students thought of surgeons themselves as male, but that surgical stereotypes and masculine stereotypes were closely aligned, meaning the wider culture of surgery was perceived as masculine. The masculine qualities perceived necessary for success were believed to be held by both male and female surgeons alike, qualities which students did not ordinarily associate with women. Female surgeons, necessarily displaying these qualities in order to participate in the surgical domain, were seen as remarkable, and "manly".

"[discussing the surgeon stereotype] My mum actually had a routine operation last year but her surgeon was female, but she actually fitted 
that description quite well as well! *laughs* but I think it does tend to fit in more with, sort of, male stereotypes and surgical stereotypes kind of overlap a bit if you get me? As in... if you look at stereotypical gender roles *laughs* and like men tend be seen as more of like you know, the macho type, "I'm gonna do this by myself and I don't need anyone's help" and go in and save the day... and I think there's therefore the crossover [of masculine stereotypes and surgical stereotypes]."

Ben, 1st year, not considering surgery

"I'd imagine they'd [female surgeons] just be like, quite manly. *laughs* Not... in a bad way, but... if they're working within a predominantly male environment they have to sort of adapt slightly."

Joanne, 2nd year, not considering surgery

Participants did describe a female surgeon stereotype distinct from the male stereotype, though they often had not met any women surgeons. Female surgeons were seen as "confident", "extremely competent", "strong-willed", "motivated", "hard-working", "focussed" and "ambitious" but also "scary", "competitive", "stressed", "abrasive", "highly strung", "cold" and "stern". Although students were quick to justify why female surgeons might appear this way, they could not deny the effect this preconception had on their thoughts about surgery. This meant that, for some female students who were interested in surgery, the female surgeon stereotypes did not fit with their ideas of who they wanted to be in the future.

\section{Requires sacrifice}

Sacrifice was seen as an integral part of commitment to a surgical career, requiring substantial time and energy, given willingly by "driven" surgeons at the expense of other areas of life and in a way that exceeded that required by other medical specialties.

"The drive that surgeons have, I feel it's 'cause it's competitive, maybe that's why they feel like they have to have that drive, compared to if they do medicine, it just seems that the drive is different."

Charlotte, 3rd year, unsure

"I think a surgical career's very tough... if you compare it to general practice where you can be working a few days a week and... surgeons who are spending a lot of time on call, coming out in the middle of the night, and that kind of thing. Working very long hours and have a very long training thing, I think that that can put people off in terms of family life."

Tom, 5th year, considering surgery 
The perceived impossibility of a work-life balance in surgery was universal, and, for many, made surgery very unattractive. Students saw a future in which they must sacrifice their own life goals, most notably their family life, in order to have a surgical career. This sacrifice, regarded by most as hugely unattractive, was perceived as positive by those considering surgery, for whom the arduous requirements were symbolic of their perceived "prestige" of being a surgeon. Work-life balance was deemed particularly important for female students, many of whom refused to consider surgery even at an early stage in medical school as they assumed they could not be a good mother and a surgeon.

"[On why she doesn't want to do surgery] I feel like 'cause I'm female and if I was to have a family I want to be able to... look after my kids and at the same time have a good part time job, one that's easy to get as well, and do my job at the same time."

Charlotte, 3rd year, unsure

"The timetabling and the work-life balance is a large thing... for those that are looking into having families especially. Erm, I think that's probably actually quite a big thing but especially for women. Because if you know you want to have kids you don't necessarily want to be on nights and on call all the time."

Isabella, 2nd year, considering surgery

\section{Influence of stereotypes on medical students' perceptions of surgery Fit in to succeed}

Students felt they must "fit in" to surgical stereotypes and the culture of surgery in order to succeed in a surgical career. It was not simply that students opted out of surgery having experienced it, but rather that the perceived culture of surgery made it very difficult for many students to ever consider opting in.

"I think there are these stereotypes associated to surgeons and surgery, and yeah, I think maybe if you thought that you were gonna be really different from the rest of your peers it might make you think twice... I think if you've got your heart set on being a surgeon... you're going to be a surgeon. I think maybe the stereotype more affects whether you sort of you want to set your heart on being a surgeon in the first place."

Ben, 1st year, not considering surgery

An individual surgeon's deviation from the stereotype was always conspicuous. Further, a students' desire to become a surgeon was surprising to others if they 
did not fit the stereotype, repeatedly causing them to reflect on how they did not meet society's expectations of a future surgeon.

"When I tell people that I want to do surgery they're like, "Really?!" Like, "Are you sure you want to? You don't seem like the typical, you don't have the typical surgical character about you."'"

Neela, 5th year, considering surgery

Students were discouraged from pursuing surgery by their understanding that if you were unable to fit into surgery your experiences would be very unpleasant.

"Erm, and I think that the fear of, like the fear of it being like the stereotype, the fear of turning up and everyone like laughing at you and making loads of jokes and like, just, yeah... Like, if... I think the kind of fear of like walking in and if you know all of the surgeons know each other and they're all like having banter and just feeling like kind of small and left out and like you're not, you know, not included, like that at first might be pretty scary..."

Isabella, 2nd year, considering surgery

\section{If you're going to be different, you have to be better}

Deviating from the stereotype meant being 'othered'; always being remarkable for standing out. This meant that success, for anyone not fitting the stereotype, required exceptional characteristics - working harder, being tougher, being better.

"I think there's that kind of [stereotypical] surgeon, and I feel like there's surgeons who are just really, really, really, really smart and they can just go ahead without being like that... If the people who are blunt, erm, wanna get respect, they'll get respect anyway because they're quite authoritative people... But if they're really smart they'll get respect 'cause they're smart..."

Charlotte, 3rd year, unsure

It was easier for men to see themselves as fitting in to the surgical stereotype as they were more likely to be seen to possess the requisite masculine qualities. Students believed that female surgeons faced a harder career trajectory than their male counterparts; in addition to embodying the masculine characteristics expected, they had to work harder to succeed.

"If you are the only female in a male workplace you just have to be confident that like, you are equally as good, if not better than them." Joanne, 2nd year, not considering surgery 
"To be a female surgeon you have to be really quite a powerful person and come across as quite motivated and you have to, it's very competitive field so you really, really have to go for it. It's, I don't know I, I think to be a female surgeon you have to be pretty amazing to be able to compete with all the big competitive fierce manliness, and I know this is all stereotype you know but at the end of the day there's some truth in it."

Hannah, 4th year, not considering surgery

\section{Discussion}

Students held stereotypes of surgeons as self-confident and intimidating, and of surgical culture as competitive, masculine, and requiring sacrifice. Students thought they must fit these stereotypes to become a surgeon, which deterred many from considering a surgical career. Further, to remain successful while deviating from the stereotypes required displaying valued characteristics to a level exceptional even for surgery, excluding a further subset who did not believe this was a realistic possibility. Stereotypes exerted their influence even before medical students encountered surgery, and published research suggests the influence may persist throughout residency (Peters et al. 2012). The existence of stereotypes may contribute to both falling applications to surgical residency and to attrition once in surgical training, for example among female trainees in the UK (McNally 2012).

The strength of the stereotype becomes the issue, then, because of the type of person it demands; the question becomes not one of who chooses a surgical career, but of who is unable to; of who is excluded from the possibility of doing so. Our data suggest that a change in surgical stereotypes may increase the number and diversity of students considering surgery as a career in general, and in particular may address the issue of women's under-representation. In agreement with other international studies, our participants perceived surgery as a masculine domain, which was off-putting to those of both genders, but more notably women, who did not see themselves as able or willing to work in such a culture (Riska \& Novelskaite 2008; Hill \& Vaughan 2013). A similar workplace culture exists in financial services and management consultancy, and has been described as 'competitive masculinity' (Kerfoot \& Knights 1993; Meriläinen et al. 2004). As such, a macho culture of competitiveness and sacrifice is symptomatic of a normalizing gendered discourse of what it is to be an 'ideal' surgeon, to the exclusion of many of both genders. Prescriptive gender stereotypes provide a cultural framework for what are and are not suitable behaviors for surgeons (Heilman \& Parks-Stamm 2007): 
"You know, there are stereotypes, about the monster female surgeon, how scary she is... She is not feminine. Nobody likes her. How dare she, she's supposed to be raising children." Middle-aged female surgeon

Riska \& Novelskaite (2008)

In occupying this masculine domain, female surgeons may be perceived negatively since they violate the prescribed stereotypical behaviors of both a surgeon and a woman. Hence the perceived culture of surgery may explain under-representation of women in surgery.

To address this issue, we must consider how such strongly-held, remarkably uniform negative stereotypes can be challenged. One approach is via role modeling, which increases students' attraction to surgery (Nicholson 2002; Lempp \& Seale 2004; Rose et al. 2005; Sanfey et al. 2006; Ravindra \& Fitzgerald 2011). Role models are a way of encountering the 'reality' of surgery, and thus countering the prevailing stereotypes. The more diverse the role models available to students are, the more potential there will be to dispel the stereotype that all surgeons fit a single persona (Hill \& Vaughan 2013). Yet our data suggest role modeling alone may not suffice: stereotypes persisted even when students were consciously aware that their ideas were stereotypical and had real-life counter-examples drawn from their own experiences. The challenge, then, in addition to an approach at the level of the individual, is to alter the stereotypes on a macro-scale.

Awareness of stereotypes is a powerful position in itself, if it provokes controversy and discussion; awareness provides an opportunity to collectively challenge widespread perceptions of surgery and surgeons, allowing reinterpretation of existing stereotypes into something more inclusive. Let us consider a hypothetical alternative to Cassell's description, where surgeons are "friendly and approachable. A diverse group who always work hard and play hard, combining their clinical commitments with family life. They are excellent teachers, technically brilliant and prioritize their patients, communicating empathetically, to strive for the best surgical outcomes." This alternative account does not devalue surgeons' skills, or weaken the specialty, though it undoubtedly tackles some of our participants' concerns about surgery. Such a change may subsequently alter students' expectations; for example, a direct communication style may be perceived as honest and helpful rather than harsh or mean.

While negative stereotypes of surgery and surgeons prevail, they will continue to jeopardize recruitment in terms of numbers and quality. Surgeons, and particularly surgical educators, should be aware of the stereotypes, notice them and challenge them, whether it be in the way surgeons are spoken about by 


\section{CHAPTER 4}

colleagues or portrayed in written communications. Engagement with students to discuss their perceptions may not be enough, as even those students aware of stereotypes subscribe to them strongly. There is, however, growing evidence that offering experiences of participation in surgery and alternative stories of 'real-life' surgeons may dispel their negative assumptions (Drolet et al. 2014). Future work is needed to evaluate how students' views of surgery can change, and whether interventions countering surgical stereotypes are effective.

This study takes a novel approach to a long-established problem within surgical education. By focusing on the voices of the medical students, we were able to capture their perceptions of surgery and how these shape their career intentions. A significant strength of our study, therefore, is that it begins to address the mechanisms underlying patterns identified by previous studies.

In qualitative research, the prioritization of rich, detailed data comes at the expense of the observation of broader patterns and factors across a population. This study, therefore, makes limited claims to generalizability; however, we took several steps to address this issue. First, we drew on previous large-scale questionnaire studies investigating recruitment to surgery in a number of studies to inform our study design. Second, we sampled purposively, to include a breadth of participants in our analysis. Third, the research team comprised a medical student, surgical resident, Dean, researcher, and educator, whose diverse perspectives posed rigorous challenge to the analysis. Further, $\mathrm{EH}$ and KB maintained reflexive diaries to counter the influence of their own assumptions and biases on the analysis. Yet, our study does examine a particular group in a particular setting and it is possible that a microclimate of surgical culture existed; for example, Manchester Medical School has a large, active undergraduate surgical society set up to promote surgical careers. Further work is needed to compare and contrast these findings with data from other contexts.

\section{Conclusion}

Strong stereotypes of surgery and surgeons existed amongst medical students. These stereotypes deterred many from considering a surgical career. Surgeons and surgical educators should be aware of stereotypes, encourage participation in surgery and share 'real-life' narratives to challenge and dispel the negative stereotypes that are influencing surgical recruitment. 


\section{References}

Are C, Stoddard HA, O'Holleran B, Thompson JS (2012). A multinational perspective on 'lifestyle' and other perceptions of contemporary medical students about general surgery. Ann Surg, 256(2):378-386.

Are C, Stoddard HA, Prete F, et al. (2011). An international perspective on interest in a general surgery career among final-year medical students. Am J Surg, 202(3):352356.

Azizzadeh A, McCollum CH, Miller CC, et al. (2003). Factors influencing career choice among medical students interested in surgery. Curr Surg, 60(2):210-213.

Braun V, Clarke V (2006). Using thematic analysis in psychology. Qual Res Psychol, 3(2): 77-101.

Cassell J (2000). The Woman in the Surgeon's Body. London: Harvard University Press.

Center for Workforce Studies (2012). 2012 Physician Specialty Data Book. Washington, DC: Association of American Medical Colleges.

Cleland J, Johnston PW, French FH, Needham G (2012). Associations between medical school and career preferences in Year 1 medical students in Scotland. Med Educ, 46(5):473-484.

Cockerham WT, Cofer JB, Biderman MD, Lewis PL, Roe SM (2004). Is there declining interest in general surgery training? Curr Surg, 61(2):231-235.

Cofer JB, Burns RP (2008). The Developing Crisis in the National General Surgery Workforce. J Am Coll Surg, 206(5):790-795.

Davis EC, Risucci DA, Blair PG, Sachdeva AK (2011). Women in surgery residency programs: evolving trends from a national perspective. J Am Coll Surg, 212(3):320326.

Drinkwater J, Dornan T, Tully MP (2008). The effect of gender on medical students' aspirations: a qualitative study. Med Educ, 42(4):420-426.

Drolet BC, Sangisetty S, Mulvaney PM, Ryder BA, Cioffi WG (2014). A mentorship-based preclinical elective increases exposure, confidence, and interest in surgery. $\mathrm{Am} J$ Surg, 207(2):179-186.

Ek EW, Ek ET, Mackay SD (2005). Undergraduate experience of surgical teaching and its influence and its influence on career choice. ANZ J Surg, 75(8):713-718.

Fischer JE (2007). The impending disappearance of the general surgeon. JAMA, 298(18): 2191-2193.

Gee JP (2005). An introduction to discourse analysis: Theory and method, 2nd ed. London: Routledge.

Gooberman-Hill R, Fox R (2011). What can qualitative approaches bring to trauma outcome research? Injury, 42(4):321-323.

Heilman M, Parks-Stamm EJ (2007). Gender stereotypes in the workplace: Obstacles to women's career progress. Advances in Group Processes, 24:47-77.

Hill E, Vaughan S (2013). The only girl in the room: how paradigmatic trajectories deter female students from surgical careers. Med Educ, 47(6):547-556.

Kerfoot D, Knights D (1993). Management, masculinity and manipulation: from paternalism to corporate strategy in financial services in Britain. J Manag Stud, 30(4): 659-677.

Laurence C, Elliott T (2007). When, what and how South Australian pre-registration junior medical officers' career choices are made. Med Educ, 41(5):467-475. 


\section{CHAPTER 4}

Lempp $\mathrm{H}$, Seale $\mathrm{C}$ (2004). The hidden curriculum in undergraduate medical education: qualitative study of medical students' perceptions of teaching. BMJ, 329(7469):770773.

Maiorova T, Stevens F, Scherpbier A, van der Zee J (2008). The impact of clerkships on students' specialty preferences: what do undergraduates learn for their profession? Med Educ, 42(6):554-562.

Marschall JG, Karimuddin AA (2003). Decline in popularity of general surgery as a career choice in North America: review of postgraduate residency training selection in Canada, 1996-2001. World J Surg, 27(3):249-252.

McDonald K, Sutton J (2009). Surgical workforce: an emerging crisis. Bull Am Coll Surg, 94(5):21-26.

McHugh S, Corrigan M, Sheikh A, et al. (2011). Factors influencing career choice after initial training in surgery. World J Surg, 35(3):487-492.

McNally SA (2012). Surgical Training: Still Highly Competitive But Still Very Male. Bull $R$ Coll Surg Engl, 94(2):53-55.

Meriläinen S, Tienari J, Thomas R, Davies A (2004). Management Consultant Talk: A Cross-Cultural Comparison of Normalizing Discourse and Resistance. Health, 11(4): 539-564.

Mihalynuk T, Leung G, Fraser J, Bates J, Snadden D (2006). Free choice and career choice: Clerkship electives in medical education. Med Educ, 40(11):1065-1071.

Neumayer L, Kaiser S, Anderson K (2002). Perceptions of women medical students and their influence on career choice. Am J Surg, 183(2):146-150.

Nicholson S (2002). 'So you row, do you? You don't look like a rower.' An account of medical students' experience of sexism. Med Educ, 36(11):1057-1063.

Peters K, Ryan M, Haslam SA, Fernandes H (2012). To belong or not to belong: Evidence that women's occupational disidentification is promoted by lack of fit with masculine occupational prototypes. J Personnel Psychol, 11(3):148-158.

Pikoulis E, Avgerinos ED, Pedeli X, et al. (2010). Medical students' perceptions on factors influencing a surgical career: the fate of general surgery in Greece. Surgery, 148(3): 510-515.

Ravindra P, Fitzgerald JEF (2011). Defining surgical role models and their influence on career choice. World J Surg, 35(4):704-709.

Rich JA, Grey CM (2003). Qualitative research on trauma surgery: getting beyond the numbers. World J Surg, 27(8):957-61- discussion 961-2.

Riska E, Novelskaite A (2008). Gendered Careers in Post-Soviet Society: Views on Professional Qualifications in Surgery and Pediatrics. Gender Issues, 25(4):229-245.

Rose G, Rukstalis MR, Schuckit MA (2005). Informal Mentoring Between Faculty and Medical Students. Acad Med, 80(4):344-348.

Sanfey HA, Saalwachter-Schulman AR, Nyhof-Young JM, Eidelson B, Mann BD (2006). Influences on Medical Student Career Choice: Gender or Generation? Arch Surg, 141(11):1086-1094.

Signer MM, Beran RL (2005). Results of the National Resident Matching Program for 2005. Acad Med, 80(6):610-612.

Silverman D (2009). Doing Qualitative Research. London: Sage Publications.

Stewart RM, Liao LF, West M, Sirinek KR (2013). The general surgery workforce shortage is worse when assessed at county level. Am J Surg, 206(6):1016-1023. 
Tambyraja AL, McCrea CA, Parks RW, Garden OJ (2008). Attitudes of medical students toward careers in general surgery. World J Surg, 32(6):960-963.

Ziebland S, McPherson A (2006). Making sense of qualitative data analysis: an introduction with illustrations from DIPEx (personal experiences of health and illness). Med Educ, 40(5):405-414. 



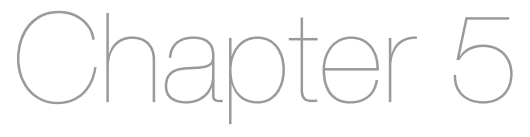

COMMENTARY

\section{Career decisions and gender: the illusion of choice?}

Published as:

Hill EJR, Giles JA (2014). Career decisions and gender: the illusion of choice? Perspect Med Educ, 3(3):151-4. 


\section{CHAPTER 5}

In their article published in this issue, van Tongeren-Alers et al. (2014) conducted a systematic review of the evidence for gender differences in specialty preference among medical students. Male students were more likely to be interested in surgery, while female students were more likely to be interested in gynaecology, paediatrics and general practice. Writing in a thought-provoking article in Medical Education, Bleakley made a recent call for a move beyond traditional demography (and indeed biology) to consider gender issues as cultural, in terms of gendered ways of thinking (Bleakley 2013). With such a stance in mind, it is striking that the majority of the studies avaliable for van Tongeren-Alers et al.'s review framed the problem in terms of 'career choice'. Given such pronounced gender differences, that van Tongeren-Alers et al. show hold consistently across countries, can students be truly said to have a 'choice' of career? To what extent are their available career options socially and culturally mediated by gender?

We know that certain factors affect students' career decisions. Chief among these is experience: if students are exposed to a specialty and enjoy it, they are more likely to pursue that career (Maiorova et al. 2008). However, there is evidence that students of different genders experience clinical placements differently. Females have been shown to have differing and more negative experiences of surgery (Hill \& Vaughan 2013). while, equally, males have differing and more negative experiences of gynaecology (Schnuth et al. 2003; Chang et al. 2010). Experiences are mediated by the culture of a specialty; in gynaecology, male students are treated differently because of differing expectations within the specialty of male and female students (Akkad et al. 2008). It seems, then, that while experience is all important, certain genders are better able to access participation in certain specialties because of current cultural understandings of gender and the specialties themselves - in other words, because of commonly-held gendered understandings of what it is to be a man or women, or a surgeon or gynaecologist.

Role models are another influence on students' career decisions, especially during clinical placements (Lempp \& Seale 2004). Here, again, gender is an important factor (Nicholson 2002; Lempp \& Seale 2004; Rose et al. 2005). Indeed, female students training in centres with more female surgeons were significantly more likely to show an interest in surgery (Sanfey et al. 2006) potentially explaining how current gender patterns are reproduced over time. Previous work has shown that what students see, hear, and do when encountering a specialty affect whether they can imagine themselves therein (Hill \& Vaughan 2013). This idea, of a 'paradigmatic trajectory', goes further than role modelling, to encompass how a specialty as a community and culture influences the possible futures students can imagine for themselves. Surgical paradigmatic trajectories are more accessible to male students and deter 
female students (Hill \& Vaughan 2013); there is also evidence that paradigmatic trajectories in female-dominated specialties, such as gynaecology, deter male students (Schnuth et al. 2003).

The above arguments indicate that social and cultural processes influence career decisions, but can such processes be said to restrict choice? Consideration of discourses may allow deeper exploration of these phenomena. Discourses of masculinity include characteristics of strength, decisiveness, independence, whilst those of femininity include empathy, communication, collaboration (Williams \& Best 1982). Discursively, surgery is constructed as strongly masculine: its culture is masculine, wherein masculine qualities are valued (Riska \& Novelskaite 2008). Conversely paediatrics is constructed as feminine, highly prizing communication skills and the ability to 'care' for children (Riska \& Novelskaite 2008).

Poststructuralist feminist critique considers gender not as biological, but as performative - in terms of learned behaviours and beliefs; 'women' (insofar as the word denotes a common identity) tend to embody discourses considered feminine, and 'men' masculine, because they learn to 'do gender' (Butler 2007). Importantly, this is not to say that men cannot ever embody feminine discourses, nor that individuals can only embody either masculine or feminine discourses. Indeed, men do embody, and operate within, feminine discourses, and women masculine (Holmes \& Marra 2010) - we have hugely successful male paediatricians and female surgeons as evidence. However, what we do suggest is that in a domain where masculine discourses predominate, such as surgery, feminine qualities have less cultural worth and are therefore more marginalised. It therefore follows that it is harder for those who have constructed a feminine identity for themselves - more usually, though not exclusively, women - to imagine, access and engage in such a practice, especially when they simultaneously compare it (imaginatively or otherwise) to a practice like paediatrics, which discursively embraces and values those same aspects of their identity.

Different theoretical stances attribute differing degrees of agency - the capacity for self-direction - to individuals 'making choices' in the world. The sociocultural stance we adopt above holds that discursive constraints, such as gender, class, ethnicity and sexuality operate to restrict available options; or, to put it another way, the possibilities that are available are largely determined by an individual's background - or rather their embodied history-in-person - and the conditions of the society in which they operate (Holland et al. 1998). Discourses, then, become a "highly rigid regulatory frame" (Butler 2007). 


\section{CHAPTER 5}

More individualistic perspectives differ in that individuals become the 'locus' of agency; individuals are free to decide their future, taking into account how they see the world. It is towards this end of the epistemological spectrum that we position the literature on 'career choice' in medical education, one of whose features as a field is, what Bleakley terms, the "widespread uncritical acceptance of andragogy" (Bleakley 2013), which seeks to emphasise the autonomy and 'self-direction' of each learner (Bleakley et al. 2011). These theories are critiqued for their 'denial of the social world' - not acknowledging the cultural constraints working against those marginalised or less privileged in a society (Bourdieu 1977; 1984).

So, how to proceed? Likely we can all agree on the importance of supporting medical students to navigate the various careers available, and take the best path for themselves. As van Tongeren-Alers et al. (2014) suggest, the method of gender mainstreaming may be useful (Verdonk et al. 2008); it renders issues of gender, and what it means to be male and female, 'up for negotiation'. We suggest that discussion of what surgery or gynaecology is, in a cultural sense, could also lead to renegotiation and broadening of who should practice them. There may also be space within medical education for further consideration of the influence of gendered discourses in day-to-day practice - of how gender 'works' within a culture; this approach allows exploration of demographic inequalities from another angle, theoretically complementing past work.

Studies to identify gender imbalance in medical education, are often accompanied by a desire to address the issue. The contemporary social sciences have given us the tools to do so, to move beyond demography and biology in our discussions, in teaching and learning, and in research, and to begin to better address the gender issues that so concern us. 


\section{References}

Akkad A, Bonas S, Stark P (2008). Gender differences in final year medical students' experience of teaching of intimate examinations: a questionnaire study. BJOG, 115(5):625-632.

Bleakley A (2013). Gender matters in medical education. Med Educ, 47(1):59-70.

Bleakley A, Bligh J, Browne J (2011). Socio-cultural Learning Theories. In: Medical Education for the Future. London: Springer, p43-60.

Bourdieu P (1977). Outline of a Theory of Practice. Cambridge: Cambridge University Press.

Bourdieu P (1984). Introduction. In: Distinction: A Social Critique of the Judgment of Taste. Cambridge, MA: Harvard University Press, p1-7.

Butler JP (2007). Gender Trouble, 2nd ed. London: Routledge.

Chang JC, Odrobina MR, McIntyre-Seltman K (2010). The Effect of Student Gender on the Obstetrics and Gynecology Clerkship Experience. J Womens Health, 19(1):87-92.

Hill E, Vaughan S (2013). The only girl in the room: how paradigmatic trajectories deter female students from surgical careers. Med Educ, 47(6):547-556.

Holland D, Lachicotte W Jr, Skinner D, Cain C (1998). Identity and Agency in Cultural Worlds. London: Harvard University Press.

Holmes J, Marra M (2010). Introduction. In: Femininity, Feminism and Gendered Discourse. Newcastle: Cambridge Scholars Publishing, p1-18.

Lempp $\mathrm{H}$, Seale $\mathrm{C}$ (2004). The hidden curriculum in undergraduate medical education: qualitative study of medical students' perceptions of teaching. BMJ, 329(7469):770773.

Maiorova T, Stevens F, Scherpbier A, van der Zee J (2008). The impact of clerkships on students' specialty preferences: what do undergraduates learn for their profession? Med Educ, 42(6):554-562.

Nicholson S (2002). 'So you row, do you? You don't look like a rower.' An account of medical students' experience of sexism. Med Educ, 36(11):1057-1063.

Riska E, Novelskaite A (2008). Gendered Careers in Post-Soviet Society: Views on Professional Qualifications in Surgery and Pediatrics. Gender Issues, 25(4):229-245.

Rose G, Rukstalis MR, Schuckit MA (2005). Informal Mentoring Between Faculty and Medical Students. Acad Med, 80(4):344-348.

Sanfey HA, Saalwachter-Schulman AR, Nyhof-Young JM, Eidelson B, Mann BD (2006). Influences on Medical Student Career Choice: Gender or Generation? Arch Surg, 141(11):1086-1094.

Schnuth RL, Vasilenko P, Mavis B, Marshall J (2003). What influences medical students to pursue careers in obstetrics and gynecology? AJOG, 189(3):639-643.

van Tongeren-Alers M, Dielissen P, van Leerdam L, Lagro-Janssen A (2014). Gendered specialties during medical education: a literature review. Perspect Med Educ, In Press.

Verdonk P, Benschop YWM, De Haes JCJM, Lagro-Janssen ALM (2008). Making a gender difference: case studies of gender mainstreaming in medical education. Med Teach, 30(7):e194-201.

Williams JE, Best DL (1982). Measuring Sex Stereotypes: A Thirty-Nation Study. Newbury Park, CA: Sage Publications. 



\section{Chapter 6}

\section{BEING A WOMAN IN SURGERY}

\section{You become a man in a man's world:}

is there discursive space for women in surgery?

Submitted as:

Hill EJR, Solomon Y, Dornan T, Stalmeijer RE (2014). You become a man in a man's world: is there discursive space for women in surgery? 


\section{CHAPTER 6}

\section{Abstract}

\section{Background}

The UK set a 2009 target for a $20 \%$ female surgical consultant workforce - in 2012, it remains 7\%. Previous studies have attributed this shortfall to the nature of a career in surgery and differing career aspirations among females. Rather than exploring barriers to participation, this study aims to explore the selfnarratives of those women who do undertake surgical careers and who do come to see themselves as surgeons.

\section{Summary of Work}

The study comprises fifteen individual interviews with women throughout surgical careers, from medical students aspiring to surgery, to senior and retired surgeons. Data were explored via discourse analysis with a priori themes derived from the literature on women in surgery and Holland et al.'s theoretical framework of Figured Worlds.

\section{Summary of Results}

Discourses of being a surgeon and discourses of being a woman existed in competition. Female surgeons figured surgery as a career requiring $100 \%$ dedication, as they did motherhood, though the demands of these two roles differed; consequently these roles were not discursively compatible. Many related powerfully negative, even traumatic, experiences where their female gender marked them out as 'other' within the surgical world. Some had refigured these and drew upon them as sources of strength, constructing their own practice in opposition to what had hurt them. Women described how they were expected to show masculine traits as a surgeon, and the ways in which they could consequently become legitimate in the surgical world as a 'womansurgeon'. They found creative ways to articulate how women in general, and feminine qualities in particular, enhanced surgery. Finally, some women engaged in powerful identity work, termed world-making - the creative orchestration of discourses of surgeonhood and motherhood to be mutually sustaining.

\section{Conclusions}

There is little discursive space to be a successful woman and a successful surgeon. Those who do combine these two roles must either be innovative in refiguring either what it means to be female or what it means to be a surgeon; or they must author a new space for themselves, a powerful discursive process termed 'world-making'. 


\section{Introduction}

The increase in the proportion of women at medical school has changed the gender demography of the medical profession. One specialty in which women remain under-represented despite this change is surgery. Though the number of women entering postgraduate surgical training has increased, by the end of training few women remain (Davis et al. 2011; Center for Workforce Studies 2012; McNally 2012). While this pattern exists in many countries, it is particularly marked in the UK. Here women represent $58 \%$ of medical students, $33 \%$ of core surgical trainees (postgraduate years $3-4$ ), $16 \%$ of specialty surgical trainees (postgraduate years 5-10) and 7\% of fully-trained surgeons (Center for Workforce Studies 2012; McNally 2012). Much of the literature examining this demographic phenomenon focuses either on factors affecting the career decisions of medical students (Burack et al. 1997; Drinkwater et al. 2008; Maiorova et al. 2008; Cleland et al. 2012), or on reasons why female students do not pursue surgery (Baxter \& Cohen 1996; Neumayer et al. 2002; Yu et al. 2012; Hill \& Vaughan 2013). Yet, self-evidently, some women do engage in surgical careers. To further explore the reasons for women's underrepresentation, we focus this paper on those women who have decided to undertake a surgical career.

As women progress in surgical careers, they must form a professional identity that is situated within the structure and culture of the surgical profession. Little literature exists on the relationship between gender and identity formation in surgical careers; however, parallels can be drawn between surgery and a number of other stereotypically masculine disciplines, for example mathematics, science and engineering, and business (Meriläinen et al. 2004; Regan \& Dillon 2012). Despite the widespread elimination of organisational and legal barriers to their advancement in these careers, women continue to be under-represented in traditionally male domains. The problem has been framed in terms of the lack of a discursive space for women in male-dominated arenas, where identities are typically masculine (Walls 2009; Solomon 2012). Thus, women must position their feminine identities under a "cloak of invisibility" (Walls 2009). Yet there is evidence to show that some women in mathematics are finding new ways to be female in a masculine environment, via collective challenge to the engrained power dynamics and critical analysis of their own situation (Solomon 2012). The approach taken in mathematics, then, may be applied to examine the issue of women in surgery from a fresh theoretical perspective.

Holland et al.'s theoretical amalgam of Vygotsky, Bakhtin and Bourdieu is a lens through which we may explore women's identities in the 'figured world' of surgery (Holland et al. 1998). Identity is a word used to describe many different aspects of an individual, community or culture. Within Holland's 'Figured 


\section{CHAPTER 6}

Worlds' framework, identity is not something which is possessed; rather, it is constantly negotiated between an individual and their social world. The theory of Figured Worlds captures the way in which individuals narrate ('self-author') their identities by selectively drawing upon the norms, values, language, practices and narrativised characters ('figures') of their particular social context. Hence, people 'self-author' their identities in dialogue with, and in response to, those around them, drawing on the shared sociohistorical meanings, or discourses, that are available to them (Bakhtin 1981; 1986; Holland et al. 1998; Monrouxe 2010). This concept of self-authoring affords a degree of agency opportunity for self-determination - as individuals can selectively draw upon and position themselves within societal discourses; indeed, individuals have the ability to effect change within social worlds (Holland et al. 1998). Identity, then, may be considered a process of becoming; people are continuously shaping and being shaped by the world around them. When viewed as the point of intersection where past experiences and current practice meet, and the individual and society interact (Tsouroufli et al. 2011), identity allows us to examine gender issues in surgery at a micro and macro level simultaneously.

If we acknowledge that the interaction between identity and social structure is important, then the ways in which individuals navigate and negotiate this interaction are also important. The role of narrative in this process can be studied through discourse analysis, which describes the function of language as twofold: to support social activities and identities, and to support human affiliation within social groups, cultures and institutions (Gee 2005). Surgery has multiple social groups, cultures and institutions with which to affiliate oneself, and there is a complex interplay of social activities and positions to negotiate, which may pose differing barriers to engagement for women. One example, The Royal College of Surgeons of England, is an organisation that is exclusive, steeped in history and traditionally masculine. Similarly, the culture within an operating theatre is hierarchical, regimented and closed to outsiders (Lingard et al. 2002). In any figured world, social positioning, or positionality, is mediated by "on-the-ground relations of power, deference and entitlement, social affiliation and distance" (Holland et al. 1998, p127).

Surgery as a practice is discursively masculine, privileging embodiment of masculine characteristics (Riska \& Novelskaite 2008). How then do women experience this field, and author themselves in response to it? It may be that there is a lack of discursive space for women within the surgical world. This study aims to explore how those females who do undertake surgical careers and who do come to see themselves as surgeons experience these institutional environments, and how they use language to identify or disidentify therein. Hence, this study uses discourse analysis and the Figured Worlds framework to 
answer the research question: how do female surgeons self-narrate their identities?

\section{Methods}

\section{Research ethics}

Ethical approval for the study was granted by The University of Manchester Committee for the Ethics of Research on Human Beings (Ref: 11314).

\section{Theoretical framework}

We undertook an in-depth qualitative study using Figured Worlds as a theoretical framework (Holland et al. 1998). This theory facilitated exploration of identity in two ways. Firstly, in terms of 'figured identity', i.e. identity pertaining to an individual's own experiences, the narratives of others, the figured world of surgery and its figures. This allows us to understand how individuals' pasts have influenced their identities, and how they imagine themselves and the world around them. Second, in terms of 'positional identity', i.e. identity pertaining to an individual's position within a social world in relation to others. This provides a tool to explore relationships, power and hierarchy. The use of Figured Worlds predisposes an epistemological stance: the way people choose to talk about themselves, particularly in relation to others, is the way they narrate their own self (to themselves as well as to others), and thus their identities. Therefore, by interviewing participants we can study their identities.

\section{Setting}

Medical student participants attended a large UK medical school with a fiveyear problem-based learning curriculum. All doctors were working, or had worked in hospitals within the UK National Health Service (NHS): junior doctors in their first two postgraduate years were undertaking a Foundation Programme in medicine, surgery and general practice, and applying to surgical training; surgical trainees were undergoing two years of core surgical training and at least a further five years of specialist surgical training; consultant (fully trained) surgeons were either currently practising or retired. 


\section{CHAPTER 6}

\section{Participants}

Fifteen women were invited to participate, comprising a purposive, longitudinal sample of the surgical training pathway representing aspiring, training, fully qualified and retired surgeons (Table 1), including those who had undertaken both direct and more indirect routes through surgical training. The sample included participants with and without families, those working less than fulltime, those who had taken time out for research or to have children, and surgeons from different sub-specialties. More detailed backgrounds of individual participants have been withheld to ensure confidentiality.

\begin{tabular}{|c|c|c|}
\hline Pseudonym & Grade & Sample Group \\
\hline Kate & 1st year medical student & Aspiring female surgeons: \\
\hline Christina & 2 nd year medical student & $\begin{array}{l}\text { Contemplating whether to } \\
\text { 'opt in' to a surgical career }\end{array}$ \\
\hline Michelle & 3rd year medical student & \\
\hline Zaineb & 4th year medical student & \\
\hline Indira & 5 th year medical student & \\
\hline Nadia & 1st year postgraduate doctor & \\
\hline 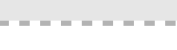 & 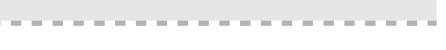 & 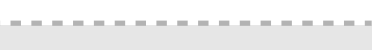 \\
\hline Laura & 2nd year postgraduate doctor & Surgical trainees: \\
\hline Emily & Junior core surgical trainee & $\begin{array}{l}\text { Deciding whether to 'opt } \\
\text { out' or continue training }\end{array}$ \\
\hline Anna & Junior specialist surgical trainee & in surgery \\
\hline Sarisha & $\begin{array}{l}\text { Mid-level specialist surgical } \\
\text { trainee }\end{array}$ & \\
\hline Leah & $\begin{array}{l}\text { Senior specialist surgical } \\
\text { trainee }\end{array}$ & \\
\hline$----m----$ & 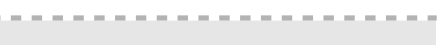 & \\
\hline Jane & Junior consultant surgeon & Fully qualified surgeons: \\
\hline Carolyn & Consultant surgeon & $\begin{array}{c}\text { Succeeded or established } \\
\text { in a surgical career }\end{array}$ \\
\hline Juliette & Senior consultant surgeon & \\
\hline Helen & Retired consultant surgeon & \\
\hline
\end{tabular}

Table 1 - Participants by career grade 


\section{Data collection}

Semi-structured individual interviews were conducted by $\mathrm{EH}$ at university or hospital sites. Interviews lasted a maximum of one hour, and were guided by a discussion schedule derived from the literature and pilot interviews, informed by Figured Worlds. Interviews used open-ended questions to encourage participants to reflect on their experiences, thoughts and opinions on their career, as well as on surgery in general. Questions were designed to facilitate exploration of professional identities and important events, for example, "What does being a surgeon mean to you?" and "Have there been any moments when you felt you particularly belonged, or felt included in surgery? How about moments when you felt you didn't belong, or felt excluded?" $\mathrm{EH}$, at the time a senior medical student, and aspiring surgeon, conducted the interviews. Interviews were audio recorded, transcribed verbatim, and pseudonymised.

\section{Analysis}

Discourse analysis was undertaken, in accordance with Gee, with a priori themes drawn from the literature on women in surgery, coupled with theoretical themes from Figured Worlds to act as sensitising concepts (Holland et al. 1998; Gee 2005). Common themes arising from the data were initially coded by $\mathrm{EH}$, with transcripts read and re-read by the entire research team to challenge previous interpretations of the data. As new themes emerged, the analysis was adapted in an iterative process. To ensure analytical rigour, interview transcripts were coded separately, then collaboratively, to highlight any differences and similarities between interpretations. Additionally, a sample of data was re-coded by a researcher outside the research team and compared to the analysis (Fairclough 2001).

\section{Reflexivity}

Epistemologically, this work acknowledges that data were co-constructed between the interviewer and interviewees. Therefore, the research team were cognisant not only of how the researcher positioned the participant, but also of how interviewees responded to and positioned the researcher. In response to this, EH maintained reflexivity via a reflexive diary, in which she recorded any preconceived ideas about the data and topic. Throughout data collection and analysis, she recorded further reflections with the potential to influence analysis. The diary was regularly discussed within the research team. Further, $\mathrm{EH}$ kept detailed records that focused specifically on critical reflexivity of the dataset, considering not simply whom the interviewee was answering or addressing, but whom $\mathrm{EH}$, as researcher, was answering and addressing, and which shared discourses were drawn upon, by whom and with what result. 


\section{CHAPTER 6}

\section{Results \\ Competing discourses of being a surgeon and being a woman}

The female surgeons interviewed identified very strongly as surgeons. Yet being a surgeon and being a woman were competing components of their narratives; thus, when narrating their identities as surgeons, they always gave a parallel, and often unprompted, account of themselves as women.

Elspeth: "Do you think being a surgeon is a big part of who you are?

Helen: I suppose it, it has to be. I think it has to be because I, when I trained, when I qualified, we used to do eighty to a hundred hours a week, we did the one in two, one in three rotas [nights on call]... So l've worked long hours and that, that's been me, you know. Erm, it's been the major part of my life. If you're working seventy, eighty hours a week for something, it is your life, you're sleeping some of it, aren't you? Yes. It doesn't leave room for much else. I do think nowadays that people have outside interests and other things and their job, their medicine is a small part of their life, quite often, but it has been my whole life. I suppose I've given my life to it, really. I don't know if you want to hear about marriage and husbands and things but, as you know, I'm not married, I've not got a husband, l've not got children. Erm, I haven't sacrificed anything, I've never said to somebody, "No, I'm not marrying you because I'm a surgeon." The opportunities haven't come; there hasn't been anybody l've wanted to marry. But as a consequence of that I put my time into my work... And even as a consultant I would stay late at night and look at results and things... Because it's the way l've always done it. And I also put a lot of time into it, a lot of extra time into it. So yes I am who I am because, you know, I am a surgeon and that's me. You can't separate it from me."

Helen, retired consultant surgeon

Here, Helen discusses her dedication to surgery and offers an unbidden account of the reasons she did not marry or have children. Her narrative draws on a discourse of surgeonhood as the core of a person; implicit is that being a surgeon means there is little space for anything else. Her narrative demonstrates how directly the discourse of being a surgeon competes with the discourse of being a woman, and the simultaneous but contradictory requirement for female surgeons to be both. For women surgeons, without direct juxtaposition of accounts of themselves as women, it would sound as if they had given up that part of themselves; to give an account of oneself solely as a surgeon equated to an account of oneself as lacking as a woman, particularly in terms of family life. In the next quotation, Sarisha prefaces her strong identification as a surgeon with an account of her motivation to fulfil 
female roles in family life - again demonstrating that female surgeons must answer to both these discourses.

"I want to be a good, you know, daughter, a good wife, a good sister, a good surgeon...l don't just see myself as a doctor, I see myself as a surgeon... I wouldn't say it's the be all and end all but it's pretty much getting there... *laughter*... It's almost everything. I couldn't see myself doing anything else. And if somebody told me I couldn't operate l'd be truly gutted."

Sarisha, mid-level surgical trainee

The discursive competition between being a surgeon and being female was also apparent in the narratives of the aspiring female surgeons.

"And obviously particularly from a female's point of view, erm, you know, a plan one day-getting married, having children, having a family, but I don't see where that could fit in. I have difficulty seeing where that could fit in sort of when I'm, you know, 35 and doing on-calls and quite crazy hours."

Zaineb, 4th year medical student

Kate, a first year student, struggles to articulate a critique of the discourses regarding women in surgery. Importantly, she acknowledges that women who "don't want a family" are seen as "really weird", and implicitly, that there are differing expectations of female surgeons when compared to their male counterparts. Even at her early stage in medical school, and despite her strong interest in surgery, Kate has formulated an understanding that being a surgeon and being a woman are difficult to combine, if not at odds.

"...the stereotype of all the... women that are surgeons... they're really hard women... people think that women that don't want a family or children straightaway are kind of really weird, erm... like, because no-one looks at a male surgeon as, like, "Oh, I wonder if they've had a family or not."'”

Kate, 1st year medical student

\section{Irreconcilable discourses of being a surgeon and being a good mother}

Central to the discourse of surgeonhood was complete dedication to the role, most notably in terms of time - working "full time", "doing all the on call". Dedication was also important in the discourse of motherhood, for example "being there for bedtime". Attempting to operate within these competing discourses, Jane articulates that the roles are "kind of mutually exclusive"; there is very little space, in both discursive and practical terms, to be a good surgeon 


\section{CHAPTER 6}

and a good mother. To compromise on either was tantamount to failure in the role: Carolyn contemplates compromising the "respect" of her colleagues by working part-time, while Jane discusses feeling "guilt" as a mother by working full-time.

"...there are still men in my peer group who will never respect a female surgeon unless she's full time, doing all the on call, not going off to see the kids in the Christmas play, you know, unless she's a fully-fledged bloke. There's a man in my department who said, "Carolyn, I'll never respect you because you didn't do it the way we did it."... and it's not very long ago that he said that either."

Carolyn, consultant surgeon

Here, Carolyn is defiant in her tone, recognising the injustice inherent in the discursive competition between being a surgeon and being a woman. Worse than embodying opposing discourses as a female surgeon, being a mother and a surgeon require enacting mutually exclusive discourses, leading to competition for a female surgeon's time and attention in a very real sense. Jane, like Carolyn, recognises and resists the competing and unjust nature of the expectations of her as a surgeon and as mother; indeed she contrasts this with expectations of working fathers.

"I don't think many fathers are at home stressing that they're really bad at work because they're... fathers. I think it's more, it is more of a woman thing and I think, a mum thing... And a lot of women feel very guilty about things all the time which, usually unnecessarily, you have to say... So you've just got to get rid of that whole guilt thing as well. That's how it works for me. I think quite a few people have said that they do feel guilty when they're at work or if they're working late at work, which I thought was interesting. I'm sure most do actually..."

Jane, junior consultant surgeon

Hence, both Carolyn and Jane recognise the injustice that, discursively, a woman cannot be a good mother if she is a surgeon. Although Jane and Carolyn's resistance offers a challenge to discourses of being a surgeon and being a woman, their narratives still operate within these discourses. Indeed, Jane cannot maintain her stance of resistance; the competition between these discourses influences the way she feels about herself as a mother.

"...I mean there has been the odd time when... when have I felt bad? Erm, sometimes you can have just a really busy week and it's just, erm, for example, I don't go away much now with work. I, I just try not to do it and I don't have to do it but, erm, a couple of weeks ago I went away and 
I stayed overnight and I really don't like doing that because I feel, erm, I feel... I like to be there at bedtime, I like to be there when they wake up so I felt a bit bad about that, erm, not bad enough not to do it because I do it about once every, oh God, probably not even once a year. So no it's not a frequent thing. I think mothers who are away from home as part of their work would, that would be a really big issue. Hmm. I mean, I'm, I'm home for... I put the kids to bed most nights, pretty much every night really..."

Jane, junior consultant surgeon

\section{Positioned by others}

As well as negotiating a position for themselves within these discourses, female surgeons were aware of how they were positioned by others - particularly in terms of the expectations placed on them as a surgeon and as a woman, both by those within surgery and those without. Here, Jane discusses how being a surgeon had been met with surprise both from patients at work, due to her gender, and from other mothers outside work, due to her career. Notably, such occurrences caused her to reflect on how, as a 'female surgeon', she fitted neither the figured world of surgery nor the figured world of the middle-class mother.

"I mean, I've had over the years [patients] come in and say to me, "Oh you're not, you're not what I expected," or, "You're not... you don't look like a surgeon,"... So they, people do have a perception... and it is to do with gender...

...l still now will go out and, again, not talk to anyone and they'll say, "What do you do?" and you tell them and you still get a moment of, "Oh my God!"... say I'm out with my kids on what I call my mummy days so I wear my jeans looking like any other mum and, erm, I think after, you know, especially amongst the school mums there's... a perception that you don't work at all so that when you say you, you do work and they ask you what you do, then I, I suppose it's completely not what they're expecting so there's this element of surprise."

Jane, junior consultant surgeon

Female surgeons were also positioned by their colleagues within the world of surgery: Leah describes how senior doctors had repeatedly attempted to steer her out of surgery, explicitly explaining that she did not fit with their understanding of a surgeon.

"Seniors... they didn't see me in surgery because they felt that I was too sociable a person, you know, and not driven enough... they could see me, 


\section{CHAPTER 6}

you know, being a GP [general practitioner] or an anaesthetist... so there were a few times people said things like that but nobody ever specifically said don't do it, you know... I think that's what people probably saw in me as well, was that actually I like to go home at the end of the day and switch off, you know I have my hobbies that I do and I go out and do them. And I think probably that's what people recognised in me, you know, that maybe they didn't think that I had the motivation to then start studying when I needed to."

Leah, senior surgical trainee

Leah's narrative illustrates how the strength of the discourse of a surgeon, and the more powerful status of those who fit it, act to render such interventions by seniors more or less acceptable as 'careers advice'; though Leah feels a sense of injustice at the interventions, she understands clearly why they occurred. However, some positioning by seniors was particularly unacceptable.

"...people go for a drink after work... and there would be a couple of consultants there... but I remember going in one time, my consultant was sitting at the bar with his double gin and tonic and his fawning registrar and a couple of... you know, other people round. And I rushed along and I was, you know, a nice pencil skirt and I was... because like, erm, I had just passed FRCS [Fellowship exam of The Royal College of Surgeons] so I was in my jacket rather than a white coat, you know. So a nice silk shirt, and as I rushed in, you know, with my, you know, really nice, really like crisp kind of... and he just stared at my, my chest and said, er, "Oh cold out there, is it?" I just thought, that's my boss and he can't even hold it in, you know. And he, he... just, you know, and I'm still referring him patients; he's still in the same neck of the woods."

Juliette, senior consultant surgeon

Here Juliette's narrative describes another account of the exercise of power by seniors in the figured world of surgery. Her increased legitimacy in surgery, conferred by success in the fellowship exam, is undermined by her male boss who repositions her as inferior by drawing attention to her gender. Some, notably the most senior surgeons, had had such terrible experiences that, though they were long past and rarely discussed, continued to be an important part of their identities. Yet these formative negative experiences were often carried as mantles and drawn on as a source of strength, becoming refigured changing in their meaning over time as these women's understanding of themselves and their lives changed. They became part of their narrated selves in a dialogic sense - dialogically opposed but mutually sustaining - providing the negative from which they constructed the relief of their own practice. Here, 
Jane narrates how she has developed her own way to mentor trainees borne of negative experiences during her training.

"I tend to be around quite a lot so I see the trainees quite a lot, erm, and I'd like to think I'm quite easy to talk to or approach. I, I would hope I'm quite approachable and if they had a problem they would feel it's okay to, to come and talk to me... and not, you know. Again, l've worked with people who... when I was a trainee who, you know, er, seemed to have this kind of, erm, fear thing going on - you know, everyone was absolutely petrified of them or they would never approach them or, you know..."

Jane, junior consultant surgeon

Rather than drawing on the previously dominant training discourse of detachment, seniority and paternalism, Jane attempts to build more collaborative relationships.

\section{Identity work as a female surgeon \\ Cloak of invisibility}

Some women consciously undertook 'identity work' in order to 'hide' certain parts of themselves in order to have legitimacy within surgery. Leah does not discuss her children at work, because of the threat she feels that being positioned as a mother and a woman in that context would compromise her position within the figured world of surgery.

Leah: "I think the difference is not so much being a female, it's having kids... Very, very much so, because before I had my baby I wouldn't have said there was any difference at all... When you're going for consultant jobs they do look at you as if to say, "You're just going to have babies and go and work part-time", you know, this sort of thing. But after having my kid, you see it more and more, that people do think... you know, that you're going to disappear off and do the childcare run and things.

Elspeth: Even though you've been working full-time?

Leah: Oh yeah, yeah. And you do, you very, very consciously don't talk about your kid at work. ...if we were doing something that was a bit more accepting of women having kids, then it would be different, but, erm, I very consciously don't talk about my kid, very consciously. If I've got issues with childcare I sort it with my husband and don't bring it to work. So, erm, no I don't think there's any bias to work, but women who want to have kids? Yes.

Elspeth: And will you deal with it by consciously just not, erm...? 


\section{CHAPTER 6}

Leah: You become a man in a man's world, definitely that way, yeah, which is weird and I 100\% wouldn't have said that at all before having kids but, erm, yeah that's, that's the big difference, definitely."

Leah, senior surgical trainee

For Leah, having children made distancing herself at work from feminine discourses much more difficult and, simultaneously, imperative. She overcame this by not talking about her child in a work context, and hiding her identity as a mother under a 'cloak of invisibility'. However, this was not the only form of identity work undertaken by female surgeons.

\section{Refiguring the good surgeon}

Female surgeons also creatively refigured what it was to be a good surgeon. Sarisha's refiguring extends the discursive ideal of a surgeon to include aspects that she feels female surgeons can offer over their male counterparts. Notably she can make no concession to inferiority in dialogue with the discourse of the male surgeon; female surgeons are still "doing the same thing" as male surgeons, but with added extras. This conveys legitimacy to the discursive refiguring, being firmly rooted in the existing masculine discourse of an ideal surgeon.

"I think women are good surgeons. I think a lot of us pay a lot of attention to detail and I think it's really important. I think we have a lot to offer in the way that we interact with patients, you know, erm, in what we can offer skill wise. I think it's, it's different."

Sarisha, mid-level surgical trainee

Emily draws on the figure of a male supervisor who, for her, combined success in surgery with empathy for patients and surgeon colleagues.

“...my supervisor... was just an absolute gem; he's such a lovely man. And I think he's not just lovely with the patients, he's really interested in training as well. Erm, so I guess he inspired me a lot to do surgery and also probably dispelled the notion for me that, to be a surgeon... you have to be, you know, a not very nice person, but you can actually be a nice bloke or a nice, you know, a nice person, be empathetic with your patients and still get ahead..."

Emily, junior surgical trainee

She uses the figure of her supervisor to articulate her own identity, which, again, exists dialogically with that of the male surgeon, whose identity is extended to include more feminine priorities. 


\section{World-making}

Rather than aligning with or rejecting existing discourses, some women orchestrated discourses to try to articulate a totally new discursive space to be a surgeon and female, actively positioning themselves (rather than passively being positioned) within new spaces in which their previously conflicting identities could co-exist. The gendered nature of surgical identity meant that women were always positioned as 'other' within the surgical world, specifically as a "female surgeon" or "woman surgeon". Emily articulated how liberating it might be to simply be seen as a "surgeon".

"I hope it will get to a point where, that, you know, people don't see you as a woman surgeon; they just see you as a surgeon. But I think at the moment people would still see you as a woman surgeon... If that makes sense. I hope it just gets to the point where it doesn't matter that you are a woman, that you are just seen for being a surgeon and that's no different from being a male surgeon... that people will, erm, sort of be, er, judged or be looked at for their surgical skill rather than their gender. That's, that's the dream! *Laughter*."

Emily, junior surgical trainee

Though she is unable to describe its detail, Emily imagines an alternative figured world, where she is judged purely on her ability to do the job without her gender colouring the way she is seen. Jane takes this imagined world further to articulate her own act of 'world-making' - the creative orchestration of discourses to transform the existing figured world of surgery - by discussing how the similarities between motherhood and surgeonhood worked in practice.

"I actually think having kids... it's, kind of, similar to having patients in some ways... The way you, you look after your, your family, the way you organise things, your priorities, is the same as when I'm at work... i.e. when I'm at home the thing that really matters is my children and when I'm at work... your priority is, is, is your patients. So it's a similar kind of mindset and the skills you need as a, as a, as a mum are quite... there's quite a lot of crossover to, to being a surgeon - being able to organise, being able to, to delegate, erm, making decisions, getting up in the middle of the night, having a lot of energy. All those things are quite... you know, there is, there is a bit of overlap there between the two."

Jane, junior consultant surgeon

Jane creatively aligns the skill-sets of mother and surgeon in a mutually strengthening way, rather than in opposition, positioning herself more positively within the existing discourses and at the same time creating a new discursive space. World-making is a discursively powerful phenomenon, 


\section{CHAPTER 6}

enabling these women to re-narrate their feminine and surgical identities as mutually compatible, building upon each other in a complementary and strengthening way.

\section{Discussion}

Discourses of being a surgeon competed with discourses of being female. The female surgeons figured surgery as a career requiring $100 \%$ dedication, as they did motherhood, though the requirements of these two worlds were seen as differing. Consequently these roles were not discursively compatible, and each participant told of experiences where their female gender marked them out as 'other' within the surgical world. Some had had powerfully negative, even traumatic, experiences, yet had refigured these and drew upon them as sources of strength, discursively creating a position for themselves far away from what had hurt them. Women described the masculinity expected of them as a surgeon, and the ways in which this was experienced and negotiated to be legitimate in the surgical world as a 'woman-surgeon'. They also found creative ways to feminise what it was to be a 'good surgeon', discursively moving it away from the traditionally masculine archetype to articulate how women in general, and feminine qualities in particular, enhanced surgery. Finally, some women engaged in powerful identity work, termed world-making - the creative orchestration of the discourses of surgeonhood and motherhood so they were no longer mutually exclusive, but instead became mutually sustaining.

Most research in the area of women in surgery has focused on barriers to participation. Here, we have considered the issue from the perspective of those who do undertake a surgical career. We have demonstrated how women draw on gendered experiences of surgery to self-author their identity as surgeons, and, importantly, how such experiences may be refigured to further support their self-narration as a woman in surgery. This further builds on anthropological studies that explored the masculine culture of surgery (Cassell 2000). Indeed, the very title of Cassell's seminal work 'The Woman in a Surgeon's Body' indicates the masculine nature of surgery, its mismatch with womanhood and the discursive discomfort in female surgeons' narratives of occupying this role as a woman.

Although tensions existed between being female and a surgeon in these narratives, the greatest incompatibility pertained to combining motherhood and surgery. This adds to demographic work showing female surgeons are less likely to have children (Halperin et al. 2010). The incompatibility was not only manifest in cultural or identity terms, but also in practical terms of time: with 'presentee-ism' discursively integral to showing dedication to these two roles compounded by the discursive impossibility of doing both things at once, self- 
identifying as a good surgeon (by putting in the extra hours) and as a good mother (by reliable attendance at bedtime) was extremely challenging. In the figured world of surgery the competing discourse of efficiency and of each team member giving their all outweighed the more feminine 'caring' contributions, that women could bring to surgical practice. A recent paper considered this discursive conflict between the masculine 'efficiency' and the feminine 'care' within medicine in general, concluding that, as both are undoubtedly important, they should not be considered in opposition (Bleakley 2013). While one discourse is ranged against the other (and winning) women having children will continue to be figured as an obstacle in the surgical world.

Although Figured Worlds has not been widely employed in the medical education domain, women have been found to undertake similar 'identity work' in mathematics (Solomon et al. 2011; Solomon 2012). Female mathematicians undertook world-making through collaboration, subverting the traditionally independent practice of mathematics, and, in doing so, they self-authored strong identities as mathematicians which did not exclude being female. Our analysis, therefore, has implications beyond how women form their identities in the masculine domain of surgery; by employing a novel theoretical analysis we have learned something of experience and identity formation of minorities operating within a prevailing discourse that excludes a major part of their identities. If we understand how a subset from within a minority group survive, develop and flourish within a culture in which they are disprivileged and 'othered' then, by making explicit the ways in which they do this, we can herald innovative ways to support others in these groups to succeed in domains previously 'out of bounds' to them.

In our purposive sample, we recruited fifteen participants who all studied or worked in the UK. A significant strength of this approach was the capture of narratives of women from a variety of backgrounds and training grades, and also their reflections on past and future times. The data, however, can make only limited claims to generalisability in terms of participants' experiences of surgery. There may have been factors specific to the research setting that influenced responses, for example, the UK has a prominent national organisation called 'Women in Surgery', to which many participants referred, and which may have primed discussions of gender issues. Equally, British surgery is steeped in history, which largely reinforces the prevailing masculine discourses; for example, historic peculiarities in the titles of surgeons, who give up being a ' $\mathrm{Dr}$ ' to become a 'Mr'. This leaves female surgeons to opt for 'Miss', 'Mrs' or 'Ms', each carrying connotations of marital status, and marking them out as 'other' simply by not being a 'Mr'. 


\section{CHAPTER 6}

Our analysis was strengthened by the complementary expertise and perspectives of a medical student, senior doctor and education researchers. This facilitated creative disturbances and enhanced analysis (Fairclough 2001). Interviews were carried out by a single individual (EH). As a senior medical student 'insider', she shared with participants a significant understanding of the surgical world. While this may have afforded her deeper access to participants' experiences, it is also possible that some understanding remained implicit during interviews. Therefore different data and subsequent analysis may have arisen had the interviews been conducted by someone of another background.

The theoretical framework of Figured Worlds (Holland et al. 1998) was a powerful tool with which to explore issues of identity and agency within the figured world of surgery. While we used Figured Worlds to explore how women in surgery self-narrate their identities, a future study could investigate attrition and the narratives of those women who have left a surgical career. Given that being a surgeon was so important to the identities of our participants, such a study would to gain insight into factors which influence a woman's decision to 'drop out' and how they construct an identity from that position. A further point of interest in our data was how the narratives included 'figures' narrated real 'embodied' or symbolic personas of surgeons that existed for our participants. These figures were used dialogically within their narratives to construct identity, perhaps by their use as role models or villains. A future study could therefore explore how figures are used by women in surgery to construct their identities within that world.

Our work has practical implications for surgical education. The data show that discursive positioning is powerful, and could be orchestrated in the media, policy or in conversation for the advancement of women in surgery. We provide evidence of female surgeons undertaking what we term 'world-making' refiguring existing practices to become more inclusive. There may also be great value in creating supportive relationships between individuals in underrepresented groups to facilitate such activities, which may provide evidence for initiatives such as the UK's 'Women in Surgery'. What is clear from these data is that discursive innovation is required to challenge prevailing discourses of surgical practice, so we can better value and support those women who do undertake a surgical career.

\section{Conclusions}

There is little discursive space to be a successful woman and a successful surgeon. Those who do combine these two roles must either be innovative in refiguring what it means to be female or what it means to be a surgeon; or they must author a new space for themselves, a powerful discursive process we term 'world-making'. 


\section{References}

Bakhtin MM (1981). The dialogic imagination: four essays. Austin, TX: University of Texas Press.

Bakhtin MM (1986). Speech genres and other late essays. Austin, TX: University of Texas Press.

Baxter N, Cohen R (1996). The impact of gender on the choice of surgery as a career. Am J Surg, 172(4):373-376.

Bleakley A (2013). Gender matters in medical education. Med Educ, 47(1):59-70.

Burack JH, Irby DM, Carline JD, et al. (1997). A study of medical students' specialty-choice pathways: trying on possible selves. Acad Med, 72(6):534-541.

Cassell J (2000). The Woman in the Surgeon's Body. London: Harvard University Press.

Center for Workforce Studies (2012). 2012 Physician Specialty Data Book. Washington, DC: Association of American Medical Colleges.

Cleland J, Johnston PW, French FH, Needham G (2012). Associations between medical school and career preferences in Year 1 medical students in Scotland. Med Educ, 46(5):473-484.

Davis EC, Risucci DA, Blair PG, Sachdeva AK (2011). Women in surgery residency programs: evolving trends from a national perspective. J Am Coll Surg, 212(3):320326.

Drinkwater J, Dornan T, Tully MP (2008). The effect of gender on medical students' aspirations: a qualitative study. Med Educ, 42(4):420-426.

Fairclough N (2001). Language and Power, 2nd ed. London: Pearson Education.

Gee JP (2005). An introduction to discourse analysis: Theory and method, 2nd ed. London: Routledge.

Halperin TJ, Werler MM, Mulliken JB (2010). Gender differences in the professional and private lives of plastic surgeons. Ann Plast Surg, 64(6):775-779.

Hill E, Vaughan S (2013). The only girl in the room: how paradigmatic trajectories deter female students from surgical careers. Med Educ, 47(6):547-556.

Holland D, Lachicotte W Jr, Skinner D, Cain C (1998). Identity and Agency in Cultural Worlds. London: Harvard University Press.

Lingard L, Reznick R, Espin S, Regehr G, DeVito I (2002). Team communications in the operating room: talk patterns, sites of tension, and implications for novices. Acad Med, 77(3):232-237.

Maiorova T, Stevens F, Scherpbier A, van der Zee J (2008). The impact of clerkships on students' specialty preferences: what do undergraduates learn for their profession? Med Educ, 42(6):554-562.

McNally SA (2012). Surgical Training: Still Highly Competitive But Still Very Male. Bull $R$ Coll Surg Engl, 94(2):53-55.

Meriläinen S, Tienari J, Thomas R, Davies A (2004). Management Consultant Talk: A Cross-Cultural Comparison of Normalizing Discourse and Resistance. Health, 11(4): 539-564.

Monrouxe LV (2010). Identity, identification and medical education: why should we care? Med Educ, 44(1):40-49.

Neumayer L, Kaiser S, Anderson K (2002). Perceptions of women medical students and their influence on career choice. Am J Surg, 183(2):146-150. 


\section{CHAPTER 6}

Regan E, Dillon J (2012). Undergraduate students' narrations of gender and choice ? a focus group study. In: Proceedings of the HEA STEM Learning and Teaching Conference. London: The Higher Education Academy.

Riska E, Novelskaite A (2008). Gendered Careers in Post-Soviet Society: Views on Professional Qualifications in Surgery and Pediatrics. Gender Issues, 25(4):229-245.

Solomon Y (2012). Finding a Voice? Narrating the Female Self in Mathematics. Educ Stud Math, 80(2):171-183.

Solomon Y, Lawson D, Croft T (2011). Dealing with 'fragile identities': resistance and refiguring in women mathematics students. Gender and Education, 23(5):565-583.

Tsouroufli M, Rees CE, Monrouxe LV, Sundaram V (2011). Gender, identities and intersectionality in medical education research. Med Educ, 45(3):213-216.

Walls F (2009). Whose Mathematics Education?: Mathematical Discourses as Cultural Matricide. In: Critical Issues in Mathematics Education. Missoula, MT: Information Age Publishing, p45-52.

Yu T-C, Jain A, Chakraborty M, Wilson NC, Hill AG (2012). Factors influencing intentions of female medical students to pursue a surgical career. J Am Coll Surg, 215(6):878889. 
Chapter 7

DISCUSSION

The figured world of surgery: culture, identification and inequity 


\section{CHAPTER 7}

\section{Background}

The under-representation of women in surgery is a well-described phenomenon which has persisted even while the proportion of female doctors in other specialties has increased. Although there have been numerous studies and interventions undertaken to address the issue, the proportion of female surgeons remains low in many countries, and particularly low, at 7\%, in the UK (Greatorex \& Sarafidou 2010). This poses a number of problems to surgery as a field. First, surgery prides itself on recruiting the "brightest and the best" (Gelfand et al. 2002); on a background of falling applications to general surgery residencies (McDonald \& Sutton 2009; Stewart et al. 2013), it would appear imperative for the specialty to widen its recruitment pool to be more inclusive to female students, who now comprise the majority of students at medical schools (NHS Health and Social Care Information Centre 2011). Second, is an issue of social justice - of equity of opportunity; those women who do engage in surgical careers should be supported in their endeavours as well as any male student with such aspirations. Third, surgery is represented in the literature as having a culture unconducive to maintaining a work-life balance (Ahmadiyeh et al. 2010), and there is evidence that women are more concerned with this issue than men (Drinkwater et al. 2008); hence, examination of the culture of surgery may help explain women's continued under-representation. While prior research has uncovered a number of predictive factors for an individual engaging in a surgical career, the majority of published studies have taken a population level view and have yet to explain the reasons underlying identified patterns. Having identified a niche for research that examines in detail how the culture of surgery is negotiated and experienced by individuals, this thesis took a sociocultural perspective to build upon existing knowledge of the importance of role models, the culture of surgery and stereotypes. Hence, this thesis sought to explore the culture of the figured world of surgery, how individuals experience this, and how certain groups, and specifically women, are positioned within this culture. Further, it sought to examine how individuals identify within the figured world of surgery. Although the thesis as a whole was conducted within a Figured Worlds theoretical framework (Holland et al. 1998), individual chapters used different sociocultural theories to answer individual research questions.

\section{Main findings and conclusions}

Chapter 2 used the sociocultural learning theory, Communities of Practice (Wenger 1998), to consider the differences between male and female students' experiences of surgery. The concept of 'paradigmatic trajectories' was a useful theoretical tool with which to understand how students' experiences shaped their career decisions. This study found that four key processes - seeing, hearing, doing and imagining - facilitated students' understanding of these possible career trajectories. The experiences of female students within surgery 
were strongly gendered, and they felt 'othered' in the surgical world. Female students' understanding of paradigmatic trajectories were based on these experiences of surgery and thus deterred them from considering surgical careers.

Chapter 3 further explored differential access to engagement in surgery. Constructivist grounded theory was used, with sensitising concepts from Bourdieu (1977a,b; 1990a,b; 1993), to investigate how students encounter surgical culture and practice, and develop an identity for themselves therein. The study explored not only the circulating discourses regarding what future surgeons were like, but also how such discourses were uncovered, understood and drawn on, and, importantly, how they acted to position some students as 'future surgeons' while excluding others. In terms of a 'curriculum' - the components of a programme of study - there were important discourses which students needed to understand and act on: to be successful in the surgical world, students had to accrue the symbolic capital valued - research publications and prizes - and embody surgery's privileged characteristics confidence, proactivity and competitiveness.

The use of discourse analysis in Chapter $\mathbf{4}$ more fully explored students' perceptions of surgery and surgeons, and their influence on students' identification. This chapter was an investigation of how medical students perceived surgery and surgeons, and the effect stereotypes had on their career intentions. Surgery was discursively constructed as masculine, competitive and requiring sacrifice. Surgeons were figured as driven, self-confident and intimidating. To succeed in surgery, students felt they had to fit these stereotypes, leaving many unwilling or feeling unable to do so. Hence, in a similar way to paradigmatic trajectories in Chapter 2, the strong stereotypes of surgery deterred students from a surgical career.

Chapter 5 built on Chapters 2-4 through critique of the individualist theories that have dominated the medical education literature on career choice, which do not incorporate a significant role for the sociocultural factors found to be important in this thesis. Hence, Chapter 5 questioned the extent to which medical students can be said to have a free choice in deciding their career.

Chapter 6 moved beyond medical students' sociocultural understanding of surgery in previous chapters to explore female surgeons' experiences and identities within the figured world of surgery, using sociocultural perspectives of identity and agency drawn from Figured Worlds (Holland et al. 1998). Interviews with surgeons and aspiring surgeons revealed that there was little discursive space to be both a woman and a surgeon, as discourses of being a woman existed in competition with discourses of being a surgeon. Female surgeons 


\section{CHAPTER 7}

undertook 'identity work' to exist in the surgical domain. This included hiding their femininity under a 'cloak of invisibility' in the workplace, the refigurement of what it meant to be female or a surgeon, and 'world-making' - the creative orchestration of discourses to articulate a new discursive space to be a woman in surgery.

\section{Culture and discourse in the surgical world}

An important aim of this thesis was to understand the discourses circulating in the figured world of surgery. The prevailing discourses of surgery and surgeons were strongly held by students, and there was a very close discursive fit between these and surgery's requirements of its future practitioners; indeed, many of the forms of symbolic capital are to be found 'reified' in the UK national person specification for recruitment to Core Surgical Training (NHS Core Surgery National Recruitment Office 2013). Thus, though students assessed discourses of surgery from a variety of sources, these discourses remained remarkably uniform. The ubiquity of the prevailing discourse had a sense of the hegemonic - of being accepted as a truism, understood as 'common sense' - and, therefore, it existed beyond challenge and was unchangeable: surgeons must be like this; surgery as a practice must be like this.

Examples of surgical discourses existing beyond challenge are found in Chapters 3, 4 and 6, which contain remarkable student narratives of finding surgeon's behaviour "rude", yet beyond question. Discursively, if a surgeon was good at performing surgery in the operating theatre, they could be excused any such behaviour. Hence, it was understood that operating required arrogance and a communication style that would, in other contexts, be considered rude. For Holland et al., positional identity is constructed in dialogue with the spaces that people occupy:

"Spaces, too, imbue and are imbued by the kinds of persons who frequent them; conventional forms of activity likewise become impersonated."

Holland et al. (1998, p127)

Thus the data in Chapter 6 includes numerous examples where senior surgeons describe 'bad' or 'inappropriate' behaviour from their colleagues, excused by comments such as, "he was a very good, technically, a very, very good surgeon. People get away with it if they are very good". Holland et al. (1998, p131) discuss 'markers' which act as shortcuts to social 'categories' from which positional identities are constructed that comprise the social structure of 
figured worlds; hence, the arrogance and rudeness become as much a marker of the social position of a 'surgeon' as a scrub hat, scalpel or name badge.

Surgical culture was masculine, again drawing on the discourse of the operating theatre as a site of a surgeon's agency that required discursively masculine characteristics - decisiveness, self-confidence, proactivity. This masculinity was historical, and pervaded many aspects of the figured world of surgery, including its privileged activities, language, dispositions and artefacts. For some individuals - Bourdieu's "fish in water" - the masculine nature of surgical culture was 'invisible'; they did not feel tension existing in the surgical world, or have cause to reflect on its masculinity. In Bourdieusian terms, their habitus was the product of a similar social world and integrated effortlessly with the field of surgery. However, this was not the case for everyone and many medical students, both men and women, felt uncomfortable within surgical culture, lacking an understanding of how to engage, or questioning or disidentifying with the privileged surgical activities, language, dispositions or artifacts. The competitiveness of surgery is a good example of this. The culture of competitiveness, purely for its own sake, is discussed in Chapter 4, and illustrates not only how this is experienced negatively by medical students, but also excludes many from considering a surgical career. Competition is part of the culture of other professions, such as management consultancy, where the dominant discourses are of "competitive masculinity" wherein "the 'ideal' consultant competes not only with other consultants but - and above all - with her/himself." (Meriläinen et al. 2004) Those whose habitus was a product of such a culture of competitive masculinity, implicitly understood how to operationalise the discourse to get on in surgery, in terms of their language, dispositions, and strategic accrual of capital. Others felt unable or were unwilling to do so, not seeing themselves as 'that type of person' or not valuing becoming such a person. In the surgical figured world, then, competition was figured as inherently positive - competitiveness a fundamental prerequisite of a good surgeon, and competition with others and yourself fundamental to good surgical practice - and this informed students' understanding of surgical stereotypes.

In Chapter 4, the stereotypes of surgeons, constructed in the individual and collective imaginations of students, held even when students encountered a real surgeon who strongly contradicted the discourses; rather than refiguring their notions of surgery, students figured the individual surgeon as an exception. This was another way in which surgery's culture seemed unchangeable - an understanding that current surgeons choose the future surgeons from those most like them and therefore, to be considered, you had to be like them. To be different was to put yourself at risk of not fitting in, of not being legitimate in the domain and therefore less likely to be admitted to the profession or more likely to face a harder career trajectory. Being different was 


\section{CHAPTER 7}

commonly discussed in terms of gender. In Chapter 2's study of surgical paradigmatic trajectories, female students saw an absence of women surgeons and heard strong narratives of the difficulties of being a female surgeon. With only these discourses upon which to draw, it was difficult for them to imagine a surgical career for themselves. This was not only found in data from medical students, but also existed in the career narratives of established female surgeons; Chapter 6 considers how little discursive space there was to be a woman in surgery, particularly if you planned to have children. Those who did pursue a surgical career undertook 'identity work' in order to exist and thrive in the figured world of surgery.

\section{Identification within the surgical world}

Within the Figured Worlds framework, identities are constructed dialogically within figured worlds, specifically in dialogue with privileged discourses and figures. There was a discursive requirement within the figured world of surgery for absolute dedication from its practitioners - another aspect surgery shared with the competitive masculinity of consultancy where "work orientation and full-time availability" were central to the identities of management consultants (Meriläinen et al. 2004). For the female surgeons interviewed in Chapter 6, being a surgeon fulfilled this discursive requirement as a very important aspect of their identities. This discourse also manifest in the identities of medical students aspiring to a surgical career; identifying oneself as 'in pursuit of' and devoted to a career in surgery was an important part of the hidden curriculum. Those that understood this and wanted to pursue surgery literally declared their intention, publicly and often, in addition to embodying the privileged dispositions of the surgical world - being outwardly competitive and proactive. Thus, their behaviour made them clearly identifiable to others as 'future surgeons'. There were some students that, though they identified as future surgeons, were not identified by others as such, having not constructed an identity for themselves in terms of privileged surgical discourses. Hence an individual's legitimacy as a surgeon was negotiated dialogically within the figured world of surgery.

The privileging of masculine discourses within surgery meant that those who did not identify or who were not identifiable as masculine felt 'othered'. Being positioned with less legitimacy due to being feminine, or even just relatively less masculine, caused them to reflect on the gendered characteristics which were out of place or not valued in surgery; this cultivated within them a sense of 'not fitting in'. This may offer an alternative understanding of previous findings that female surgical trainees perceive a 'lack of fit' between their sense of themselves and their sense of a senior surgeon (Peters et al. 2012). Adopting 
more masculine dispositions to fit in - 'identity work' termed 'passing' (as another) in Figured Worlds - was a possibility, for both men and women.

"Passing implies impersonation, acting as if one is someone or something one is not. Hence gender passing suggests masquerading or presenting a persona or some personae that contradict the literal images of the marginalised or doubly refracted other."

Fordham (1993, p3)

The need to align with surgical discourse, and hence be able to develop an identity as a surgeon, as well a sense of belonging, is a recurrent finding in the studies of this thesis. Chapter 2 shows that fitting into the surgical paradigmatic trajectories facilitated identification with and imagination of a surgical career pathway. Chapter 3 illustrates how medical students needed to identify with surgery, and fit in, in order to gain legitimacy and participation in the surgical world. Chapter 4 highlights, again, students' beliefs that fitting into the surgical stereotype was necessary, and to that be different required being outstanding; meaning being outstanding surgically - 'more surgical' - in order for others to tolerate the difference. Chapter 6, again, illustrates this via the narratives of female surgeons who, due to gendered aspects of their identities, did not fit in so easily.

Yet some medical students in Chapters 3 and 4 expressed reluctance or felt an inability to fit in. Some students' narratives included figures of others especially figures of female surgeons - whom they saw as having adopted masculinity. In doing so, these female surgeons were deemed to have deviated too far from the students', and society's, expectations of them as women. Further, the female surgeons in Chapter 6 discuss feeling this conflict themselves, as it was necessary to 'pass' as masculine by embodying at least some masculine characteristics, yet they felt compromised for doing so. This phenomenon has been called 'double deviancy': a woman not only breaks a societal rule by being masculine, but is doubly deviant for having broken the social rules governing what a woman is, and should be (Smart 2012).

Holland et al. (1998) discuss the sociocultural cost of fitting in, drawing on Fordham's (1993) concept of 'passing' as "Other", derived from work in an American high school where, although the majority of students were AfroCaribbean women, the dominant discourses privileged a white male habitus:

Too much passing, [Fordham argues] can result in a potentially subversive self where the person can no longer speak or even think in his or her "native voice." Such persons lose their creativity: "because they are compelled to assume the identity of the 'Other' - in exchange for 


\section{CHAPTER 7}

academic success - they cannot represent themselves; they are forced to masquerade as the authentic, idealized "Other".

Fordham in Holland et al. (1998, p132)

It has been shown that a sense of belonging to a domain is emotionally important and, therefore, important to learning (Walton \& Cohen 2011). Hence, refiguring of one's identity through the exclusive adoption of masculine characteristics comes at a cost to an individual's preexisting sense of self, and ones ability to learn. Though there are other possibilities for 'identity work'; as Holland et al. put it, habitus has "an agenda and momentum of its own" (Holland et al. 1998, p46). In Chapter 6, Jane, rather than losing her creativity, adopts a powerfully agentic stance by orchestrating her identities as a surgeon and as a mother into alignment; she refigures the world of surgery termed 'world-making' in Figured Worlds - to legitimise her 'native self' within the otherwise hostile discourses of the figured world.

Yet such powerful discursive positions were rare for female surgeons, whose legitimacy often lacked stability in the figured world of surgery; in a sense, female surgeons had fragile identities as surgeons - a concept that has been explored with reference to women in mathematics (Solomon et al. 2011). In Chapter 6, Juliette tells a story of passing her Royal College of Surgeons fellowship exam; on informing her male surgeon supervisor in a bar, "he just stared at [her] chest and said, "Oh, cold out there, is it?". Holland et al. (1998, p154) discuss a similar example, where a woman is undermined in the figured world of work, when a male colleague invokes the figured world of sexuality, where women are "treated as objects of desire". Having gained the FRCS and, in doing so, secured symbolic capital conferring a more senior position within the surgical profession, Juliette's legitimacy and 'footing' in the figured world of surgery was undermined by her male boss, who positioned her, not as an equal in that world, but as an object in the world of sexuality, where, as a female, she was his inferior. Juliette's expectations of being treated as a surgical colleague, were replaced with a reality where not only was she 'othered' as a female outsider and an object of desire, but also where she was positioned, involuntarily, as inferior in the figured world of surgery. Holland et al. (1998, p153), in discussion of their own empirical findings, recount "situations in which women were suddenly, without warning removed from the context of work, treated as objects of desire and positioned in the world of romance... the women invariably described as "intensely embarrassed". They felt belittled and unable to counterattack."

This illustrates 'intersectionality' - a concept which emphasises the interaction of categories of difference (Holland et al. 1998; Tsouroufli et al. 2011), considering "the interactions between gender, race and other categories of 
difference in individual lives, social practices, institutional arrangements and cultural ideologies and the outcomes of these interactions in terms of power" (Davis 2008). Female surgeons' identities comprise the intersectionality of their identity as women in general society and their identity as surgeons in the figured world of surgery. Hence, the identities of these women become the locus of struggle between discourses. The outcome of this is that their identities become something else - as Emily puts it in Chapter 6, neither fully a woman or a surgeon, but a 'woman surgeon'. This was a 'fragile identity' as others could discursively challenge their surgeonhood, as in Juliette's story, or their femininity, as in medical students' accounts of female surgeons as "manly". In this sense, there was little discursive space to build an identity as a woman in surgery - a key sociocultural finding of this thesis in terms of the inequity underpinning women's under-representation in the specialty.

\section{Challenging inequity in the surgical world}

Chapters 2-6 examined surgical culture and discourses, finding the figured world of surgery to be discursively constructed as masculine, which excluded many, especially women, from fuller participation. However, clearly, some women do aspire to, do engage in and do find meaning from a surgical career. For these women, studied in Chapter 6, it was apparent that their femininity marked them as 'other' in the figured world of surgery; they stood out for being women, and were sometimes positioned within the surgical world by their gender rather than their status as a surgeon. There was little discursive space to combine being a surgeon with being a woman, and even less to combine motherhood and surgery. Discourses of surgery valued masculine characteristics as those of a good surgeon, which meant that the culture disprivileged female surgeons' femininity. The implications for the female surgeons in Chapter 6 were significant. If they expressed femininity through, for example, prioritising time as a mother with their children, they felt less legitimate as a surgeon. Equally, in wider society, by being devoted to their career and, for example, working late at the hospital, they contravened the expectations of a good mother who could put their children to bed every night. Hence, the lack of discursive space to combine the two roles was a source of gendered inequity for practicing female surgeons, as well as medical students. The numerous sociocultural bases for gendered inequity in surgical careers explored in this thesis contribute a new perspective from which to consider women's under-representation in surgery; they hold substantial power to explain why, although women comprise $58 \%$ of medical students, they form just $7 \%$ of the consultant surgical workforce.

Inequity, and particularly gendered inequity, was present at many stages in surgical careers and manifested in many different ways. Chapter 3 explored the 


\section{CHAPTER 7}

differential access of medical students to the hidden curriculum of surgical careers. Some students had only vague encounters with the hidden curriculum, and couldn't uncover its complexities as they lacked a network of relationships to help them understand it. This was a cause of anxiety for them, as they sensed there were things they ought to understand and be doing in order to avoid becoming disadvantaged. Hence, a network of relationships was vital, yet access to this was also unequally distributed; some had pre-existing networks and some already had the dispositions and implicit understanding - the habitus - that made building a network in the surgical world effortless. For those better able to develop a sens pratique - Bourdieu's 'feel for the game' - of surgical careers, it was easier to embody the dispositions and accrue the forms of capital necessary to more strongly identify and be identified as a future surgeon. This afforded participation in the practice of surgery, and, given that not all developed an equal sens pratique, participation was available to students in differing degrees. This differential advantage tended to reinforce itself in a positive feedback loop, as participation led to deeper understanding of the 'rules of the game'.

Another set of students, although they had a well-developed sens pratique, were unwilling or felt unable to adapt their ideas of themselves - to identify as future surgeons - in order to gain advantage in the surgical world; they experienced a tension between who they felt they were and whom surgery required them to be. This situation may result in a 'double-bind', where a person must choose between being true to their prior selves or adapting to a new practice (Lau et al. 2009). Rees \& Monrouxe (2011) discuss 'moral distress' as a symptom of experiencing these conflicts of identity, when students were asked to perform intimate procedures without consent on anaesthetised patients. In this situation, the student faces a choice between refusing to perform the procedure due to a lack of consent, with fitted with their prior identity, or to undertake it, thereby gaining participation in the medical world to do one is to compromise on the other. There are further examples in Chapter 3's data: Luke does not "like doing the blokey banter stuff" but recognises he would have to do so during a surgical job interview, during which it would be most important to gain participation in the surgical world and be identified as a future surgeon; hence, again, there was conflict between his sense of himself and his sense of what surgery required him to be. This was a source of inequity, as some students' sense of themselves aligned well with surgery's requirements; it was these students who were afforded greater participation and experienced less identity 'distress' in the surgical world.

In terms of gendered inequity, Chapter 2 highlights differential access to participation for female students on surgical placements, where they were limited in their learning because of their gender. These women had differing 
and negative experiences of surgery compared to their male counterparts. While female students did describe being able to participate in the operating theatre and moments of engagement with surgery, men more often gained 'hands-in participation', which more powerfully developed their identities as future surgeons. This was mediated by a lack of paradigmatic trajectories within surgery for female students; they had fewer cultural resources on which to draw when imagining themselves in a surgical career, as too did the surgeons in the operating theatre who afforded them participation. This dialogic process of identification, whereby surgeons and future surgeons are constantly authoring themselves in response to others, ensures that, so long as there is lack of diversity in cultural figures within surgery and, hence, a limited range of paradigmatic trajectories, then minorities will continue to be relatively excluded from its practice as they struggle to identify, and be identifiable, as future surgeons.

\section{Strengths and limitations}

The specific strengths and weaknesses of individual studies are discussed within Chapters 2-6. A significant strength of this thesis as a whole was its grounding in sociocultural theories. Within the existing literature, and discussed in Chapter 1 , there existed a significant niche for research using the explanatory power of the contemporary social sciences to explore the culture of surgery and students' career decisions therein. There has also been a call within medical education for consideration of 'gender matters' in sociocultural terms, extending the existing literature beyond demography and biology to include sociocultural theory (Bleakley 2013). Hence, the studies in Chapters 2-6 extended understanding of the processes underlying women's continued under-representation in surgery. Yet, the use of sociocultural theories is also a significant limitation. The empirical studies undertaken in this thesis are, necessarily, contextually bound. Thus to generalise from their findings requires inductive reasoning to extrapolate meaning to wider situations. Such arguments are not valued within medicine as a discipline, whose dominant epistemological stance is one of positivism - of an objectively discoverable world. The epistemology of this thesis is of a social world that can only be subjectively experienced and hence understood. 'Rigour' within these two epistemologies therefore differs, with the former dependent on objectivity and validity, and the latter on careful, reflexive analysis of qualitative data. Given this, studies employing sociocultural theories are likely to lack legitimacy within medicine (and surgery), a concern that has been raised before in the medical literature (Greenhalgh et al. 2012). Within medical education, however, there has been a call for better theorised empirical work that seeks 'clarification', rather than of 'description' or 'justification' which dominate the literature (Cook et al. 2008). While there is significant value in rich descriptive studies, such as the account of surgical 


\section{CHAPTER 7}

stereotypes in Chapter 3, much of the work in this thesis has sought to explain, in sociocultural terms, students' career decisions regarding surgical careers and the under-representation of women within surgery.

The strength of applying a sociocultural lens to address these aims, rather than adopting an explicitly feminist stance, is that it allows a more complex sociocultural analysis of processes of identification, and how gender mediates these. However, an explicitly feminist stance could have better privileged marginalised feminine voices, moving away from a broad analysis of culture and discourse to focus on gendered aspects of identities. There could also have been more consideration of the intersectionality of identities, a key concept in poststructuralist feminism; other aspects of identity such as class or ethnicity have been shown to be important in differential learning in medical education, and in career decisions (McManus et al. 2013; Sánchez et al. 2013; Svirko et al. 2014).

In addition to strong theoretical underpinnings, this thesis has benefitted from a diverse research team. Reflexivity is critical to rigorous qualitative research, and the inclusion of researchers able to take different perspectives on the data is important; they facilitate 'creative disturbances', whereby existing analyses are challenged throughout (Fairclough 2001). This was especially important due to the primary researcher's position as a medical student and 'future female surgeon' and, hence, an 'insider' with many of the research participants. EH was deeply embedded in the surgical world, actively involved in surgical careers promotion as President of Manchester's undergraduate surgical society and via working with the Royal College of Surgeons of England, particularly with its Women in Surgery working group. During this time she was also transitioning from medical student to doctor and planning a surgical career. Her positioning, therefore, heavily influenced the direction of the thesis, but most importantly the research questions and analysis. The main strengths of this were the insight afforded by the 'inside perspective' and access to networks of participants in terms of medical students and surgeons. Evident in the data was a common understanding of the surgical world that the primary investigator shared with participants. For example, during Chapter 6's interviews there were several episodes of laughter at a shared discourse, the crux of which was not intelligible without explanation to the rest of the research team. For this reason, consideration was given to the best placed individuals to collect the data for each study. In Chapter 2, SV undertook all interviews, a sociologist 'outsider' who encouraged participants to discuss explicitly the 'taken for granted' something facilitated by her being a 'newcomer' to the world of medicine. This would have been an example of a stance unavailable to $\mathrm{EH}$, as a medical student. In Chapters 3 and 4, KB, a medical student who was undecided about a future career conducted the interviews. Here, a shared understanding and 
honesty were important, ensuring there was no pressure on participants to 'look good' in the eyes of the interviewer. EH, at the time, was relatively prominent as outgoing President of the surgical society; some students, particularly future surgeons may therefore have felt accountable to any judgements of them that she may have made as an interviewer. In Chapter 6, $\mathrm{EH}$ undertook all interviews; in this circumstance her shared repertoire with participants, in terms of the surgical world, afforded better access to narratives of their careers. Throughout the period of doctoral study, EH kept a reflexive diary, which paid particular attention to researcher positioning by participants, and participant positioning by the researcher and, hence, the dialogic nature of the data. Further, the first layer of analysis of the datasets involved a 'critical reflexivity', highlighting discursive positioning in the data, use of different voices and shared reference points, which were discussed extensively within the research team. EH critically examined her own 'value judgements' or emotional responses to the data, taking care to record these and understand if or how these affected analysis.

\section{Implications and valorisation Implications for practice}

The studies in Chapters 2-6 may inform practical applications of benefit to students and surgeons. This thesis has several important findings in terms of differential access to engagement in surgery. It is clear that, from a sociocultural perspective, the surgical world is complex; myriad factors interact to determine an individual's trajectory in the domain, from their own individual history to the immediate social contexts in which they find themselves day-to-day. While the individual chapter discussions in Chapters 2-6 may delineate practical applications of the work in terms of dealing with inequity, there must be acknowledgment that there is no simple solution; it is likely that no single answer will increase the representation of women in surgery, nor is it predictable precisely what effect any such interventions may have.

There is a delicate balance when considering any interventions to 'encourage' women into surgical careers: whilst this thesis and the literature suggest an increased number of female surgeons would be beneficial for future cohorts, Chapter 6 suggests that for those women that do enter the career it is likely to be a more difficult path to take. It may be considered irresponsible, then, to 'push' anyone in any direction. Conversely, to draw attention to the difficulties inherent in being a female surgeon may further deter women from the career, worsening the situation for both those in the specialty and those considering a surgical career. Hence, the practical applications suggested here are based on equipping individuals with an understanding of surgical discourses, and the tools to negotiate, and even challenge, the surgical status quo. Given the 


\section{CHAPTER 7}

importance of local context, such a strategy allows individuals to apply this work to their individual social worlds.

\section{Tackling differential access to participation}

A major finding of this thesis was the differential access medical students had to uncovering, enacting and engaging in the hidden curriculum of surgical careers. Another key finding was that different students experience the same thing differently; female students do not experience participation in the same ways as male students during surgical placements, are unable to see or interact with many female surgeons, and are exposed to negative stories of female surgeons. There are several practical steps that could be taken to address these points. First is to understand the importance of making the hidden curriculum more explicit and, hence, more widely available to students. Discussions of what forms of capital and behaviour are privileged in surgery, and why, could help more students to understand this, as well as providing a forum to openly debate their implications. The literature and this thesis are clear that relationships are very important. Mentoring, whether from surgeons or peers, at an early stage in medical school regarding how to 'practically negotiate' career options - understanding 'what counts', where, at what time and why are integral concepts to developing a sens pratique of a career.

Students could be better helped to build useful relationships, perhaps, for example, by providing 'scripts' for engagement in the operating theatre - one such stock question might be, "I'm really interested in a surgical career, but I'm not sure what I need to do; please can I hear about your experiences?" Institution-level interventions may also be of benefit - for example, a hospitalwide policy that medical students should 'scrub in' when on placement and have a role as part of an operating theatre team; if theatre staff know it is important for students to 'scrub in', and also legitimate to ask them to help with tasks, this may facilitate 'belonging' and feeling useful - 'supported participation' - which have been shown to be of central importance to 'experience-based learning' in clinical settings (Dornan et al. 2007). Thus, it may be of benefit to clarify the role of students in the operating theatre to be more akin to the North American model, where students are expected to scrub for every case during their surgical rotation (unless there is a compelling or clinical reason not to) (Tahiri \& Liberman 2013). With female students shown to be less likely to negotiate to 'scrub in', this may be especially beneficial in equipping them with better tools to engage in surgical placements.

However, there are also ramifications of these strategies that must be considered, as some involve fitting individuals better to the practice of surgery, rather than changing the practice itself. Deliberate intervention with a view to changing the ways in which people identify carries significant ethical 
implications, and concerns have been raised over fitting school students from lower socioeconomic groups into the middle-class practice of university (Moore 2014). Figured Worlds would hold that the practice and the identities of its individuals exist in dialogue, hence, even taking such an 'identity approach' may change the practice itself.

\section{Figures and relationships}

This thesis supports previous research on the value of female surgical role models (Sanfey et al. 2006). There is likely to be much benefit in actively gathering and disseminating diverse narratives of surgery and surgeons. From the Figured Worlds perspective, 'figures' are a wider concept than role models; hence, medical students and surgeons could draw on more diverse 'figures', in relation to whom they could narrate their own identities. Further, in terms of 'paradigmatic trajectories', this would arguably increase the diversity of trajectories available for medical students, making it easier to 'see' and 'hear' about successful female surgeons, thus facilitating medical students' imagination of themselves in surgical careers. On a practical note, this strategy would need to discursively depart from many 'professional profiles' of surgeons available online and in the media, which tend to reinforce surgical discourses (Royal College of Surgeons of England 2013). Rather, a more frank and unusual insight into these people's lives would hold more value: Where are they from?; What other careers did they consider?; How did they train?; What do they enjoy?; What is challenging about their work?; What do they enjoy outside of work?; What do they wish they had known before embarking on a surgical career?; What are their patients like?; What is an average day like for them? Answers to these questions do not form a typical surgical narrative, and could significantly disrupt underlying discourses and disseminate alternative (and less stereotypical) ways to be a surgeon - thereby highlighting other aspects of surgeons' identities so a wider variety of medical students could identify with them, rather a profile portraying every surgeon in terms of the homogenous 'ideal surgeon' stereotype.

While increased access to figures in the abstract may be beneficial in challenging existing discourses, facilitating relationships with these same people would also be helpful. As described in Chapter 3, it is not merely relationships with the most senior surgeons that are important; relationships with medical students and surgical trainees via workshops, mentorship schemes, and social media could, in addition to promoting the existing diversity of surgeons, build useful relationships for students. This recommendation is also supported by numerous other studies demonstrating the value of mentorship and role modelling (Neumayer et al. 2002; Sanfey et al. 2006; Drinkwater et al. 2008; Drolet et al. 2014). 'Mentors', then, represent a powerful opportunity to bring about change in the practice of surgery - to refigure surgery for medical 


\section{CHAPTER 7}

students, but also for surgeons. Mentors have the opportunity to orchestrate what students see, hear, do, and thus imagine; they can provide positive and diverse stories, in the awareness that these narratives are influential. These same people can more actively invite students to engage and participate, knowing that this facilitates identification and belonging in surgery, but also that students might want to engage but not know how. For example, if a student seems quiet or awkward, a mentor could assume that they don't know how to interact, rather than that they are uninterested. In this regard, surgeons, in their day-to-day activities and interactions with students can powerfully improve the surgical experiences of both male and female medical students.

\section{Challenging existing discourses}

Another major finding of this thesis is the masculine nature of the prevailing discourses in surgery, and their, at times, polarising effect on students. Making students aware of the discourses that they are drawing on may act to facilitate a more agentic authorial stance. This may assist the challenge and renegotiation of the prevailing discourses that marginalise some students. Although the studies used interview transcripts as data, it is not just language that is gendered. Other cultural tools - including colours, images, objects, activities, buildings - also have historical and cultural meanings that can have gendered connotations. Attention paid at an institutional level to reified discourses could help to broaden the diversity of imagined trajectories in surgery - from the language used in policy documents to the portraits that hang in institutions (Martimianakis \& Hafferty 2013).

Competition was a major discursive component of the figured world of surgery for medical students and surgeons in this thesis. It was both reified in surgical literature and unchallengeable - 'surgical' almost became a byword for 'competitive'. For many surgeons interviewed, the competitiveness was a source of pride in their own success and considered as a force for improvement within the specialty. Yet, data in Chapter 3 showed how the perceived competitiveness excluded many students from the possibility of beginning to consider the career. Hence, there may be benefit in beginning to consider how surgery as a practice could become 'less competitive', not in terms of application ratios, but in terms of communality. Such a discursive change could make the practice more open to female students and more amenable to patients. That is not to say that communal discourses should be ranged in opposition to those of competition, but that there may be a way to include both perspectives, which both have much to offer, in the surgery of the future.

A powerful challenge to the masculine surgical discourse was discussed in Chapter 6: 'world-making' is the orchestration of existing discourses to author new ways of being - for example, stating that being a mother and a surgeon 
require the same skills. It is important to be aware of this kind of identity work, so that it can be incorporated into a future sense of surgery as a practice, in order to benefit others in similar positions. This could be supported by wide dissemination of new examples of discursive world-making, and by giving people forums in which to discuss their practice and experiment with discursive orchestration.

\section{Implications for theory}

The empirical studies undertaken in this thesis have also made a contribution to sociocultural theory in medical education. The Figured Worlds framework has not been used empirically before in medical education, though there has been an interest in extending to medical students' narratives the consideration of identity and agency that Figured Worlds allows (Vagan 2011). It is clear from Chapter 6 that such a perspective can be used to explore how minorities survive and even thrive in environments where they are marginalised or disprivileged, and Holland et al. consider numerous examples of this (Holland et al. 1998). Given the strong interest within medical education, and political imperative within the UK, on widening participation in medical school, Figured Worlds could be also used to study students from less privileged groups during school and university as they embark on medical careers.

Use of the concept of paradigmatic trajectories, drawn from Communities of Practice (Wenger 1998), is novel in medical education. Wenger (1998, p156) cites these trajectories as "likely to be the most influential factor shaping the learning of newcomers" and, hence, of critical importance to those encountering the specialty of surgery for the first time. The theoretical concept of 'paradigmatic trajectories' was especially useful to explore how newcomers learned about a community of practice - particularly about its beliefs, culture, and potential trajectories for themselves therein. Therefore the concept may also be of use in medical education when researching 'early clinical experience' at medical school, students moving from specialty to specialty, and the undergraduate to postgraduate transition.

The concept of paradigmatic trajectories is complemented by the model generated from constructivist grounded theory in Chapter 3, which applies sociocultural theories to how students encounter and negotiate surgery's hidden curriculum. Indeed, this suggests there may be other specialty-specific hidden curricula, which are likely also bound by local context. There exists much discrepancy in how the hidden curriculum is considered within medical education. Most studies consider it a sociocultural phenomenon, as a process of socialisation; though this perspective does not explain why it is framed as a 'curriculum'. The use of the word 'curriculum' encompasses the aspects of the culture that students need to know to progress. It would appear that 


\section{CHAPTER 7}

considering it as a process of socialisation includes wider aspects than merely what students need to know or operationalise in order to progress. There are aspects to socialisation that are wider than development of a sens pratique; imagination of a place for oneself in a world is important to socialisation, but does not necessarily confer a practical understanding of the world. Is it more that the hidden curriculum is akin to Bourdieu's sens pratique - a feel for the game of a medical career? Thus, there are different understandings within the literature of the hidden curriculum that may hamper its theoretical and practical utility as a concept.

The commentary in Chapter 5 considered the issues of inequity in Chapters 2-4 within the field of medical education. Such issues were framed as 'invisible' to the field, as medical students' career trajectories have largely been considered in terms of a 'choice', which attributes substantial agency to all medical students in determining their futures. Hence, within medical education, there may be little discursive space to discuss and challenge issues of unequal access. A sociocultural critique of the 'invisibility' of inequity in medical education would assign importance to making such issues 'discussable' - creating a space to discuss and challenge assumptions, power, positioning and access to various careers. From a Figured Worlds perspective, such an approach may afford students more agency - more specifically a stronger authorial stance from which to narrate their identities in the figured world of medicine - due to increased awareness of the effect of discourses. Chapter 5 attributed the 'invisibility' of inequity to the historical roots of medical education in behaviourist and cognitivist perspectives on learning, and, hence, theories that are more individualist than the sociocultural theories used in this thesis. Though both perspectives have a role, contemporary sociocultural theory can contribute much more than at present to researching inequity in medical education.

\section{Future research}

\section{Attrition}

One of the demographic phenomena that this thesis has not considered is the attrition of women in surgery; in the UK, the proportion of women in surgery approximately halves at each of the three stages of reapplication (Greatorex \& Sarafidou 2010; McNally 2012). The sociocultural underpinnings of the attrition rate are likely complex. From the perspective of attrition, there are three categories of people (from which a purposive sample was drawn in Chapter 6): those considering whether to 'opt in' (medical students and first-year doctors), those deciding whether to continue in training (surgical trainees) and those that are fully trained (surgical consultants). This thesis has focussed on these three groups. It would be of value to study the experiences and identification of those who do leave surgery, at whatever stage - especially as leaving was strongly 
framed as 'not an option' by our sample of female surgeons in Chapter 6. Future research into attrition might help to understand why they leave, and give an insight into what could change, culturally or otherwise, that would have made a difference. It is also important to understand surgery's positioning of those that do leave, and the sociocultural implications of this.

\section{Social networks analysis}

Although this thesis used a sociocultural theoretical perspective, there is a place for large-scale demographic research. Contemporary technology makes possible a richer demography, whereby we can study narratives and relationships at a population level. Social networks analysis considers the relationships between people, and seeks to map these while simultaneously measuring their impact in terms of individuals. This seeks to answer the question of what flows through relationships. It has been used extensively in medical epidemiology to demonstrate the 'social contagiousness' of obesity and smoking (Christakis \& Fowler 2007; 2008). It can also be combined with qualitative analysis to consider the spread and effects of discourses within a community. Given the repeated evidence in this thesis and the literature for the importance of relationships in mediating both participation and exclusion, a social networks approach may be of great future interest.

\section{Intersectionality}

Although this thesis has begun to understand the experiences and identity work of female surgeons, there is far more to understand. For the female surgeons in Chapter 6, the intersectionality of their identities as women and as surgeons held significance. We know that other aspects of identity such as class or ethnicity affect learning, and sociocultural theory would indicate their importance. Hence, intersectionality could be used to explore female surgeons' sense of 'sacrifice', how such sacrifice is experienced and its implications, both for the individual possibly in terms of wellbeing and burnout, and the wider community, in terms of discourses.

\section{Ethnographic studies}

The empirical studies in this thesis employed interview data. For our research questions this was deemed most appropriate, as we sought to understand how and what participants thought, and how they saw the world and themselves. However, it means there were no data on what they actually do; there was no direct access for the research team to their practice or the events that they describe. There are also no follow-up data to consider how participants, particularly medical students and trainees, acted on their intentions with regard to pursuing a surgical career. Hence, to complement a sociocultural theoretical approach, ethnographic studies of participants in context would be beneficial to better understand how they interact with their social world. 


\section{CHAPTER 7}

\section{Conclusion}

This thesis took a sociocultural approach to explore reasons underlying women's under-representation in surgery. The figured world of surgery was strongly gendered; its culture privileged masculine dispositions and characteristics. Female medical students had differing access to the hidden curriculum of surgical careers and differing and negative experiences of the practice of surgery; they consequently struggled to imagine a future place for themselves in the career. For those women who were surgeons, being a surgeon and being a woman existed in discursive competition, making it difficult to combine the two; there was little discursive space to be a woman in surgery. Although a minority of women were creating new ways to be female in the masculine surgical domain, the prevailing discourse remained strong; surgeons were required to fit the existing ideals in order to be legitimate in the surgical world. The empirical findings of this thesis suggest that unless the discourses of surgery diversify to encompass other ways to be a surgeon, women will continue to be an under-represented group. 


\section{References}

Ahmadiyeh N, Cho NL, Kellogg KC, et al. (2010). Career Satisfaction of Women in Surgery: Perceptions, Factors, and Strategies. J Am Coll Surg, 210(1):23-28.

Bleakley A (2013). Gender matters in medical education. Med Educ, 47(1):59-70.

Bourdieu P (1977a). Outline of a Theory of Practice. Cambridge: Cambridge University Press.

Bourdieu P (1977b). Reproduction in education, society and culture. London: Sage Publications.

Bourdieu P (1990a). In Other Words: Essays Towards a Reflexive Sociology. Cambridge: Polity Press.

Bourdieu P (1990b). The Logic of Practice. Palo Alto, CA: Stanford University Press.

Bourdieu P (1993). Some Properties of Fields. In: Sociology in Question. Thousand Oaks, CA: Sage Publications, p72-77.

Christakis NA, Fowler JH (2007). The spread of obesity in a large social network over 32 years. N Engl J Med, 357(4):370-379.

Christakis NA, Fowler JH (2008). The collective dynamics of smoking in a large social network. N Engl J Med, 358(21):2249-2258.

Cook DA, Bordage G, Schmidt HG (2008). Description, justification and clarification: a framework for classifying the purposes of research in medical education. Med Educ, 42(2):128-133.

Davis K (2008). Intersectionality as buzzword: a sociology of science perspective on what makes a feminist theory successful. Feminist Theory, 9:67-85.

Dornan T, Boshuizen H, King N, Scherpbier A (2007). Experience-based learning: a model linking the processes and outcomes of medical students' workplace learning. Med Educ, 41(1):84-91.

Drinkwater J, Dornan T, Tully MP (2008). The effect of gender on medical students' aspirations: a qualitative study. Med Educ, 42(4):420-426.

Drolet BC, Sangisetty S, Mulvaney PM, Ryder BA, Cioffi WG (2014). A mentorship-based preclinical elective increases exposure, confidence, and interest in surgery. Am $J$ Surg, 207(2):179-186.

Fairclough N (2001). Language and Power, 2nd ed. London: Pearson Education.

Fordham S (1993). "Those Loud Black Girls": (Black) Women, Silence, and Gender 'Passing' in the Academy. Anthropol Educ Quart, 24(1):3-32.

Gelfand DV, Podnos YD, Wilson SE, Cooke J, Williams RA (2002). Choosing General Surgery: Insights Into Career Choices of Current Medical Students. Arch Surg, 137(8): 941-947.

Greatorex R, Sarafidou K (2010). Surgical Workforce 2010: Profile and Trends. London: Royal College of Surgeons of England.

Greenhalgh T, Procter R, Wherton J, Sugarhood P, Shaw S (2012). The organising vision for telehealth and telecare: discourse analysis. BMJ Open, 2(4):e001574.

Holland D, Lachicotte W Jr, Skinner D, Cain C (1998). Identity and Agency in Cultural Worlds. London: Harvard University Press.

Lau AS, Fung J, Wang S-W, Kang S-M (2009). Explaining elevated social anxiety among Asian Americans: emotional attunement and a cultural double bind. Cultur Divers Ethnic Minor Psychol, 15(1):77-85. 


\section{CHAPTER 7}

Martimianakis MA, Hafferty FW (2013). The world as the new local clinic: a critical analysis of three discourses of global medical competency. Soc Sci Med, 87:31-38.

McDonald K, Sutton J (2009). Surgical workforce: an emerging crisis. Bull Am Coll Surg, 94(5):21-26.

McManus IC, Woolf K, Dacre J, Paice E, Dewberry C (2013). The Academic Backbone: longitudinal continuities in educational achievement from secondary school and medical school to MRCP(UK) and the specialist register in UK medical students and doctors. BMC Med, 11(1):242.

McNally SA (2012). Surgical Training: Still Highly Competitive But Still Very Male. Bull $R$ Coll Surg Engl, 94(2):53-55.

Meriläinen S, Tienari J, Thomas R, Davies A (2004). Management Consultant Talk: A Cross-Cultural Comparison of Normalizing Discourse and Resistance. Health, 11(4): 539-564.

Moore S (2014). Working-class kids shouldn't have to be more middle class to "fit in". London: Guardian News \& Media. Available from: http://www.theguardian.com/ commentisfree/2014/mar/03/working-class-kids-middle-class-fit-in [Accessed 21 April 2014]

Neumayer L, Kaiser S, Anderson K (2002). Perceptions of women medical students and their influence on career choice. Am J Surg, 183(2):146-150.

NHS Core Surgery National Recruitment Office (2013). 2014 Person Specification - Core Surgical Training. London: NHS CSNRO.

NHS Health and Social Care Information Centre (2011). NHS Staff 2001-2011 (Medical and Dental). Leeds: NHS Health and Social Care Information Centre.

Peters K, Ryan M, Haslam SA, Fernandes H (2012). To belong or not to belong: Evidence that women's occupational disidentification is promoted by lack of fit with masculine occupational prototypes. J Personnel Psychol, 11(3):148-158.

Rees CE, Monrouxe LV (2011). Medical students learning intimate examinations without valid consent: a multicentre study. Med Educ, 45(3):261-272.

Royal College of Surgeons of England (2013). Council Biographies. London: Royal College of Surgeons of England.

Sanfey HA, Saalwachter-Schulman AR, Nyhof-Young JM, Eidelson B, Mann BD (2006). Influences on Medical Student Career Choice: Gender or Generation? Arch Surg, 141(11):1086-1094.

Sánchez JP, Peters L, Lee-Rey E, et al. (2013). Racial and ethnic minority medical students' perceptions of and interest in careers in academic medicine. Acad Med, 88(9):1299-1307.

Smart C (2012). Women, Crime and Criminology: A Feminist Critique, Reprint. Abingdon: Routledge.

Solomon Y, Lawson D, Croft T (2011). Dealing with 'fragile identities': resistance and refiguring in women mathematics students. Gender and Education, 23(5):565-583.

Stewart RM, Liao LF, West M, Sirinek KR (2013). The general surgery workforce shortage is worse when assessed at county level. Am J Surg, 206(6):1016-1023.

Svirko E, Lambert T, Goldacre MJ (2014). Gender, ethnicity and graduate status, and junior doctors' self-reported preparedness for clinical practice: national questionnaire surveys. J R Soc Med, 107(2):66-74. 
Tahiri M, Liberman M (2013). What is an ideal surgical clerkship? Can J Surg, 56(3):151152.

Tsouroufli M, Rees CE, Monrouxe LV, Sundaram V (2011). Gender, identities and intersectionality in medical education research. Med Educ, 45(3):213-216.

Vagan A (2011). Towards a Sociocultural Perspective on Identity Formation in Education. Mind, Culture, and Activity, 18(1):43-57.

Walton GM, Cohen GL (2011). A brief social-belonging intervention improves academic and health outcomes of minority students. Science, 331(6023):1447-1451.

Wenger E (1998). Communities of Practice. Cambridge: Cambridge University Press. 



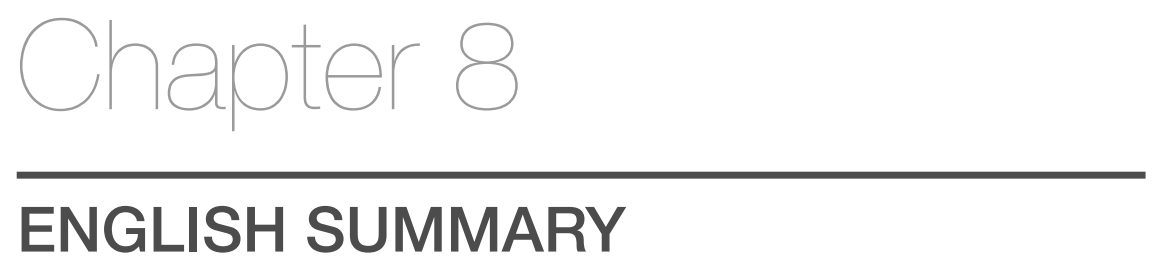




\section{CHAPTER 8}

\section{Summary}

This thesis comprises seven chapters that explore surgical culture and its influence on career decisions, with a focus on women's under-representation in surgery.

Women now form the majority of medical students in many countries worldwide (Wolfe 2005; Elston 2010). Over the last 25 years, this demographic change has also affected the proportion of female doctors in almost all medical specialties, with the notable exception of surgery. In the USA women currently make up $10 \%$ of fully-trained surgeons (Center for Workforce Studies 2012), 9\% in Australia (Li et al. 2013) and 7\% in the Netherlands (Pas et al. 2011). In the UK, which provided the context for this thesis, only $7 \%$ of consultant (fullytrained) surgeons in the UK are female (Greatorex \& Sarafidou 2010). The proportion of female consultant surgeons in the UK reached a peak of around 8\% in 2005 and has since plateaued around this level, despite national initiatives to increase the number of women in surgery (McNally 2012; Royal College of Surgeons of England 2013). There are compelling reasons to better understand this phenomenon, both in terms of equity of opportunity in surgical careers, and in terms of how to provide the best surgical care for patients in the future. Past studies have identified several factors that affect medical students' career decisions, including the availability of role models (Sanfey et al. 2006), the perceived lifestyle of a specialty (Drinkwater et al. 2008), and experiences at medical school (Burack et al. 1997). The emphasis of existing research has been on descriptive demography of the phenomenon, an individualist approach to how students make career decisions, and a biological definition of gender. Through contemporary social science, this thesis aimed to move beyond these studies to a sociocultural understanding of how medical students and doctors negotiate career options, with particular reference to women in surgery.

The main theoretical framework of this thesis is Figured Worlds (Holland et al. 1998), an amalgam of sociocultural theories comprising elements from Vygotsky, Bakhtin and Bourdieu. Figured Worlds is a theory of 'identity in practice', meaning it concerns itself with how identity is constantly negotiated within sociocultural contexts. The thesis also makes use of the closely allied social theory of learning, Wenger's Communities of Practice (1998). Though the primary approach taken to gender was sociocultural, the theoretical background to this thesis was informed by poststructuralist feminist thought, particularly Butler's critique of feminism (1990) and the more recent concept of the intersectionality of identities. These theories consider the social world, including its people, discourses and structure to be both inherently social and dynamic; meanings and identities are constantly being socially negotiated - for example, negotiation of individual identities in relation to others and the social world, or negotiation of the meanings of language and cultural tools. Hence, 
sociocultural theories acknowledge that people exist within the social structure, or regulatory framework, of a figured world. Agency, then - the capacity for self-determination - must be negotiated in relation to such a framework. Such a stance has explanatory power to examine how culture works 'in practice'. Hence, this thesis sought to explore the culture of the figured world of surgery, how individuals experience this, and how certain groups, and specifically women, are positioned within this culture. Further, it sought to examine how individuals identify within the figured world of surgery.

Chapter 1 acts as a general introduction to this thesis, first problematising the under-representation of women in surgery and justifying its importance as a research topic. Second, a review of relevant literature is presented in order to situate this research within the wider research on gender and career choice. This chapter also includes a sociocultural critique of the published literature, which identifies a significant niche for the study of how certain groups are privileged and disprivileged, and how individuals identify and are positioned within surgical culture - in essence, how culture 'works' in practice - as a means to explain the under-representation of women in surgery. Third, the theoretical framework of Figured Worlds, and the epistemological stance of this thesis in relation to identity, agency, learning and gender are outlined. Finally, the aims and research questions of this thesis are discussed with an overview of the structure of this thesis's empirical chapters.

Chapter 2 explores medical students' experiences of surgery, employing the sociocultural theory of learning Communities of Practice, developed by Wenger (1998). Specifically, the study used the concept of 'paradigmatic trajectories' visible career paths provided by a community that shape how individuals negotiate and find meaning in their own experiences. Constructed via community members, paradigmatic trajectories comprise living and imagined examples of potential developmental journeys through a community - potential career trajectories; composite trajectories can be constructed from many people's experiences. Paradigmatic trajectories offered a useful theoretical lens to study the possible paths students feel are available to them, and how these inform their career decisions. This study was a secondary analysis of interviews with 19 students about their medical school experiences during clinical training. A stark difference in experiences of surgery was apparent between male and female students. Female students' experiences of surgery were strongly gendered; they were positioned as 'other' in the surgical domain. What was seen, heard and done during their surgical placements mediated what students could imagine in terms of possible futures. These four key processes - seeing, hearing, doing and imagining - facilitated the formation of paradigmatic trajectories, on which students could draw when making career decisions. Based on paradigmatic trajectories constructed from exposure to surgery, 


\section{CHAPTER 8}

female students decided surgical careers were not for them. By contrast, male students had more positive experiences of 'hands-in' participation and were not marginalised by paradigmatic trajectories. Paradigmatic trajectories were a novel theoretical tool with which to explore students' experiences of surgery. Yet, within surgery, hierarchy and power seemed to play an important role and, though Communities of Practice does give space to explore these issues, it is principally a theory of learning, and not a macro-sociological theory. It is therefore not best equipped to explore issues of culture and hierarchy at a societal level; hence, other, more global theories were used to more fully explore surgical culture and students' identity formation therein.

Chapter 3 reports an empirical study which used a constructivist grounded theory approach to investigate the mechanism by which medical students encounter surgery as a career option and navigate its culture in order to become successful. The study used the concept of the 'hidden curriculum', framed as the culture, beliefs, and behaviours enacted by those within a community, passed to students, who subsequently enact it themselves (Hafferty \& Hafler 2011). An exploratory questionnaire gathered a broad range of medical students' thoughts and experiences of surgeons, surgery and surgical careers. This guided in-depth interviews with twelve medical students about surgical careers and how they had discovered what was required to become a surgeon. The study found students had a clear sense of a surgical hidden curriculum, and an emergent model was generated of how students encountered and operationalised this hidden curriculum. To successfully negotiate a surgical career, students first must build a network, as careers information flowed through relationships. They subsequently enacted what was learned, by appropriating the dispositions ('walking the talk') and accruing the accolades ('ticking the boxes') of 'future surgeons'. This allowed them to identify themselves and be identified by others as a 'future surgeon', and thus gain access to participation in the surgical world. Participation, for example assisting in the operating theatre, enabled further network building and access to careers information in a positive feedback loop. For some, negotiating the hidden curriculum was challenging, and a surgical career was unattractive or felt unattainable; hence, they were effectively excluded from a surgical career because their sense of themselves did not align well with the hidden curriculum; they did not feel they fitted with the type of person that the culture of surgery required them to be. This built on Chapter 2's findings, in that it explored sociocultural reasons underpinning the differential participation of male and female students using sensitising concepts from Bourdieu's macrosociological theories (1977a,b; 1990a,b; 1993), allowing discussion of the emergent model, and how at each and every stage of the model, students had differing access to the hidden curriculum of surgical careers within the field of surgery. The issue of power was addressed via explanation of the complex ways 
social, cultural and symbolic capital were distributed, exchanged and withheld within the field of surgery.

Chapter 4 explores surgical culture via a study of medical students' perceptions of surgery and surgeons to produce a rich description of surgical stereotypes and an analysis of how these affected students' career decisions. This study was a discourse analysis of interviews of medical students of different year groups, genders, and career intentions. Discourse analysis seeks to uncover the shared narratives, norms, values, perceptions and practices of a society through the study of language (Gee 2005). As a methodology, it acknowledges the sociallyconstructed nature of surgical culture (Gee 2011). This enabled a deeper analysis of students' thoughts and assumptions regarding surgery, building on the findings of Chapter 3, as well as the ways in which students were positioned by prevailing discourses. Medical students held remarkably uniform stereotypes of surgeons as excessively self-confident, and intimidating. These stereotypes were held strongly despite numerous positive experiences of surgeons. According to the stereotypes, the culture of surgery was ruthlessly competitive; it was further perceived as masculine, with the display of masculine qualities necessary for success. Students believed a surgical career demanded sacrifice of time and energy, most notably at the expense of family life. To succeed in surgery, students felt they must fit these stereotypes, excluding those who were unwilling or who felt unable to conform. Deviating from the stereotypes required displaying valued characteristics to a level exceptional even for surgery. Consequently surgery was neither an attractive nor realistic career option for many medical students.

Chapter 5 comprises a commentary piece, published to accompany a metaanalysis of gender and medical students' career intentions (van Tongeren-Alers et al. 2014). The commentary explores potential sociocultural explanations for differential career preferences amongst male and female medical students. In this sense, it embeds the findings of Chapters 2-4 in the wider literature, as well as including a sociocultural critique of published studies on 'career choice' in medical education. The majority of previous research has focused on factors affecting moments of career choice, which necessarily attributes much agency the capacity for self-determination - to individuals. This stance does not allow room for consideration of sociocultural factors that act to restrict the number of options practically available to individuals. Drawing a contrast between individualist (more agentic) and sociocultural (more deterministic), theories, the commentary questions the extent to which students are 'free' to 'choose' a career. In particular, it discusses how sociocultural constraints affect individuals differently, and how such constraints, for example differential access to participation, may influence the career paths accessible to students. 


\section{CHAPTER 8}

Chapter 6 comprises the fourth and final empirical study. Previous chapters have explored various reasons for medical students not entering surgical careers. This study captured the voices and experiences of aspiring and current female surgeons who have engaged in surgical careers. This interview study included fifteen women spanning the surgical career trajectory, from medical students aspiring to a surgical career to senior consultant surgeons, and sought to understand the processes of identification of those who had pursued a surgical career. Figured Worlds provided the theoretical and epistemological stance, in addition to a priori analytical themes. Figured Worlds draws together concepts of trajectories and imagination from Chapter 2; culture, power and positioning from Chapter 3; and discourses from Chapter 4, to enable a fuller theoretical exploration of processes of identification. Analysis of female surgeons' narratives demonstrated that discourses of being a woman and being a surgeon existed in competition, and thus there was little discursive space to be a successful female surgeon. To overcome this women undertook identity work: they refigured what it was to be female, or a surgeon, or orchestrated societal discourses to create new ways of being, termed world-making.

Chapter 7 forms the discussion chapter of this thesis. It presents the background, main findings and conclusions of the thesis. The discussion situates the full body of work within the existing literature, and emphasises how this thesis has furthered understanding of women's under-representation in surgery. It gives a detailed account of the figured world of surgery: first, in terms of surgical culture and discourses of surgery; second, in terms of the ways people identify within the figured world; and third, via discussion of inequity present in the surgical world. Surgical culture was strongly masculine, which meant feminine dispositions and characteristics were disprivileged within the domain. Female medical students had differing and negative experiences of surgery, and differential access to the hidden curriculum of surgical careers. This meant it was harder for women to identify themselves as 'future surgeons'; for those women who did become surgeons, it was difficult to combine being a surgeon with being a woman, as discourses of each existed in competition. Some female surgeons undertook creative 'identity work' and articulated new discursive spaces in which they could identify as a woman and surgeon simultaneously. Chapter 7 also addresses the strengths and limitations of the thesis as a whole. Valorisation of the thesis is discussed, via detailed exploration of the practical and theoretical implications of this work, and how its studies can inform future work. 


\section{References}

Bourdieu P (1977a). Outline of a Theory of Practice. Cambridge: Cambridge University Press.

Bourdieu P (1977b). Reproduction in education, society and culture. London: Sage Publications.

Bourdieu P (1990a). In Other Words: Essays Towards a Reflexive Sociology. Cambridge: Polity Press.

Bourdieu P (1990b). The Logic of Practice. Palo Alto, CA: Stanford University Press.

Bourdieu P (1993). Some Properties of Fields. In: Sociology in Question. Thousand Oaks, CA: Sage Publications, p72-77.

Burack JH, Irby DM, Carline JD, et al. (1997). A study of medical students' specialty-choice pathways: trying on possible selves. Acad Med, 72(6):534-541.

Butler JP (1990). Gender Trouble. London: Routledge.

Center for Workforce Studies (2012). 2012 Physician Specialty Data Book. Washington, DC: Association of American Medical Colleges.

Drinkwater J, Dornan T, Tully MP (2008). The effect of gender on medical students' aspirations: a qualitative study. Med Educ, 42(4):420-426.

Elston MA (2010). Women and Medicine. London: Royal College of Physicians.

Gee JP (2005). An introduction to discourse analysis: Theory and method, 2nd ed. London: Routledge.

Gee JP (2011). How to do Discourse Analysis. London: Routledge.

Greatorex R, Sarafidou K (2010). Surgical Workforce 2010: Profile and Trends. London: Royal College of Surgeons of England.

Hafferty FW, Hafler JP (2011). The Hidden Curriculum, Structural Disconnects and the Socialization of New Professionals. Innov Change Profess Educ, 6:17-35.

Holland D, Lachicotte W Jr, Skinner D, Cain C (1998). Identity and Agency in Cultural Worlds. London: Harvard University Press.

Li R, Buxey K, Ashrafi A, Drummond KJ (2013). Assessment of the role of a student-led surgical interest group in surgical education. J Surg Educ, 70(1):55-58.

McNally SA (2012). Surgical Training: Still Highly Competitive But Still Very Male. Bull $R$ Coll Surg Engl, 94(2):53-55.

Pas B, Peters P, Eisinga R, Doorewaard H, Lagro-Janssen T (2011). Explaining career motivation among female doctors in the Netherlands: the effects of children, views on motherhood and work-home cultures. Work Employment Society, 25(3):487-505.

Royal College of Surgeons of England (2013). Women in Surgery (WinS). Available from: http://surgicalcareers.rcseng.ac.uk/wins [Accessed 21 April 2014]

Sanfey HA, Saalwachter-Schulman AR, Nyhof-Young JM, Eidelson B, Mann BD (2006). Influences on Medical Student Career Choice: Gender or Generation? Arch Surg, 141(11):1086-1094.

van Tongeren-Alers M, Dielissen P, van Leerdam L, Lagro-Janssen A (2014). Gendered specialties during medical education: a literature review. Perspect Med Educ, In Press.

Wenger E (1998). Communities of Practice. Cambridge: Cambridge University Press.

Wolfe CV (2005). Women in medicine: an unceasing journey. Arch Phys Med Rehabil, 86(7):1283-1286. 



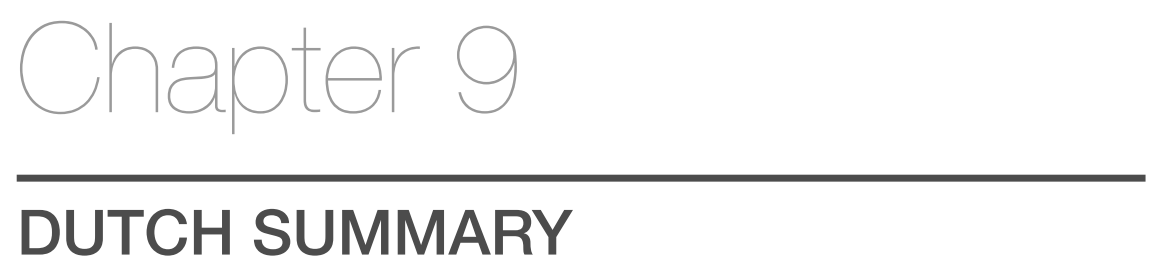




\section{CHAPTER 9}

\section{Samenvatting}

Dit proefschrift bestaat uit zeven hoofdstukken die de cultuur binnen de chirurgie verkennen en onderzoeken hoe deze cultuur loopbaankeuzes van medische studenten beïnvloedt. In het bijzonder wordt aandacht besteed aan de ondervertegenwoordiging van vrouwen binnen de chirurgie.

Tegenwoordig vormen vrouwelijke studenten wereldwijd de meerderheid binnen medische faculteiten (Wolfe 2005; Elston 2010). De afgelopen 25 jaar heeft deze demografische verandering tevens de vertegenwoordiging van vrouwelijke artsen binnen bijna alle medische disciplines beïnvloed, met de chirurgie als nadrukkelijke uitzondering. In de Verenigde Staten is $10 \%$ van de stafleden chirurgie vrouw (Center for Workforce Studies 2010), in Australië is dit 9\% (Li et al. 2013) en in Nederland 7\% (Pas et al. 2011). In Groot-Brittannië, waar het onderzoek dat is beschreven in dit proefschrift werd uitgevoerd, is slechts $7 \%$ van de stafleden binnen de chirurgie vrouw (Greatorex \& Sarafiou 2010). In 2005 bereikte het aandeel vrouwelijke chirurgen een piek met $8 \%$. Sindsdien blijft dit percentage ongewijzigd, ondanks verschillende initiatieven om het aantal vrouwelijke chirurgen toe te laten nemen (McNally 2012; Royal College of Surgeons of England 2013). Een beter begrip van dit fenomeen is noodzakelijk, niet alleen omwille van het creëren van gelijke kansen op een carrière binnen de chirurgie, maar ook om optimale chirurgische zorg voor toekomstige patiënten te garanderen. In eerdere studies werden verschillende factoren gevonden die de loopbaankeuzes van medische studenten beïnvloeden, zoals de aanwezigheid van geschikte rolmodellen (Sanfey et al. 2006), de indruk die studenten hebben van de levensstijl die samenhangt met een discipline (Drinkwater et al. 2008) en de ervaringen tijdens de medische opleiding (Burak et al. 1997). Bestaand onderzoek legde de nadruk op beschrijvende statistiek van het fenomeen, een individualistische benadering tot hoe studenten loopbaankeuzes maken, en een biologische definitie van gender. Dit proefschrift heeft als belangrijkste doel om vanuit de hedendaagse sociale wetenschappen een beter beeld te krijgen van de manier waarop medische studenten en artsen, met de nadruk op vrouwen, hun loopbaanmogelijkheden binnen chirurgische disciplines vormgeven.

Figured Worlds (Holland et al. 1998) vormt het belangrijkste theoretische kader binnen dit proefschrift. Het is een amalgaam van sociaal-culturele theorieën en bevat elementen van het gedachtegoed van Vygotsky, Bakhtin en Bourdieu. Figured Worlds is een theorie over 'identiteit in de praktijk', wat suggereert dat iemands identiteit voortdurend wordt gevormd en bijgesteld in wisselwerking met de sociaal-culturele omgeving waarin iemand zich beweegt. In dit proefschrift wordt daarnaast gebruik gemaakt van een sterk hieraan gerelateerde sociale leertheorie, Communities of Practice (Wenger, 1998). Hoewel gender primair benaderd wordt als sociaal-cultureel construct, werd de 
theoretische achtergrond van dit proefschrift beïnvloed door poststructuralistisch feministisch gedachtegoed, met name Butler's kritiek op het feminisme (1990) en het meer recente concept van de intersectionaliteit van identiteiten. Deze theorieën beschouwen de sociale wereld, inclusief mensen, discours en organisatie in deze wereld als sociaal en dynamisch; betekenis en identiteit worden continu sociaal bepaald- bijvoorbeeld, bepaling van individuele identiteiten in relatie tot anderen en de sociale wereld, of bepaling van de betekenis van taal en culturele artefacten. Binnen deze sociaal-culturele theorieën stelt men dat mensen leven binnen de sociale structuur of het regulerend raamwerk van een 'Figured World'. Een 'Figured World' is een deels imaginaire wereld waarin mensen een bepaalde positie krijgen en een identiteit kunnen aannemen door te 'doen alsof'. 'Agency' - het vermogen autonoom te handelen en daarmee het concreet vormgeven van een bepaalde identiteit moet dan ook verkregen worden in relatie tot de in een specifieke cultuur geldende regels en procedures. Dit perspectief biedt de mogelijkheid om te onderzoeken hoe cultuur zich manifesteert 'in de praktijk'. Dit proefschrift heeft tot doel om de cultuur van de 'Figured World van de chirurgie' te exploreren; hoe individuen deze cultuur ervaren en op welke manier bepaalde groepen, met name vrouwen, zich binnen deze cultuur positioneren.

Hoofdstuk 1 vormt een algemene introductie van het proefschrift. De problematiek van de ondervertegenwoordiging van vrouwen binnen de chirurgie, en daarmee het belang van het onderzoek, wordt beschreven. Vervolgens wordt een review van de relevante literatuur gepresenteerd om het onderzoeksonderwerp te situeren binnen het onderzoek naar gender en loopbaankeuzes. Dit hoofdstuk bevat ook een sociaal-culturele kritiek op de reeds gepubliceerde literatuur. Op deze wijze wordt de niche van het onderzoek naar bevoor- en benadeling van bepaalde groepen, en hoe individuen zich identificeren met en zich positioneren binnen de chirurgische cultuur - in essentie, hoe cultuur 'werkt' in de praktijk - gebruikt om de ondervertegenwoordiging van vrouwen in de chirurgie te verklaren. Ten derde wordt het theoretisch kader van Figured Worlds en het epistemologisch standpunt van dit proefschrift in relatie tot identiteit, agency, leren en gender uiteengezet. Ten slotte worden de doelen en bijhorende onderzoeksvragen van het proefschrift uiteengezet en de structuur van het proefschrift omschreven.

Hoofdstuk 2 verkent de ervaringen van medische studenten met chirurgie en maakt daarbij gebruik van de sociaal-culturele leertheorie Communities of Practice, zoals ontwikkeld door Wenger (1998). Meer specifiek werd in deze studie gebruik gemaakt van het concept 'paradigmatic trajectories' - zichtbare, prototype carrièrepaden die gecreëerd worden door een gemeenschap en mede bepalen hoe individuen betekenis geven aan hun eigen ervaringen en hoe zij deze ervaringen interpreteren. Vormgegeven door mensen van de 


\section{CHAPTER 9}

gemeenschap omvatten paradigmatic trajectories - bestaande en denkbeeldige voorbeelden van potentiële ontwikkelingstrajecten binnen de gemeenschap potentiële (samengestelde) carrièrepaden die gevolgd kunnen worden op basis van de ervaringen van verschillende mensen. Het concept van paradigmatic trajectories biedt een bruikbare theoretische lens om percepties van studenten over mogelijke carrièrepaden en op welke manier deze hun loopbaankeuzes beïnvloeden te onderzoeken. Deze studie omvat een secundaire analyse van 19 interviews met studenten waarin hun ervaringen met de medische opleiding tijdens de coschappen werden onderzocht. Er bleek een groot verschil te zijn tussen de ervaringen van mannelijke en vrouwelijke studenten binnen de chirurgie. De ervaringen van vrouwelijke studenten werden sterk bepaald door gender; ze werden gepositioneerd als 'anders' binnen de chirurgie. Wat studenten zagen, hoorden en deden tijdens hun coschap chirurgie beïnvloedde in sterke mate wat studenten zich konden voorstellen in het kader van een mogelijke toekomst in de chirurgie. Deze vier kernprocessen - zien, horen, doen en voorstellen - bleken de vorming van paradigmatic trajectories te faciliteren, op basis waarvan studenten vervolgens hun loopbaankeuzes konden baseren. Op basis van deze ervaringen met de discipline chirurgie en de gecreëerde paradigmatic trajectories, besloten vrouwelijke studenten dat een carrière binnen de chirurgie 'niets voor hen' was. Mannelijke studenten hadden daarentegen meer positieve ervaringen met de 'hands-in' participatie binnen de chirurgie en werden zij niet gemarginaliseerd door de paradigmatic trajectories. Paradigmatic trajectories is een nieuwe theoretische tool waarmee de ervaringen van studenten binnen de chirurgie verkend konden worden.

Hiërarchie en macht leken een belangrijke rol te spelen binnen de discipline chirurgie. Hoewel Communities of Practice de mogelijkheid biedt deze aspecten te onderzoeken, is het voornamelijk een leertheorie en geen macrosociologische theorie. Om deze reden is het dan ook niet volledig geschikt om concepten zoals cultuur en hiërarchie op het niveau van de samenleving te onderzoeken; daarom werden meer globale theorieën gebruikt om de chirurgische cultuur en de identiteitsvorming van studenten binnen deze cultuur in kaart te brengen.

Hoofdstuk 3 beschrijft een empirische studie waarin constructivistische Grounded Theory gebruikt word om in kaart te brengen hoe studenten geneeskunde aankijken tegen de chirurgie als carrièremogelijkheid en hoe zij zich binnen deze cultuur bewegen om succesvol te zijn. De studie maakt gebruik van het concept 'hidden curriculum', gedefinieerd als de cultuur, overtuigingen en gedragingen van de mensen binnen een gemeenschap, overgedragen op studenten die dit vervolgens overnemen (Hafferty \& Hafler 2011). Met behulp van een vragenlijst werden de ideeën en ervaringen van medische studenten met betrekking tot chirurgen, de discipline chirurgie en een mogelijke carrière in de chirurgie in kaart gebracht. De bevindingen gaven richting aan diepte 
interviews met twaalf medische studenten over chirurgische carrières en hoe ze ontdekten wat vereist is om chirurg te worden. Resultaten toonden aan dat studenten een duidelijk beeld hadden over het chirurgische hidden curriculum op basis waarvan een model werd ontwikkeld dat beschrijft hoe studenten dit hidden curriculum tegenkwamen en operationaliseerden.

Om op succesvolle wijze een carrière binnen de discipline chirurgie te bereiken dienden studenten eerst een netwerk te creëren aangezien loopbaaninformatie zich verspreidde via deze relaties. Vervolgens zetten studenten wat ze geleerd hadden om in de praktijk door zich bepaalde gedragingen eigen te maken ('walking the talk') en accolades op te bouwen ('ticking the boxes') die hoorden bij een toekomstig chirurg. Dit gaf hen de mogelijkheid zichzelf te identificeren als en zich door anderen te laten identificeren als een 'toekomstig chirurg', en zodoende toegang te krijgen tot de chirurgische wereld. Participeren, bijvoorbeeld door te assisteren op de operatie kamer, gaf hen de mogelijkheid hun netwerk uit te breiden en bood toegang tot informatie over een chirurgische carrière middels een positieve feedback loop. Voor sommigen was het moeilijk om met dit hidden curriculum om te gaan. Zij ervoeren een carrière in de chirurgie als onwenselijk of onhaalbaar; en werden zo uitgesloten van een carrière in de chirurgie. Ze hadden het gevoel dat ze niet met het hidden curriculum uit de voeten konden en voelden dat ze niet het type persoon waren welke paste binnen deze chirurgische cultuur. Door aandacht te schenken aan de sociaal-culturele redenen die onderliggend zijn aan de verschillende mate van deelname van mannelijke en vrouwelijke studenten binnen het chirurgisch domein, bouwen de bevindingen van Hoofdstuk 3 voort op Hoofdstuk 2. Het gebruik van sensitiserende concepten uit de macro-sociologische theorieën van Bourdieu (1977a,b; 1990a,b; 1993) ondersteunde de uiteenzetting van een model in ontwikkeling over hoe binnen iedere fase van dit model studenten in verschillende mate toegang hadden tot het hidden curriculum van een chirurgische loopbaan. Het concept macht werd besproken door een uitleg van de complexe manieren waarop sociaal, cultureel en symbolisch kapitaal werd verdeeld, uitgewisseld en ontzegd binnen het chirurgisch domein.

In Hoofdstuk 4 verkent de chirurgische cultuur door percepties van studenten over de discipline chirurgie en chirurgen te bestuderen en zo een beschrijving te creëren van chirurgische stereotypes. Vervolgens wordt geanalyseerd hoe deze stereotypes de loopbaankeuzes van studenten beïnvloeden. In deze studie werd een discours analyse uitgevoerd van interviews met medische studenten uit verschillende jaargroepen, zowel mannen als vrouwen met verschillende loopbaanperspectieven. Discours analyse probeert de gedeelde vertellingen, normen, waarden, percepties en praktijken van een gemeenschap bloot te leggen door het bestuderen van hun taalgebruik (Gee 2005). Deze methodologie erkent de sociaal geconstrueerde aard van de chirurgische cultuur (Gee 2011). Dit bood de mogelijkheid om een diepere analyse te maken 


\section{CHAPTER 9}

van de gedachten en aannames van studenten met betrekking tot de discipline chirurgie, daarmee tevens voortbouwend op de bevindingen uit Hoofdstuk 3 . Tevens bleek het mogelijk om te onderzoeken hoe studenten gepositioneerd werden binnen het heersende discours. Medische studenten hadden opvallend uniforme ideeën over stereotype chirurgen als overmatig zeker van zichzelf en intimiderend. Deze stereotypes hielden stand ondanks talrijke positieve ervaringen met chirurgen. Volgens de stereotypen was de chirurgische cultuur meedogenloos competitief; werd de cultuur gepercipieerd als mannelijk, waarbij het laten zien van mannelijke kwaliteiten noodzakelijk was voor succes binnen dit domein. Studenten geloofden dat een carrière in de chirurgie opoffering van tijd en energie vereiste en voornamelijk ook ten koste ging van een familieleven. Studenten waren overtuigd dat om te slagen binnen de chirurgie zij binnen dit stereotype moesten passen, daarmee mensen die niet wilden of konden conformeren buitensluitend. Om te kunnen afwijken van deze stereotypes was het nodig om eigenschappen die belangrijk gevonden worden binnen de chirurgie op een uitzonderlijk niveau te laten zien. Chirurgie werd hierdoor als niet aantrekkelijk noch realistisch ervaren door veel medische studenten.

Hoofdstuk $\mathbf{5}$ is een commentaar op een meta-analyse van gender en loopbaanambities van medische studenten (Tongeren-Alers et al. 2014). Het hoofdstuk verkent mogelijke sociaal-culturele verklaringen voor de verschillen in loopbaankeuzes tussen mannelijke en vrouwelijke studenten. De bevindingen uit hoofdstukken 2-4 worden in een breder theoretisch kader geplaatst, waarbij ook rekening gehouden wordt met de sociaal-culturele kritiek op gepubliceerde studies over loopbaankeuzes in het medisch onderwijs. Het merendeel van het eerder gepubliceerde onderzoek richt zich op keuzemomenten rondom de medische carrière, een fenomeen waarin vanzelfsprekend veel 'agency', ofwel handelingsbekwaamheid, toegekend wordt aan individuen. Deze invalshoek laat niet veel ruimte voor sociaal-culturele factoren die het aantal mogelijke opties zouden beperken. In dit hoofdstuk wordt de tegenstelling tussen individualistische theorieën (met nadruk op individuele handelingsruimte) en sociaal culturele theorieën ( meer deterministisch) geschetst en wordt de vraag gesteld in welke mate studenten echt 'vrij' zijn om een loopbaan te 'kiezen'. Er wordt in het bijzonder gewezen op de mate waarin sociaal-culturele beperkingen individuen verschillend beïnvloeden, en hoe deze verschillen, bijvoorbeeld in de mogelijkheid om actief te participeren, de mogelijke loopbaanopties van studenten zou kunnen beïnvloeden.

Hoofdstuk 6 beschrijft de vierde en laatste empirische studie. In vorige hoofdstukken werden verschillende redenen onderzocht waarom studenten niet voor een loopbaan binnen het domein chirurgie kiezen. Dit hoofdstuk gaat dieper in op de ervaringen van vrouwelijke studenten en artsen die wel voor 
een loopbaan in de discipline chirurgie hebben gekozen. De studie omvat interviews met vijftien vrouwen die zich op verschillende momenten in hun loopbaantraject binnen de chirurgie bevinden; van medisch student tot een chirurgisch specialist in ruste. Het doel van de studie was om de onderliggende identificatie processen van vrouwen met een chirurgische carrière te begrijpen. Figured Worlds bood een theoretisch en epistemologisch perspectief als toevoeging op eerder vastgestelde analyse thema's. Figured Worlds brengt concepten van trajecten en verbeelding uit Hoofdstuk 2, cultuur, macht en positionering uit Hoofdstuk 3, en discourses uit Hoofdstuk 4 samen om zo een beter beeld te krijgen van de identificatie processen. De analyse van de interviews van de vrouwelijke chirurgen toonde aan dat 'vrouw zijn' en 'chirurg zijn' in strijd was met elkaar waardoor slechts weinig ruimte beschikbaar was om een succesvol, vrouwelijk chirurg te zijn. Om dit conflict op te lossen, moesten deze vrouwen iets doen met hun identiteit: zij gaven een nieuwe definitie aan hun vrouw zijn, of aan hun identiteit als chirurg, of verhielden zich op een andere manier tot heersende maatschappelijk discoursen om zo een nieuwe manier van zijn te promoten, ook wel 'world-making' genoemd.

Hoofdstuk 7 bespreekt de bevindingen van de verschillende studies in het proefschrift. Het hoofdstuk geeft de achtergrond, belangrijkste bevindingen en conclusies uit het proefschrift weer. De discussie plaatst het werk in het breder kader van bestaande literatuur en benadrukt hoe dit onderzoek bijdraagt aan het beter begrijpen van de onder-representatie van vrouwen binnen de chirurgie. Dit proefschrift schets een gedetailleerd beeld van de 'Figured World' van de chirurgie, ter eerste door een beschrijving van de specifieke cultuur van de chirurgie, ten tweede door te beschrijven hoe mensen zich identificeren met deze 'Figured World'; en ten slotte door de discussie over ongelijkheid in de chirurgische wereld. De chirurgische wereld was sterk mannelijk getint waardoor vrouwelijke eigenschappen en karakteristieken werden geweerd binnen het domein. Vrouwelijke medische studenten hadden verschillende en negatieve ervaringen met betrekking tot chirurgie, en in verschillende mate toegang tot het 'hidden curriculum' van chirurgische carrières. Dit betekent dat het moeilijker was voor vrouwen om zich te identificeren met het beeld van een 'toekomstig chirurg'. Voor de vrouwen die chirurg werden was het moeilijk om het chirurg zijn te combineren met het vrouw zijn omdat deze concepten in strijd zijn met elkaar. Sommige vrouwen waren creatief in het hervormen van hun identiteit om zo nieuwe ruimte te ontwikkelen waarin ze zowel vrouw konden zijn als chirurg. Hoofdstuk 7 bespreekt ook de sterktes en verbeterpunten van het proefschrift. Door een gedegen beschrijving van de praktische en theoretische implicaties van de studies wordt beschreven hoe dit proefschrift bijdraagt aan kennisvermeerdering, nu en in de toekomst. 


\section{CHAPTER 9}

\section{References}

Bourdieu P (1977a). Outline of a Theory of Practice. Cambridge: Cambridge University Press.

Bourdieu P (1977b). Reproduction in education, society and culture. London: Sage Publications.

Bourdieu P (1990a). In Other Words: Essays Towards a Reflexive Sociology. Cambridge: Polity Press.

Bourdieu P (1990b). The Logic of Practice. Palo Alto, CA: Stanford University Press.

Bourdieu P (1993). Some Properties of Fields. In: Sociology in Question. Thousand Oaks, CA: Sage Publications, p72-77.

Burack JH, Irby DM, Carline JD, et al. (1997). A study of medical students' specialty-choice pathways: trying on possible selves. Acad Med, 72(6):534-541.

Butler JP (1990). Gender Trouble. London: Routledge.

Center for Workforce Studies (2012). 2012 Physician Specialty Data Book. Washington, DC: Association of American Medical Colleges.

Drinkwater J, Dornan T, Tully MP (2008). The effect of gender on medical students' aspirations: a qualitative study. Med Educ, 42(4):420-426.

Elston MA (2010). Women and Medicine. London: Royal College of Physicians.

Gee JP (2005). An introduction to discourse analysis: Theory and method, 2nd ed. London: Routledge.

Gee JP (2011). How to do Discourse Analysis. London: Routledge.

Greatorex R, Sarafidou K (2010). Surgical Workforce 2010: Profile and Trends. London: Royal College of Surgeons of England.

Hafferty FW, Hafler JP (2011). The Hidden Curriculum, Structural Disconnects and the Socialization of New Professionals. Innov Change Profess Educ, 6:17-35.

Holland D, Lachicotte W Jr, Skinner D, Cain C (1998). Identity and Agency in Cultural Worlds. London: Harvard University Press.

Li R, Buxey K, Ashrafi A, Drummond KJ (2013). Assessment of the role of a student-led surgical interest group in surgical education. J Surg Educ, 70(1):55-58.

McNally SA (2012). Surgical Training: Still Highly Competitive But Still Very Male. Bull $R$ Coll Surg Engl, 94(2):53-55.

Pas B, Peters P, Eisinga R, Doorewaard H, Lagro-Janssen T (2011). Explaining career motivation among female doctors in the Netherlands: the effects of children, views on motherhood and work-home cultures. Work Employment Society, 25(3):487-505.

Royal College of Surgeons of England (2013). Women in Surgery (WinS). Available from: http://surgicalcareers.rcseng.ac.uk/wins [Accessed 21 April 2014]

Sanfey HA, Saalwachter-Schulman AR, Nyhof-Young JM, Eidelson B, Mann BD (2006). Influences on Medical Student Career Choice: Gender or Generation? Arch Surg, 141(11):1086-1094.

van Tongeren-Alers M, Dielissen P, van Leerdam L, Lagro-Janssen A (2014). Gendered specialties during medical education: a literature review. Perspect Med Educ, In Press.

Wenger E (1998). Communities of Practice. Cambridge: Cambridge University Press.

Wolfe CV (2005). Women in medicine: an unceasing journey. Arch Phys Med Rehabil, 86(7):1283-1286. 


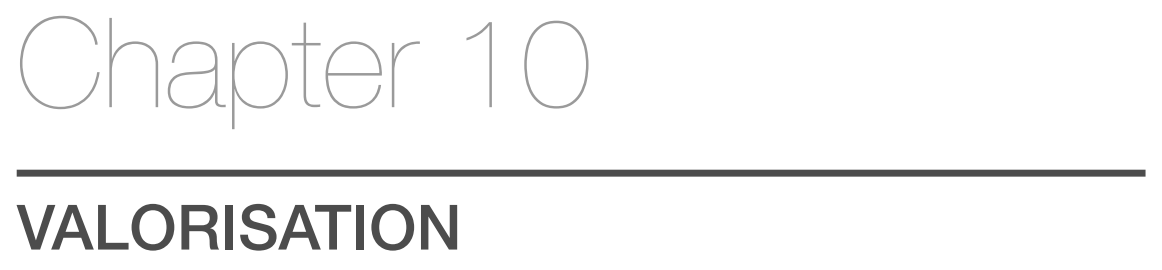




\section{CHAPTER 10}

\section{Valorisation \\ Implications for practice}

This thesis has practical applications which can directly benefit medical students and surgeons, and which may indirectly benefit patients, healthcare and society at large.

This research has several important findings in terms of differential access to surgical careers. From a sociocultural perspective, the surgical world is complex; many factors interact to determine an individual's trajectory in the domain, from their own individual history to the immediate social contexts in which they find themselves day-to-day. While the discussion sections in Chapters 2-6 delineate practical applications of the work in terms of dealing with inequity, there is no simple solution: no single intervention will increase the representation of women in surgery, nor is it predictable precisely what effect any such intervention may have.

There is a delicate balance when considering any interventions to 'encourage' women into surgical careers. Whilst this thesis and the literature suggest an increased number of female surgeons would be beneficial for future cohorts, Chapter 6 suggests that, for those women that do enter the career, it is likely to be a more difficult path to take. It may therefore be considered irresponsible to 'push' or guide any individual in any particular direction. Conversely, to draw attention to the difficulties inherent in being a female surgeon may further deter women from the career, worsening the situation for both those in the specialty and those considering a surgical career. Hence, the practical applications suggested here are based on equipping individuals with an understanding of surgical discourses, and the tools to negotiate, and even challenge, the surgical status quo. Given the importance of local context, such a strategy allows individuals to apply this work to their individual social worlds.

\section{Tackling differential access to participation}

A major finding of this thesis was the differential access medical students had to uncovering, enacting and engaging in the hidden curriculum of surgical careers - the culture, beliefs and behaviours enacted by those within a community and passed to students, who subsequently enact them themselves (Hafferty \& Hafler 2011). Another key finding was that different students experience the same thing differently; female students do not experience participation in the same ways as male students during surgical placements, are unable to see or interact with many female surgeons, and are exposed to negative stories of female surgeons. There are several practical steps that could be taken to address these points. Firstly we must understand the importance of making the hidden curriculum more explicit and, hence, more widely accessible to students. Discussions of what forms of capital and behaviour are privileged in surgery, 
and why, could help more students to understand this, as well as providing a forum to openly debate their implications. The literature and this thesis are clear that relationships are very important. Mentoring, whether from surgeons or peers, at an early stage in medical school regarding how to 'practically negotiate' career options - understanding 'what counts', where, at what time and why are integral concepts to developing a sens pratique of a career.

Students could be better helped to build useful relationships, for example by providing 'scripts' for engagement in the operating theatre - one such stock question might be, "I'm really interested in a surgical career, but I'm not sure what I need to do; please can I hear about your experiences?" Institution-level interventions may also be of benefit - for example, a hospital-wide policy that medical students should 'scrub in' when on placement and have a role as part of an operating theatre team; if theatre staff know it is important for students to 'scrub in', and also legitimate to ask them to help with tasks, this may facilitate 'belonging' and feeling useful - 'supported participation' - which has been shown to be of central importance to 'experience-based learning' in clinical settings (Dornan et al. 2007). Thus, it may be of benefit to clarify the role of students in the operating theatre to be more akin to the North American model, where students are expected to scrub for every case during their surgical rotation (unless there is a compelling or clinical reason not to) (Tahiri \& Liberman 2013). With female students less likely to negotiate to 'scrub in', this may be especially beneficial in equipping them with better tools to engage in surgical placements.

However, there are also ramifications of these strategies that must be considered, as some involve fitting individuals better to the practice of surgery, rather than changing the practice itself. Deliberate intervention with a view to changing the ways in which people identify carries significant ethical implications, and concerns have been raised over fitting school students from lower socioeconomic groups into the middle-class practice of university (Moore 2014). Figured Worlds would hold that the practice and the identities of its individuals exist in dialogue, hence, even taking such an 'identity approach' may change the practice itself.

\section{Figures and relationships}

This thesis supports previous research on the value of female surgical role models (Sanfey et al. 2006). There is likely to be much benefit in actively gathering and disseminating diverse narratives of surgery and surgeons. From the Figured Worlds perspective, 'figures' are a wider concept than role models; hence, medical students and surgeons could draw on more diverse 'figures', in relation to whom they could narrate their own identities. Further, in terms of 'paradigmatic trajectories', this would arguably increase the diversity of 


\section{CHAPTER 10}

trajectories available for medical students, making it easier to 'see' and 'hear' about successful female surgeons, thus facilitating medical students' imagination of themselves in surgical careers. On a practical note, this strategy would need to discursively depart from many 'professional profiles' of surgeons available online and in the media, which tend to reinforce surgical discourses (Royal College of Surgeons of England 2013). Rather, a more frank and unusual insight into these people's lives would hold more value: Where are they from?; What other careers did they consider?; How did they train?; What do they enjoy?; What is challenging about their work?; What do they enjoy outside of work?; What do they wish they had known before embarking on a surgical career?; What are their patients like?; What is an average day like for them? Answers to these questions do not form a typical surgical narrative, and could significantly disrupt underlying discourses and disseminate alternative (and less stereotypical) ways to be a surgeon - thereby highlighting other aspects of surgeons' identities so a wider variety of medical students could identify with them, rather than a profile portraying every surgeon in terms of the homogenous 'ideal surgeon' stereotype.

While increased access to figures in the abstract may be beneficial in challenging existing discourses, facilitating relationships with these same people would also be helpful. As described in Chapter 3, it is not merely relationships with the most senior surgeons that are important; relationships with medical students and surgical trainees via workshops, mentorship schemes, and social media could, in addition to promoting the existing diversity of surgeons, build useful relationships for students. This recommendation is also supported by numerous other studies demonstrating the value of mentorship and role modelling (Neumayer et al. 2002; Sanfey et al. 2006; Drinkwater et al. 2008; Drolet et al. 2014). 'Mentors', then, represent a powerful opportunity to bring about change in the practice of surgery - to refigure surgery for medical students, but also for surgeons. Mentors have the opportunity to orchestrate what students see, hear, do, and thus imagine; they can provide positive and diverse stories, in the awareness that these narratives are influential. These same people can more actively invite students to engage and participate, knowing that this facilitates identification and belonging in surgery, but also that students might want to engage but not know how. For example, if a student seems quiet or awkward, a mentor could assume that they don't know how to interact, rather than that they are uninterested. In this regard, surgeons, in their day-to-day activities and interactions with students can powerfully improve the surgical experiences of both male and female medical students.

\section{Challenging existing discourses}

Another major finding of this thesis is the masculine nature of the prevailing discourses in surgery, and their, at times, polarising effect on students. Making 
students aware of the discourses that they are drawing on may act to facilitate a more agentic authorial stance. This may assist the challenge and renegotiation of the prevailing discourses that marginalise some students. Although the studies used interview transcripts as data, it is not just language that is gendered. Other cultural tools - including colours, images, objects, activities, buildings - also have historical and cultural meanings that can have gendered connotations. Attention paid at an institutional level to reified discourses could help to broaden the diversity of imagined trajectories in surgery - from the language used in policy documents to the portraits that hang in institutions (Martimianakis \& Hafferty 2013).

Competition was a major discursive component of the figured world of surgery for medical students and surgeons in this thesis. It was both reified in surgical literature and unchallengeable - 'surgical' almost became a byword for 'competitive'. For many surgeons interviewed, the competitiveness was a source of pride in their own success and considered as a force for improvement within the specialty. Yet, data in Chapter 3 showed how the perceived competitiveness excluded many students from the possibility of beginning to consider the career. Hence, there may be benefit in beginning to consider how surgery as a practice could become 'less competitive', not in terms of application ratios, but in terms of communality. Such a discursive change could make the practice more open to female students and more amenable to patients. That is not to say that communal discourses should be ranged in opposition to those of competition, but that there may be a way to include these perspectives, which both have much to offer, in the surgery of the future.

A powerful challenge to the masculine surgical discourse was discussed in Chapter 6: 'world-making' is the orchestration of existing discourses to author new ways of being - for example, stating that being a mother and a surgeon require the same skills. It is important to be aware of this kind of identity work, so that it can be incorporated into a future sense of surgery as a practice, in order to benefit others in similar positions. This could be supported by wide dissemination of new examples of discursive world-making, and by giving people forums in which to discuss their practice and experiment with discursive orchestration.

\section{Implementation of practical and theoretical implications}

The papers in Chapters 2, 3, 4 and 5 have already, at the time of writing, been published in academic journals. Notably Chapters 2 and 3 attracted the publication of commentary pieces to accompany the articles, demonstrating the discussion stimulated within the field prompted by this work. Chapter 3 provoked debate in a subsequent issue, when some medical students were moved to challenge the paper's findings. Research papers have been presented 


\section{CHAPTER 10}

at Association for Medical Education in Europe conferences held in Lyon in 2012 and Prague in 2013.

An international research symposium has been organised to coincide with defence of this thesis. Central to the focus of this symposium will be theoretical issues raised by this thesis, including sociocultural perspectives on identification, gender and culture as applied to surgical education. This event will contribute to the impact this work has in the field, including wider dissemination of the theoretical advances made by this thesis and discussion of the possible direction of future work.

Copies of the PhD thesis will be distributed to members of the Opportunities in Surgery and Women in Surgery committees at the Royal College of Surgeons of England, and the US-based Women in Surgery organisation, whereby it is hoped the findings will be incorporated into policy governing UK and US surgical training.

\section{References}

Dornan T, Boshuizen H, King N, Scherpbier A (2007). Experience-based learning: a model linking the processes and outcomes of medical students' workplace learning. Med Educ, 41(1):84-91.

Drinkwater J, Dornan T, Tully MP (2008). The effect of gender on medical students' aspirations: a qualitative study. Med Educ, 42(4):420-426.

Drolet BC, Sangisetty S, Mulvaney PM, Ryder BA, Cioffi WG (2014). A mentorship-based preclinical elective increases exposure, confidence, and interest in surgery. Am J Surg, 207(2):179-186.

Hafferty FW, Hafler JP (2011). The Hidden Curriculum, Structural Disconnects and the Socialization of New Professionals. Innovation and Change in Professional Education, 6:17-35.

Martimianakis MA, Hafferty FW (2013). The world as the new local clinic: a critical analysis of three discourses of global medical competency. Soc Sci Med, 87:31-38.

Moore S (2014). Working-class kids shouldn't have to be more middle class to "fit in". London: Guardian News \& Media.

Neumayer L, Kaiser S, Anderson K (2002). Perceptions of women medical students and their influence on career choice. Am J Surg, 183(2):146-150.

Royal College of Surgeons of England (2013). Council Biographies. London: Royal College of Surgeons of England.

Sanfey HA, Saalwachter-Schulman AR, Nyhof-Young JM, Eidelson B, Mann BD (2006). Influences on Medical Student Career Choice: Gender or Generation? Arch Surg, 141(11):1086-1094.

Tahiri M, Liberman M (2013). What is an ideal surgical clerkship? Can J Surg, 56(3):151152. 


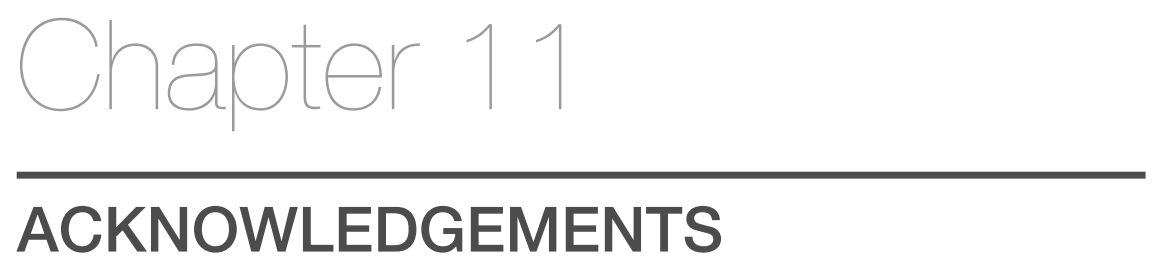




\section{Acknowledgements}

This PhD has been an adventure spanning many disciplines, years and time zones, and I would like to acknowledge the many people who have contributed to this thesis and given me their support.

Tim, thank you for introducing me to the world of medical education. If our paths hadn't crossed whilst you were my Dean at Hope Hospital, I'm sure I would not have discovered medical education so early, nor been initiated so quickly. I feel very fortunate. You have opened many doors for me, taught me how to open them for myself, and even taught me the odd lock-picking trick! very cool.

Yvette, I have absolutely loved working with you, and feel very lucky to have had the opportunity. Thank you for being so totally brilliant. I've learned more from you than any other teacher, and also that the things I've learned aren't necessarily stored in my head... which is interesting! It was the distracted conversations with you about gender and surgery when we were meant to be discussing peer-learning that got this whole thing going. Likely the most important figure in the figured world of my future career. Against everything medicine has taught me, you showed me that to struggle can be good and not a weakness, that sometimes the more you know, the more confusing things become, and that there are neither single nor best answers (the numerous 'single-best answer' exam papers I have taken during my medical career act as a case in point!).

Oh Renée, I'm not sure either of us knew what we were in for! You've been unbelievably patient and enormous fun, if weirdly punctual - a masterclass in supervision from day one. Thank you for your enthusiasm, diplomacy, pragmatism, and unwavering commitment to my supervision and this thesis. When I registered at Maastricht I couldn't have hoped for a more perfect pairing. I shan't miss the thesis, but I'll definitely miss you. And I certainly have an increased respect for the laws of straightness; every time I see M\&Ms I'll think of you and giggle!

Suzanne, my critical friend. Your name only appears on one of these papers, but you've been instrumental in them all. Far more importantly, you taught me how to rant about social justice and dream of better worlds. When you saw me off to the US your leaving card said "Everything you can imagine is real". Thank you. Our critical friendship through our PhDs might have seemed like a survivors group at times, and I'm glad you showed me how hysterical Communities of Practice can be if you read it with the right person. Plug-hard, play hard! 
Jamie, we bloody did it! Its been a blur of exams, clinics, papers, ward rounds, packing, writing, pipetting, re-packing, flights, job interviews, emigration, formatting, spreadsheets, white coats and chaos... thank you so much for all your help. With this squared away we can begin our next adventure! This thesis seems to have brought out the fanatical feminist scholar inside you. You have been a phenomenal help - the Cuban write-up period will remain one of the strangest periods in my life, but we certainly have some stories!

Thank you to all my family, Mother dearest, Dad and Jane, Daniel and Dominic, Rachel and Warwick, Jenny, Matt and the Ambler brood, Simon, Vicki and Liam, Mark, Jeanette and Jacob, and my fabulous grandparents Bill and Dod too. I took for granted that the way I was brought up meant I was very free and pretty unafraid to make some odd career decisions. And thank you to all Jamie's family, who embody encouragement like it's going out of fashion. And thank you for bringing Jamie up a raging feminist Jane, much appreciated. I also want to thank my friends, who are super-fantastico: Emily and Rick, Ambrose and Tash in particular kept me company during my write-up and I'm very grateful! And thank you to my old friend Max Downer for his photography for the cover you are very talented.

The medical education research community has been fantastically open, enthusiastic and engaging during my PhD, especially on Twitter and at AMEE, Rogano and ASME. I would particularly like to mention how much Tina Martimianakis, Fiona Webster, Esther Helmich, Janneke Frambach, Lynn Monrouxe, Rola Ajjawi, Karen Mann, Anne-Marie Cunningham, Jonathan White, Nigel King, Alan Bleakley have inspired, supported and encouraged me.

The Social Theories of Learning group at The University of Manchester was instrumental in my initiation and inculcation into the world of social theory and learning theory. Undoubtedly the conversations, tutelage and generous feedback shaped my PhD hugely. I'd particularly like to thank Julian Williams and Etienne Wenger for their feedback on 'The Only Girl', and Dave 'Vygotsky' Swanson and Sophina Qasim for patiently rehabilitating the medicalised positivist that arrived at their door.

I am very grateful for the support I received from within Manchester Medical School, and in particular to the Dean, Tony Freemont, for his backing in allowing me the freedom to pursue an external PhD, and Jo Hart for her commitment to the hidden curriculum study.

I would like to thank everyone within The School of Health Professions Education at Maastricht, but especially LIlian Swaen who has been instrumental in seeing this thesis to fruition. 
The Washington University Department of Surgery for their support in me coming to defend this PhD during a busy intern rotation, particularly the Division of Plastic and Reconstructive Surgery.

Without such enthusiastic research participants this thesis would have been very different - thank you to everyone who made time to contribute to this research, and for your frank, honest and often very amusing narratives of your experiences.

The Fastbleep team has been incredibly supportive during my PhD; Kate Bowman, it was such a pleasure to work on the medical student data! And I must mention Je Song Shin, Nicholas Boxall, Neal Brooks and Francesca Ludwinski for their help with the Big Training Survey - thank you.

Scalpel Manchester has hugely influenced this work, giving me direct insight into the world of 'future surgeons', and access to a wide network, plus learning from the fantastic people I worked alongside on the committee as President.

There are so many people at The Royal College of Surgeons who have shaped this PhD, but the Women in Surgery Group deserve special thanks, both for the insight afforded to the various issues (political and economical, to the day-today grind) at each and every level of surgical careers, but also the funding, enthusiasm, practical support, belief, and a forum to disseminate my findings. Scarlett McNally, Clare Wynn-Mackenzie, Jane Roberts, Laurie Baxter, Gill Mobb, Beryl De Souza, Jane McCue, Avril Mansfield and Helen Fernandes deserve special mention.

My surgical mentors who have been incredibly supportive, open and kind to me so that surgery always seemed like a great career, thank you. There are so many, but in particular Miss Janet Walls, who has been so important in helping me imagine who I want to be, though she might well have no idea.

To all those who repeatedly pointed out that I'm a girl when discussing my career while I was at medical school, (as if I hadn't noticed!) I'm also grateful. It planted a seed. 


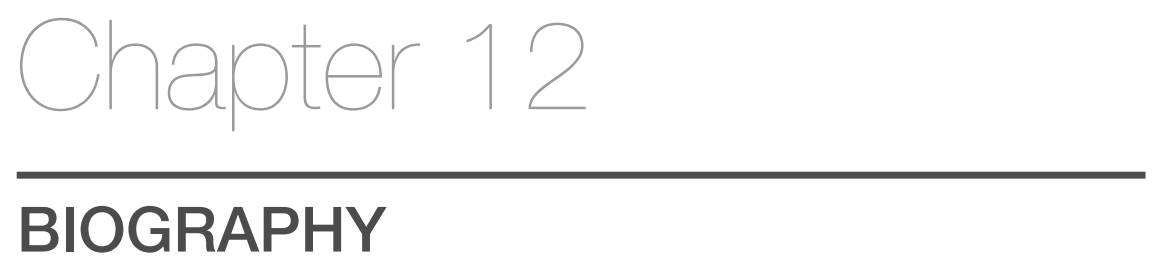




\section{CHAPTER 12}

\section{Elspeth Jane Rose Hill, MB ChB (Hons) MRes}

Elspeth Hill was born on 16 October 1986 in Taunton, Somerset, UK. From 2005-2013 she studied medicine at The University of Manchester, UK, graduating with Honours. In 2009-2010 she completed an intercalated MRes Medical Sciences. She undertook a project investigating the molecular biological basis for stroke arising from the carotid artery, winning significant external funding from both The Royal College of Surgeons of England and the UK National Institute for Health Research.

During medical school, Elspeth was actively involved in medical and surgical education. She served as President of Scalpel, The University of Manchester Surgical Society, and sat on three committees at the Royal College of Surgeons governing education and training. It was here she developed a both a passion for surgery, and a fascination with its culture, and how it seemed to marginalise so many, particularly her female peers. In 2010 she began a PhD in Health Professions Education at Maastricht University in the Netherlands investigating the under-representation of women in surgery, the research for which she completed in 2013-14 and publishes within this thesis.

Elspeth was Director of Peer-Assisted Learning at one of the The University of Manchester's teaching hospitals. In this role she developed new teaching modules and a research programme examining how the peer relationship fosters learning. She is an active collaborator with Stanford University publishing educational iBooks for patients with hand disorders. Further, in 2009, Elspeth founded Fastbleep, an organisation focused on innovation in medical education. Fastbleep Notes was established in 2010 as an online learning resource. Its award-winning editorial system allows medical students to author articles, thereby developing their academic publishing skills in a peer-led supportive environment. Fastbleep Schools is an outreach programme, which aims to widen participation in healthcare careers to students in low participation neighbourhoods', which send relatively few school leavers to university. Fastbleep Events aims to foster capacity in education, research and innovation among healthcare professionals via a busy programme of educational events. The FastForward Innovation in Healthcare competition drew students nationwide to develop and enter their ideas for the future of healthcare. Elspeth continues to serve as a Non-Executive Director of Fastbleep.

Elspeth is currently undergoing postgraduate surgical training as a Resident Physician in the Division of Plastic and Reconstructive Surgery Residency at Washington University School of Medicine, USA. She is also supervising doctoral research into undergraduate nursing education through her role as Sessional Lecturer in Education at London South Bank University, UK. She is a keen traveller, with a love for art, food, animals, yoga and skiing. 
Chapter 13 SHE DISSERTATION SERIES 


\section{CHAPTER 13}

\section{SHE dissertation series}

The SHE Dissertation Series publishes dissertations of PhD candidates from the School of Health Professions Education (SHE) who defended their PhD theses at Maastricht University. The most recent ones are listed below. For more information go to: www.maastrichtuniversity.nl/she

Berkenbosch, L. (30-06-2014) Management and leadership education for medical residents

Bergman, E.M. (30-06-2014) Dissecting anatomy education in the medical curriculum

Dijkstra, J. (25-06-2014) Guidelines for designing programmes of assessment

Van Loon, M.H. (08-05-2014) Fostering monitoring and regulation of learning

Frambach, J.M. (26-03-2014) The cultural complexity of problem-based learning across the world

Hommes, J.E. (26-02-2014) How relations, time \& size matter in medical education

Van der Zwet, J. (30-01-2014) Identity, Interaction and Power. Explaining the affordances of doctor-student interaction during clerkships

Watling, C.J. (22-01-2014) Cognition, Culture, and Credibility. Deconstructing Feedback in Medical Education

Winston, K. (12-12-2013) Remediation Theory and Practice: Transforming At-Risk Medical Students

Kamp, R.J.A. (28-11-2013) Peer Feedback to Enhance Learning in Problem-Based Tutorial Groups

Junod Perron, N. (24-10-2013) Towards a learner-centered approach to postgraduate communications skills teaching

Pratidina Susilo, A. (24-10-2013) Learning to be the Patient Advocate: The Development of a Communication Skills Course to Enhance Nurses' Contribution to the Informed Consent Process

Alves de Lima, A. (23-10-2013) Assessment of clinical competence: Reliability, Validity, Feasibility and Educational Impact of the mini-CEX

Sibbald, M. (09-10-2013) Is that your final answer? How doctors should check decisions

Ladhani, Z. (05-07-2013) Competency based education and professional competencies: a study of institutional structures, perspectives and practices in Pakistan

Jippes, M. (01-02-2013) Culture matters in medical schools: How values shape a successful curriculum change

Duvivier, R. J. (12-12-2012) Teaching and Learning Clinical Skills. Mastering the Art of Medicine

De Feijter, J.M. (09-11-2012) Learning from error to improve patient safety

Prescott, L. (09-11-2012) Ensuring the Competence of Dental Practitioners through the Development of a Workplace-Based System of Assessment

Cilliers, F.J. (05-09-2012) The Pre-assessment Learning Effects of Consequential Assessment: Modelling how the Examination Game is Played

Spanjers, I. A.E. (05-07-2012) Segmentation of Animations: Explaining the Effects on the Learning Process and Learning Outcomes

Al-Kadri, H.M.F. (28-06-2012) Does Assessment Drive Students' Learning? 
Leppink, J. (20-06-2012) Propositional manipulation for conceptual understanding of statistics

Van Zundert, M.J. (04-05-2012) Conditions of Peer Assessment for Complex Learning

Claramita, M. (30-03-2012) Doctor-patient communication in a culturally hierarchical context of Southeast Asia: A partnership approach

Kleijnen, J.C.B.M. (21-03-2012) Internal quality management and organizational values in higher education

Persoon, M.C. (19-01-2012) Learning in Urology; The influence of simulators and human factors

Pawlikowska, T.R.B. (21-12-2011) Patient Enablement; A Living Dialogue

Sok Ying Liaw, (14-12-2011) Rescuing A Patient In Deteriorating Situations (RAPIDS): A programmatic approach in developing and evaluating a simulation-based educational program

Singaram, V.S. (7-12-2011) Exploring the Impact of Diversity Factors on Problem-Based Collaborative Learning

Balslev, T. (24-11-2011) Learning to diagnose using patient video cases in paediatrics: Perceptive and cognitive processes

Widyandana, D. (19-10-2011) Integrating Pre-clinical skills training in skills laboratory and primary health care centers to prepare medical students for their clerkships

Durning, S.J. (09-09-2011) Exploring the Influence of Contextual Factors of the Clinical Encounter on Clinical Reasoning Success (Unraveling context specificity)

Govaerts, M.J.B. (08-09-2011) Climbing the Pyramid;Towards Understanding Performance Assessment

Stalmeijer, R. E. (07-07-2011) Evaluating Clinical Teaching through Cognitive Apprenticeship

Malling, B.V.G. (01-07-2011) Managing word-based postgraduate medical education in clinical departments

Veldhuijzen, J.W. (17-06-2011) Challenging the patient-centred paradigm: designing feasible guidelines for doctor patient communication

Van Blankenstein, F. (18-05-2011) Elaboration during problem-based, small group discussion: A new approach to study collaborative learning

Van Mook, W. (13-05-2011) Teaching and assessment of professional behavior: Rhetoric and reality

De Leng, B. (8-12-2009). Wired for learning. How computers can support interaction in small group learning in higher education

Maiorova, T. (29-05-2009). The role of gender in medical specialty choice and general practice preferences

Bokken, L. (04-03-2009). Innovative use of simulated patients for educational purposes

Wagenaar, A. (18-09-2008). Learning in internships. What and how students learn from experience

Driessen, E. (25-06-2008). Educating the self-critical doctor. Using portfolio to stimulate and assess medical students' reflection

Derkx, H. (18-06-2008). For your ears only. Quality of telephone triage at out-of-hours centres in the Netherlands

Niessen, Th. (30-11-2007). Emerging epistemologies: making sense of teaching practice 


\section{CHAPTER 13}

Budé, L. (05-10-2007). On the improvement of students' conceptual understanding in statistics education

Niemantsverdriet, S. (26-07-2007). Learning from international internships: A reconstruction in the medical domain

Marambe, K. (20-06-2007). Patterns of student learning in medical education - A Sri Lankan study in traditional curriculum

Pleijers, A. (19-01-2007). Tutorial group discussion in problem-based learning

Sargeant, J. (21-09-2006). Multi-source feedback for physician learning and change

Dornan, T. (12-06-2006). Experience-based learning

Wass, V. (12-05-2006). The assessment of clinical competence in high stakes examinations

Prince, K. (21-04-2006). Problem-based learning as a preparation for professional practice 